\title{
Effects of aging and exercise training on eNOS uncoupling and reactive oxygen species signaling in the endothelium of skeletal muscle arterioles
}

\author{
Amy L. Sindler \\ West Virginia University
}

Follow this and additional works at: https://researchrepository.wvu.edu/etd

\section{Recommended Citation}

Sindler, Amy L., "Effects of aging and exercise training on eNOS uncoupling and reactive oxygen species signaling in the endothelium of skeletal muscle arterioles" (2009). Graduate Theses, Dissertations, and Problem Reports. 2847.

https://researchrepository.wvu.edu/etd/2847

This Dissertation is protected by copyright and/or related rights. It has been brought to you by the The Research Repository @ WVU with permission from the rights-holder(s). You are free to use this Dissertation in any way that is permitted by the copyright and related rights legislation that applies to your use. For other uses you must obtain permission from the rights-holder(s) directly, unless additional rights are indicated by a Creative Commons license in the record and/ or on the work itself. This Dissertation has been accepted for inclusion in WVU Graduate Theses, Dissertations, and Problem Reports collection by an authorized administrator of The Research Repository @ WVU.

For more information, please contact researchrepository@mail.wvu.edu. 
Effects of aging and exercise training on eNOS uncoupling and reactive oxygen species signaling in the endothelium of skeletal muscle arterioles

\author{
Amy L. Sindler \\ Dissertation submitted to the \\ School of Medicine \\ at West Virginia University \\ in partial fulfillment of the requirements \\ for the degree of
}

Doctor of Philosophy

in

Cellular and Integrative Physiology

Judy M. Muller-Delp, Ph.D., Chair

William T. Stauber, Ph.D.

Matthew A. Boegehold, Ph.D.

Stephen E. Alway, Ph.D.

Gregory M. Dick, Ph.D.

Division of Cellular and Integrative Physiology

Morgantown, West Virginia University

2009

Keywords: Endothelium-dependent vasodilation, skeletal muscle resistance arterioles, aerobic exercise training, superoxide, hydrogen peroxide, eNOS uncoupling, reactive oxygen species, tetrahydrobiopterin 


\title{
Abstract \\ Effects of aging and exercise training on eNOS uncoupling and reactive oxygen species signaling in the endothelium of skeletal muscle arterioles
}

\begin{abstract}
Amy L. Sindler
The purpose of the first study was to determine the effects of aging and exercise training on endothelial nitric oxide synthase (eNOS) uncoupling in skeletal muscle arterioles. The results of this study confirmed our previous findings that aging impairs endothelium-dependent, NOmediated vasodilation and tetrahydrobiopterin $\left(\mathrm{BH}_{4}\right)$ levels in rat skeletal muscle arterioles. Limited availability of $\mathrm{BH}_{4}$, as observed in old sedentary rats, may contribute to eNOS uncoupling, which decreases NO signaling and increases eNOS-derived $\mathrm{O}_{2}{ }^{-}$generation. Exercise training restored $\mathrm{BH}_{4}$ levels and improved flow-induced $\mathrm{NO}$ production in arterioles from aged rats. Furthermore, exercise training increased both NO and reactive oxygen species (ROS)mediated signaling in skeletal muscle arterioles, suggesting that exercise training-induced enhancement of flow-induced vasodilation in skeletal muscle arterioles involves a balance between $\mathrm{NO}$ and $\mathrm{O}_{2}^{-}$-derived ROS.

The second study determined the role of $\mathrm{O}_{2}{ }^{-}$-derived ROS in mediating endotheliumdependent vasodilation in skeletal muscle arterioles from young and old, sedentary and exercise trained rats. The results of the second study implicated $\mathrm{O}_{2}{ }^{-}$and $\mathrm{O}_{2}{ }^{-}$-derived $\mathrm{ROS}\left(\mathrm{H}_{2} \mathrm{O}_{2}\right)$ as necessary signaling molecules required for endothelium-dependent vasodilation in soleus muscle arterioles. The dependence of ACh-induced vasodilation on $\mathrm{H}_{2} \mathrm{O}_{2}$ increased with age and decreased with exercise training. Exercise training contributed to appropriate regulation of the relative production of $\mathrm{O}_{2}{ }^{-}$and $\mathrm{H}_{2} \mathrm{O}_{2}$, which must be maintained for robust endothelium-dependent vasodilation to occur in skeletal muscle arterioles.
\end{abstract}




\section{Preface}

This dissertation will begin with an introduction that constitutes the scientific background for which these studies were conducted. The two studies that comprise this dissertation work will be reported in manuscript form, followed by a general discussion. This dissertation follows the style and format of the Journal of Applied Physiology. 


\section{Acknowledgements}

I would like to acknowledge all of those people who made the completion of this dissertation possible. First and foremost, I would like to thank my PhD advisor, Dr. Judy Delp, who welcomed me into her lab during the middle of my graduate training. She provided me with all of the resources and mentoring necessary to pursue what I am most passionate about, the benefits of exercise training in cardiovascular health. Judy, I am forever indebted to you for the excellent training and opportunities that you provided to me. I hope that in the future I make you proud.

I would like to give special thanks to my committee members, Dr. Steve Alway, Dr. Matt Boegehold, Dr. Greg Dick and Dr. Bill Stauber for all of their continued support, feedback, and encouragement. A special thanks to Dr. Stauber who has been an insightful friend for many years.

Time in the lab would not have been as "fun" without the awesome camaraderie we shared between Judy and Mike's lab. I would like to express many thanks to Dr. Mike Delp, Dr. Brad Behnke, Dr. Rhonda Prisby, Dr. Rafael Reyes, Dr. Amanda Jo LeBlanc, Jimmy Dominquez, Zack Grimm, Yan Lin and especially Dr. Lori Kang. I thoroughly enjoyed the short time we spent together and you were all important in the culmination of this work.

I would like to extend my appreciation to Dr. Bob Goodman and to the faculty and staff of the Department of Physiology and also to the faculty and staff of the Center for Cardiovascular \& Respiratory Sciences. More specifically, I would like to thank the labs of Dr. John Hollander, Dr. Tim Nurkiewicz, Dr. Rob Brock and Dr. Rob Wysomerski.

Last, but not least, thanks to all of my friends and family for their encouragement, even though most of them do not have foggiest idea what I do. I could not have done it without you. 
Table of Contents

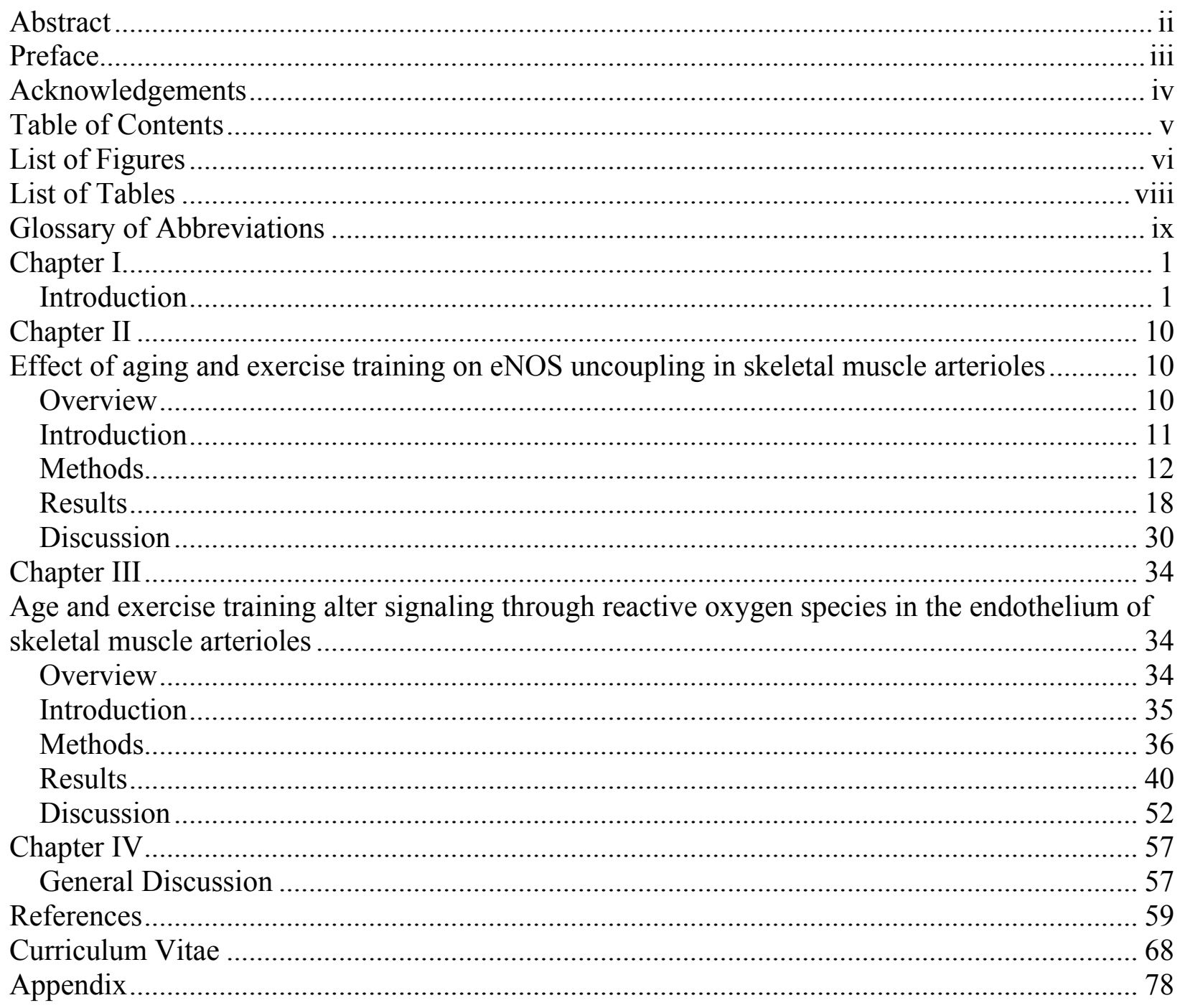


Study 1.

\section{List of Figures}

Figure 1.1 Flow-induced vasodilation in young and old, sedentary and exercise-trained rats $\ldots \ldots \ldots \ldots \ldots \ldots \ldots \ldots \ldots \ldots, 22$

Figure 1.2 Arteriolar $\mathrm{BH}_{4}$ and L-arginine content in young and old, sedentary and exercisetrained rats............................................................... 23

Figure 1.3 Flow-stimulated DAF fluorescence in young and old, sedentary and exercisetrained rats.

Figure 1.4 Flow-induced DHE fluorescence from young and old, sedentary and exercisetrained rats .25

Figure 1.5 Effects of Tempol and catalase on flow-induced vasodilation in young and old, sedentary and exercise-trained rats .26

Figure 1.6 Effects of NADPH oxidase-derived $\mathrm{O}_{2}{ }^{-}$production on flow-induced vasodilation in young and old, sedentary and exercise-trained rats

Figure 1.7 Effects of Tempol and Deferoxamine on flow-induced vasodilation in young and old, sedentary and exercise-trained rats.

Study 2 .

Figure 2.1 ACh-induced vasodilation in young and old, sedentary and exercise-trained rats. .44

Figure 2.2 Effect of Tempol and/or catalase on ACh-induced vasodilation in young and old sedentary rats 
Figure 2.3 Effect of Tempol and/or catalase on ACh-induced vasodilation in young and old exercise-trained rats..........................................46

Figure 2.4 $\quad \mathrm{H}_{2} \mathrm{O}_{2}$-induced vasodilation in young and old, sedentary and exercise trainedrats.

Figure 2.5 Pyrogallol-induced vasoactive characteristics in young and old, sedentary and exercise-trained rats.

Figure 2.6 Endothelium-independent vasodilation to Dea-NONOate in young and old, sedentary and exercise-trained rats.

Figure 2.7 Protein content of SOD-1, catalase, and GPx1 in young and old, sedentary and exercise-trained rats 


\section{List of Tables}

Study 1 .

Table 1.1 Soleus muscle and vessel characteristics of young and old, sedentary and

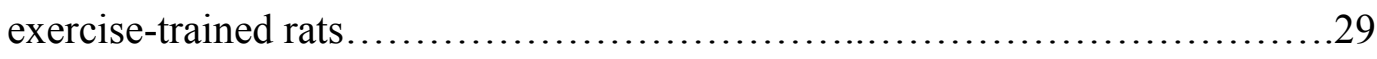

Study 2.

Table 2.1 Animal and vessel characteristics of young and old rat, sedentary and exercise-

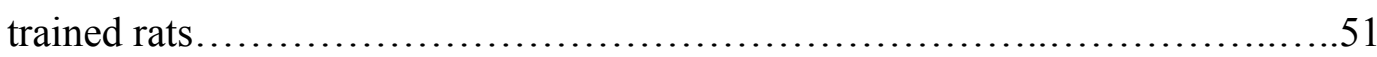


$\mathrm{ACh}$

ADMA

AEC

$\mathrm{A}-\mathrm{VO}_{2} \Delta$

$\mathrm{BH}_{3}$

$\mathrm{BH}_{4}$

BW

cAMP

cGMP

CVD

$\mathrm{D}_{\mathrm{m}}$

$\mathrm{D}_{\mathrm{s}}$

$\mathrm{D}_{\mathrm{t}}$

DAF-2DA

Dea-NONOate

DHE

EDHF

eNOS

ET

$\mathrm{H}_{2} \mathrm{O}$

$\mathrm{H}_{2} \mathrm{O}_{2}$

\section{Glossary of Abbreviations}

acetylcholine

asymmetric dimethylarginine

aortic endothelial cells

arteriovenious $\mathrm{O}_{2}$ difference

trihydrobiopterin radical

tetrahydrobiopterin

body weight

3',5'-cyclic adenosine monophosphate

3'5'-cyclic guanosine monophosphate

cardiovascular disease

maximal diameter

steady state diameter measured after intervention

steady state baseline diameter

4,5-diaminofluorescein diacetate

diethylamineNONOate

dihydroethidium

endothelial derived hyperpolarizing factor

endothelial nitric oxide synthase

exercise trained

water

hydrogen peroxide 


\begin{tabular}{ll} 
HPLC & high-performance liquid chromatography \\
GPx & glutathione peroxidase \\
GTP & guanosine-5'-triphosphate \\
GTPCH-1 & GTP cyclohydrolase \\
K $_{\text {ATP }}$ channel & ATP-sensitive potassium channel \\
$\mathrm{K}_{\mathrm{Ca}}$ channel & calcium-activated potassium channel \\
L-NAME & N ${ }^{\text {-nitro-L-arginine methyl ester }}$ \\
NADPH & nicotinamide adenine dinucleotide phosphate \\
NIH & National Institutes of Health \\
NOHA & N ${ }^{\omega}$-hydroxy-nor-L-arginine \\
NO & nitric oxide \\
NOS & nitric oxide synthase \\
$\mathrm{O}_{2}^{-}$ & superoxide anion \\
OH & vascular smooth muscle \\
ONOO & hydroxyl anion \\
PSS & peroxynitrite \\
Q & physiological saline solution \\
ROS & flow \\
\hline
\end{tabular}


$\mathrm{V}_{\mathrm{rbc}} \quad$ mean red cell velocity

$\mathrm{VO}_{2 \max }$

maximal oxygen consumption

WVU

West Virginia University 


\section{Chapter I}

\section{Introduction}

Cardiovascular disease (CVD) is the leading cause of death in the United States claiming over $36 \%$ of all deaths per year. In 2005, the Center for Disease Control estimated that over 80 million people suffered from some form of CVD and the risk for developing CVD increases with advancing age (1). In 2007, the US Census Bureau estimated that over 42 million individuals currently living in the US are 65 years of age or older. This number is estimated to double by the year 2030 (2). As our population ages, the importance of preventing and/or prolonging the development of CVD becomes a high priority. It has been well established that regular physical activity improves overall health and reduces risk factors for many chronic diseases (i.e., obesity, diabetes, hypertension, and certain cancers). However, the mechanisms by which exercise improve cardiovascular health remains largely unknown.

Age-related declines in exercise capacity due to cardiovascular adaptations

Maximal exercise capacity declines with advancing age $(47,104)$ and this is due, in part, to systemic cardiovascular adaptations. For example, maximal oxygen consumption $\left(\mathrm{VO}_{2 \max }\right)$ decreases $5-15 \%$ every decade of life after the age of 25 (63). Factors that contribute to ageassociated declines in $\mathrm{VO}_{2}$ max are decreases in maximal cardiac output and maximal arteriovenious $\mathrm{O}_{2}$ difference $\left(\mathrm{A}-\mathrm{VO}_{2} \Delta\right)(104,112,125)$. Other factors that contribute to ageassociated declines in $\mathrm{VO}_{2 \text { max }}$ include decreases in maximal heart rate and stroke volume, (112, 125) decreases in skeletal muscle mass, and increases in adiposity (104). Although systemic cardiovascular adaptations markedly influence exercise capacity in older individuals, it is possible that age-associated dysregulation of skeletal muscle blood flow limits exercise capacity in older individuals. Work in humans and animals indicates that blood flow to actively contracting muscles declines with age $(35,67)$. Proctor et al. (109) demonstrated that leg blood flow and 
vascular conductance were reduced in older males (55-68 yr) during exercise compared to young males (22-30 yr). More importantly, age alters the distribution of muscle blood flow in rats by redistributing blood flow away from highly oxidative muscles and to highly anaerobic muscles (98). Age-associated decrements in skeletal muscle blood flow during exercise may contribute to overall diminution in exercise capacity; however, little is known about age-related alterations of vascular control mechanisms in skeletal muscle.

Skeletal muscle blood flow is tightly controlled by the resistance vasculature and is dependent on a functioning endothelium. The endothelium, which lines the interior surface of blood vessels, plays an important role in maintenance of vascular tone and control of vascular resistance (65). Endothelial cells produce nitric oxide (NO) synthesized from L-arginine by endothelial nitric oxide synthase (eNOS). NO is a critical signaling molecule in vascular homeostasis. NO acts as an antiatherosclerotic molecule by inhibiting vascular smooth muscle proliferation, platelet aggregation, and leukocyte adhesion (65). Additionally, NO produced by endothelial cells rapidly diffuses to vascular smooth muscle (VSM) cells, where it activates cyclic guanosine monophosphate (cGMP) and causes vasodilation.

Age-related declines in NO-mediated endothelial-dependent vasodilation and reversal with exercise training

Decreased NO bioavailability is a consequence of aging and contributes to impaired endothelial function (17). Impaired NO-mediated endothelial function serves as both a predictor and mediator of CVD. Endothelial dysfunction is thought to be the critical determinant in development of atherosclerosis $(17,18,78)$. Many studies have demonstrated the age-associated loss of endothelium-dependent vasodilation in skeletal muscle conduit and resistance vasculature in humans and animals $(38,54,97,136,145)$. Age-associated impairments of both flow-induced and receptor-mediated endothelium-dependent vasodilation occur through reduced NO signaling 
$(122,123)$. Aerobic exercise training improves endothelium-dependent, NO-mediated vasodilation in humans $(38,130,138)$ and animals $(36,56,113,122,123,147,149,151)$. Exercise training not only reverses age-related declines in endothelial function, it also prevents the loss of endothelial function in older individuals who remain physically active throughout their lives $(38,129)$. Although, the benefits of aerobic exercise training on the cardiovascular system have been widely acknowledged, the definitive mechanisms by which exercise training improves endothelium-dependent vasodilation remain unclear. Exercise training increases both eNOS mRNA $(117,122,144)$ and protein content in arterioles and endothelial cells from animals $(31$, $68,117,122,144)$ suggesting that enhanced NO production contributes to improvement of endothelial function.

Exercise training may also increase NO bioactivity in the vessel wall by enhancing the sensitivity of vascular smooth muscle to NO. In exercise-trained rats, increased protein content of soluble guanylate cyclase (sGC) may contribute to increased NO sensitivity of the vascular smooth muscle (56). In arterioles from gastrocnemius muscle, exercise training increased sensitivity to the NO donor, sodium nitroprusside (87). Conversely, exercise training has no effect on the sensitivity of vascular smooth muscle to NO in pulmonary arteries or in resistance arterioles from skeletal muscle $(68,122)$.

Age-associated reduction in NO bioavailability

Several mechanisms may contribute to the age-associated decrease in NO bioavailability in skeletal muscle vasculature. NO production is regulated by several factors including: 1) eNOS enzyme activity or protein content, 2$)$ the formation of calcium/calmodulin complexes $(49,116)$, and 3) availability of the substrate L-arginine and the co-factor tetrahydrobiopterin $\left(\mathrm{BH}_{4}\right)$. In the skeletal muscle vasculature of aged rats, eNOS protein is elevated, suggesting that decreased eNOS protein content does not underlie reduced NO availability (122). Acute L-arginine 
treatment improves endothelium-dependent vasodilation in people with cardiovascular disease; however, L-arginine does not enhance flow-induced vasodilation in old rats (122) or humans (11, 53). Furthermore, arteriolar L-arginine levels are unaffected by age in both rats and humans (33, 53). L-arginine bioavailability may be limited by the endogenous inhibitor, asymmetric dimethlyarginine (ADMA) (22), or by increased degradation by arginase $(7,141)$; however, in human vascular endothelial cells and rat skeletal muscle arterioles, both ADMA and arginase protein levels $(33,53)$ do not increase with age. Furthermore, inhibition of arginase activity by $\mathrm{N}^{\omega}$-hydroxy-nor-L-arginine (NOHA) does not improve flow-induced vasodilation in skeletal muscle arterioles of old rats (33). The synthesis of $\mathrm{NO}$ is dependent on the availability of $\mathrm{BH}_{4}(24$, 135). With sufficient amounts of $\mathrm{BH}_{4}$ available, eNOS accepts and stores an adequate number of electrons from nicotinamide adenine dinucleotide phosphate (NADPH) to transform L-arginine and $\mathrm{O}_{2}$ into $\mathrm{NO}$ and L-citrulline (69). If the amount of $\mathrm{BH}_{4}$ is insufficient, eNOS is unable to catalyze the oxidation of L-arginine. Instead, eNOS accepts electrons from NADPH, and donates the electrons one at a time to $\mathrm{O}_{2}$, resulting in increased $\mathrm{O}_{2}{ }^{-}$production and decreased $\mathrm{NO}$ production (69). It has been reported that $\mathrm{BH}_{4}$ is reduced in skeletal muscle arterioles of old rats suggesting that limited arteriolar $\mathrm{BH}_{4}$ contributes to age-related impairment of NO-dependent vasodilation (33).

The synthesis of $\mathrm{BH}_{4}$ is regulated by two known mechanisms: 1) The de novo pathway and 2) the salvage pathway. In the de novo pathway, GTP cyclohydrolase (GTPCH-1) cleaves GTP to produce 7,8-dihydroneopterin triphosphate that is converted to 6-pyruvoyltetrahydropterin. In the final step requiring NADPH, sepiapterin reductase converts 6-pyruvoyltetrahydropterin to $\mathrm{BH}_{4}(134) . \mathrm{BH}_{4}$ is also synthesized by the salvage pathway, which recycles $\mathrm{BH}_{2}$ and quinoid-dihydrobiopterin back to $\mathrm{BH}_{4}(19)$. In the salvage pathway, the $\mathrm{BH}_{4}$ precursor, sepiapterin, is converted to $\mathrm{BH}_{4}(100)$. GTPCH-1 is the rate limiting enzyme in de novo $\mathrm{BH}_{4}$ 
synthesis and stimulation of this enzyme increases $\mathrm{BH}_{4}$ levels in human endothelial cells and in resistance mesenteric arteries $(16,43) . \mathrm{H}_{2} \mathrm{O}_{2}$ augments $\mathrm{GTPCH}-1$ protein content and $\mathrm{BH}_{4}$ synthesis in endothelial cells $(118,119)$. Shear stress also stimulates GTPCH activity in human endothelial cells (142). Reports of the effects of age on GTPCH-1 protein are limited. In carotid arteries of mice, GTPCH-1 is unaffected by age (10). Preliminary data from our lab indicate that GTPCH-1 content decreases with age in skeletal muscle resistance arteries (unpublished data).

Stimulation of $\mathrm{BH}_{4}$ synthesis improves NO production in endothelial cells (119), whereas age-induced impairment of endothelial function is accompanied by reduced $\mathrm{BH}_{4}$ in skeletal muscle arterioles. In aged humans, an acute oral supplementation with $\mathrm{BH}_{4}$ improved flow-mediated dilation (45). Moreover, $\mathrm{BH}_{4}$ co-infusion with acetylcholine increased endothelium-dependent vasodilation to a greater extent in elderly subjects compared with acetylcholine infusion alone (64). In skeletal muscle arterioles from old rats, the $\mathrm{BH}_{4}$ precursor, sepiapterin improved flowinduced vasodilation (33). Together, these reports suggest that limited $\mathrm{BH}_{4}$ availability contributes to age-related decrements in endothelial function.

$\mathrm{BH}_{4}$ and eNOS uncoupling

Uncoupled eNOS has the potential to generate considerable $\mathrm{O}_{2}{ }^{-}$based on the availability of L-arginine and $\mathrm{BH}_{4}(8,69) . \mathrm{O}_{2}^{-}$reacts with $\mathrm{NO}$ to form cytotoxic peroxynitrite, $\mathrm{ONOO}^{-}$. $\mathrm{ONOO}^{-}$ can reduce $\mathrm{BH}_{4}$ to the inactive trihydrobiopterin radical $\left(\mathrm{BH}_{3}\right)(75)$. Thus, a vicious cycle ensues in which $\mathrm{BH}_{4}$ levels are further reduced, and eNOS uncoupling is exacerbated.

One possible mechanism proposed to increase NO bioavailability is to use eNOS gene transfer to increase eNOS protein content and thus eNOS activity. However, in prehypertensive (spontaneously hypertensive) rats, elevation of eNOS protein was accompanied by decreased NO bioavailability and increased $\mathrm{O}_{2}{ }^{-}$production (25). When elevated levels of eNOS protein are sustained, it is the loss of $\mathrm{BH}_{4}$, not L-arginine, that exacerbates eNOS uncoupling (8). Similarly, 
in skeletal muscle arterioles from aged rats, increased eNOS protein abundance is accompanied by reduced $\mathrm{BH}_{4}$ levels and diminished $\mathrm{NO}$-mediated vasodilation suggesting that eNOS uncoupling reduces NO bioavailability with age $(33,122)$.

\section{Role of oxidant stress on NO bioavailability}

$\mathrm{O}_{2}{ }^{-}$reacts readily with $\mathrm{NO}$ to form $\mathrm{ONOO}^{-}(29) . \mathrm{O}_{2}{ }^{-}$is generated in the vasculature by NADPH oxidase, by xanthine oxidase, and by eNOS $(14,29,57)$. Age-associated $\mathrm{O}_{2}^{-}$production increases in vascular tissue with age and this increase is thought to be a major factor in the loss of NO bioavailability. Antioxidant defense mechanisms are present in vascular cells to sequester and buffer $\mathrm{O}_{2}{ }^{-}$and other ROS. Superoxide dismutase (SOD) dismutates $\mathrm{O}_{2}{ }^{-}$to $\mathrm{H}_{2} \mathrm{O}_{2}(91,132)$. There are three known isoforms of the enzyme (SOD-1, SOD-2, and SOD-3); two of which are Cu/Zndependent. SOD-1 is primarily located in the cytosol and nucleus and SOD-3 is abundant in the extracullar matrix $(29,94)$. SOD-2 is Mn-dependent and is most abundant in the mitochondria (143). Other ROS defense mechanisms present in the vascular cells include catalase and glutathione peroxidase (GPx), which reduce $\mathrm{H}_{2} \mathrm{O}_{2}$ to $\mathrm{H}_{2} \mathrm{O}$ and $\mathrm{O}_{2}$. Together, these defense systems regulate ROS levels in the cell. The balance of superoxide production and antioxidant regulation is thought to be critical for preservation of bioavailable $\mathrm{NO}(29,70)$.

\section{Effects of age and exercise training on regulation of vascular ROS}

The primary free radicals generated by endothelial cells are $\mathrm{O}_{2}{ }^{-}$and $\mathrm{NO}$. Free radicals are defined as an atom or molecule that contains one or more unpaired electrons and is capable of independent existence (59). $\mathrm{O}_{2}^{-}$is generated as an intermediate in many biochemical reactions by the incomplete reduction of $\mathrm{O}_{2}$ during electron transport (59). NO is generated by three known isoforms of nitric oxide synthase (NOS). $\mathrm{O}_{2}{ }^{-}$and $\mathrm{NO}$ are both highly reactive and quickly form other ROS (107). In the vascular wall, $\mathrm{O}_{2}^{-}$is generated by NADPH oxidase, by xanthine oxidase, and by eNOS $(14,29,70,92)$. Of these, NADPH oxidases are the major source of $\mathrm{O}_{2}^{-}$production 
in the vasculature (57). Thus, greater $\mathrm{O}_{2}^{-}$production is accompanied by decreased $\mathrm{NO}$ bioavailability because $\mathrm{O}_{2}^{-}$readily inactivates $\mathrm{NO}$.

SOD serves as a cellular antioxidant by dismutating $\mathrm{O}_{2}^{-}$to $\mathrm{H}_{2} \mathrm{O}_{2}$; however, in the presence of catalytic transition metals, SOD can produce hydroxyl radials $\left(\mathrm{OH}^{-}\right)(107)$. In compartments containing both $\mathrm{NO}$ and SOD, a reaction between $\mathrm{O}_{2}{ }^{-}$and $\mathrm{NO}$ occurs more readily than a reaction between $\mathrm{O}_{2}^{-}$and $\mathrm{SOD}(55)$. Thus some reactivity between $\mathrm{O}_{2}^{-}$and $\mathrm{NO}$ is likely to be present in endothelial cells, even under normal physiological conditions. Basally, $\mathrm{O}_{2}{ }^{-}$is required for normal function, serving as a signaling molecule, involved in regulation of gene expression, and force generation in skeletal muscle $(41,108,110,111,120)$. Low to moderate levels of ROS may also function in vascular signaling. In fact, many ROS, including $\mathrm{NO}, \mathrm{H}_{2} \mathrm{O}_{2}, \mathrm{ONOO}^{-}$, and $\mathrm{OH}^{-}$exhibit vasoactive properties that alter vascular tone and regulate blood flow $(27,85,102,103,115,131)$. The idea that all ROS are detrimental to the vasculature appears to be a misconception. For example, $\mathrm{H}_{2} \mathrm{O}_{2}$ is an important vasoactive substance and has been labeled as an endotheliumderived hyperpolarizing factor $(\mathrm{EDHF})$ in certain vasculature beds $(84,85,91)$. Additionally, $\mathrm{H}_{2} \mathrm{O}_{2}$ is an important regulator of eNOS protein expression and activity $(133,152)$. eNOSdependent $\mathrm{O}_{2}^{-}$generation is required to provide the substrate $\left(\mathrm{O}_{2}{ }^{-}\right)$to produce $\mathrm{H}_{2} \mathrm{O}_{2}$ in the cerebral circulation (42). Thus, support exists for a physiological role of superoxide generation through eNOS "uncoupling”.

There are numerous antioxidants that regulate free radicals and ROS including vitamin E, vitamin C, and carotenoids. However, SOD appears to be the primary regulator of ROS in vascular cells. GPx and catalase also function as an important anti-oxidant in vascular cells. There are five isoforms of GPx, and all of them catalyze the reduction of $\mathrm{H}_{2} \mathrm{O}_{2}$ to $\mathrm{H}_{2} \mathrm{O}$ using glutathione as the electron donor (9). Similar to GPx, catalase catalyzes the breakdown of $\mathrm{H}_{2} \mathrm{O}_{2}$; however, GPx has a higher affinity for $\mathrm{H}_{2} \mathrm{O}_{2}$ at low concentrations $\left(\mathrm{K}_{\mathrm{m}}=1 \mu \mathrm{M}\right)$ than catalase $\left(\mathrm{K}_{\mathrm{m}}\right.$ 
$=1 \mathrm{mM}$ ), indicating that GPx is a less effective antioxidant at higher concentrations of $\mathrm{H}_{2} \mathrm{O}_{2}(90)$. Together, these antioxidants regulate $\mathrm{O}_{2}{ }^{-}$-derived ROS, primarily $\mathrm{H}_{2} \mathrm{O}_{2}$.

SOD-1, located in the cytosol and nucleus and to a lesser extent in the mitochondria, is the predominant isoform of SOD in the vasculature $(105,106)$. The effects of age on SOD-1 expression and activity are inconclusive. For example, SOD-1 is reduced with age in skeletal muscle arterioles (145); however, SOD-1 activity increases with age in mouse aorta (58). In coronary arterioles, SOD-1 is unaffected by age (28). Exercise training increases SOD-1 protein content in coronary arterioles, aortic endothelial cells, and mouse aorta $(50,113,114)$. Elevations in shear stress induce SOD-1 mRNA and protein content in skeletal muscle arteries $(66,146)$. Although, SOD-1 content declines with age in resistance arteries from skeletal muscle (145) and mesentery (127), the interactive effects of age and exercise training on the expression of antioxidant proteins have not been thoroughly investigated in the skeletal muscle resistance vasculature.

Tempol, which is an SOD mimetic, is widely used to assess the effect of $\mathrm{O}_{2}{ }^{-}$on vascular reactivity. Many studies report a beneficial effect of scavenging excess $\mathrm{O}_{2}{ }^{-}$with Tempol on endothelial function; however, most of these studies have been conducted in diseased animals ( 3 , $46,95,153,154)$. In contrast, SOD treatment diminished acetylcholine-induced vasodilation in cerebral arteries from healthy mice (42). Furthermore, Tempol had no effect on endotheliumdependent vasodilation in cerebral arteries from young rats, but improved endothelium-dependent vasodilation in arterioles from old rats (86). The differences in these reports are probably due to the complexity of pathologies, vasculature beds, and species examined; however, these discrepant results of SOD treatment indicate that the effects of $\mathrm{O}_{2}{ }^{-}$on endothelial function remain unresolved.

It is well established that exercise training delays and/or reverses the development of many pathologies including cardiovascular disease and endothelial dysfunction. Ironically, a paradox 
emerges as these exercise-induced improvements in overall health observed are accompanied by increases in ROS generation. However, the mechanisms by which exercise training improves endothelium-dependent vasodilation remain unknown. It is plausible that the improvement in endothelial function observed with exercise training is linked to elevations of ROS that accompany exercise. Low to moderate $\mathrm{O}_{2}{ }^{-}$and $\mathrm{ROS}$ are required as modulators of normal cell function and serve as critical signaling molecules in the vasculature $(20,73)$. eNOS "uncoupling" may contribute to normal vascular function. The interactive effects of age and exercise training on regulation of vascular ROS remain unclear. Furthermore, the role of ROS in mediating age-and exercise training-induced adaptations of endothelial function has not been determined. Therefore, the overall aims of this dissertation were as follows:

- To determine the effects of $\mathrm{O}_{2}^{-}$and ROS on endothelium-dependent vasodilation in skeletal muscle arterioles from young and old, sedentary and exercise trained rats.

- To directly measure flow-induced production of $\mathrm{NO}$ and $\mathrm{O}_{2}{ }^{-}$in skeletal muscle arterioles from young and old, sedentary and exercise trained rats.

- To determine the effects of age and exercise training on protein content of enzymes involved in regulation of ROS in skeletal muscle arterioles from young and old, sedentary and exercise trained rats. 


\section{Chapter II}

\section{Effect of aging and exercise training on eNOS uncoupling in skeletal muscle arterioles}

\section{Overview}

Reduced availability of tetrahydrobiopterin $\left(\mathrm{BH}_{4}\right)$ contributes to the age-related decline of nitric oxide (NO)-mediated dilation in soleus muscle arterioles. Depending on the availability of substrate and/or necessary co-factors, endothelial nitric oxide synthase (eNOS) can generate NO and/or superoxide $\left(\mathrm{O}_{2}^{-}\right)$. We evaluated the effects of age and exercise on flow-induced vasodilation and production of $\mathrm{NO}$ and $\mathrm{O}_{2}^{-}$in soleus muscle arterioles. Young (3 mo) and old (22 mo) male rats were exercise trained (ET) or remained sedentary (SED) for 10 wks. Flow-induced $\mathrm{NO}$ and $\mathrm{O}_{2}{ }^{-}$production, as well as $\mathrm{BH}_{4}$ and $\mathrm{L}$-arginine content, were determined in soleus muscle arterioles. Flow-induced vasodilation was assessed under control conditions and during the blockade of $\mathrm{O}_{2}^{-}$and/or hydrogen peroxide. Exercise training enhanced flow-induced vasodilation in arterioles from young and old rats. Old age reduced $\mathrm{BH}_{4}$ levels and flow-induced $\mathrm{NO}$ production in SED rats; however, exercise training restored $\mathrm{BH}_{4}$ and flow-induced production of NO. Flow-induced eNOS-dependent $\mathrm{O}_{2}{ }^{-}$production was higher in arterioles from old SED compared to those from young SED rats. Exercise training increased flow-induced eNOSdependent $\mathrm{O}_{2}^{-}$production in arterioles from young but not old rats. $\mathrm{O}_{2}^{-}$scavenging with Tempol reduced flow-induced vasodilation in arterioles from all groups except young SED rats. The addition of catalase to Tempol-treated arterioles eliminated flow-induced vasodilation in arterioles from all groups of rats. Catalase alone reduced flow-induced vasodilation in arterioles from all groups except old SED rats. In Tempol-treated arterioles, flow-induced vasodilation was restored by deferoxamine, an iron chelator. These data indicate that uncoupling of eNOS contributes to the age-related decline in flow-induced vasodilation; however, reactive oxygen species are required for flow-induced vasodilation in soleus muscle arterioles from young and old rats. 


\section{Introduction}

Maximal exercise capacity declines with advancing age $(47,104)$ and, although part of this decline is associated with a reduction of maximal cardiac output (76), alterations in the local control of skeletal muscle blood flow also contribute to this abatement. Local regulatory factors that contribute to the age-associated decrement in skeletal muscle blood flow capacity include declines in vascular conductance (39). Numerous studies have demonstrated that age impairs endothelial function in skeletal muscle conduit and resistance arteries in humans and animals (38, 54, 97, 145). Age-associated reductions in endothelium-dependent dilation of skeletal muscle resistance arterioles occur in part, through reduced nitric oxide (NO) signaling (122). Mechanisms that may underlie this age-associated impairment in NO signaling may include reduced availability of substrate (L-arginine) (93) or cofactors (e.g., tetrahydrobiopterin $\left.\left[\mathrm{BH}_{4}\right]\right)(23,135)$, reduced endothelial NO synthase (eNOS) protein levels and/or activity, and increased superoxide production (29). Depending on the availability of L-arginine and/or $\mathrm{BH}_{4}$, eNOS can become uncoupled resulting in the generation of $\mathrm{NO}$ and superoxide $\left(\mathrm{O}_{2}^{-}\right)(24,137)$. Aging-induced diminution of $\mathrm{BH}_{4}$ contributes to the decline of $\mathrm{NO}$-mediated dilation to flow, and sepiapterin, a precursor to $\mathrm{BH}_{4}$ synthesis (6), improves flow-induced vasodilation in soleus muscle arterioles of aged rats (33). $\mathrm{BH}_{4}$ supplementation ameliorates endothelium-dependent dilation in humans with cardiovascular diseases or elevated risk factors $(80,126)$; however, the impact of reduced $\mathrm{BH}_{4}$ availability on eNOS function has not been directly evaluated in the skeletal muscle resistance vasculature.

Reactive oxygen species (ROS) potentially decrease NO bioavailability by two mechanisms. First, $\mathrm{O}_{2}^{-}$rapidly interacts with $\mathrm{NO}$ to form peroxynitrite, $\left(\mathrm{ONOO}^{-}\right)$a potent $\mathrm{ROS}$, which elicits cellular damage $(14,29)$. Secondly, the presence of ROS, and primarily ONOO', reduces $\mathrm{BH}_{4}$ to the inactive trihydrobiopterin radical $\left(\mathrm{BH}_{3}\right)$, thereby reducing this necessary co- 
factor and subsequent NO production. Recent reports indicate that insufficient $\mathrm{BH}_{4}$ is the major determinant of whether eNOS produces $\mathrm{O}_{2}^{-}$or $\mathrm{NO}(8,26)$.

Aerobic exercise-training restores age-associated reductions in NO-mediated dilation in human and animal models $(38,122,130)$. Exercise training may increase NO bioavailability, in part, through enhanced regulation of ROS (113) or through increased expression of eNOS protein (122); however, the effects of age and exercise training on the regulation of eNOS activity have not been evaluated. Eskurza et al., demonstrated that an acute bolus of $\mathrm{BH}_{4}$ augments endothelium function in the brachial artery of old sedentary men, but had no effect on endothelialdependent dilation in habitually active, age-matched counterparts (45). These data suggest that aerobic exercise training prevents the loss of $\mathrm{NO}$ bioavailability by preserving $\mathrm{BH}_{4}$ in aged individuals; however, the effect of exercise training on $\mathrm{BH}_{4}$ levels in the resistance vasculature of skeletal muscle has not been determined. Here, we investigate the effects of age and exercise training on $\mathrm{BH}_{4}$ availability and eNOS uncoupling in soleus muscle arterioles of male rats.

Therefore, the purpose of this study was 3-fold. First, we sought to determine whether ageinduced reductions of arteriolar $\mathrm{BH}_{4}$ are associated with eNOS uncoupling. Second, we investigated the possibility that exercise training restores arteriolar $\mathrm{BH}_{4}$ availability and reverses eNOS uncoupling with age. Third, we determined whether eNOS uncoupling in skeletal muscle arterioles is accompanied by significant increases in ROS and a concomitant decrease in NO bioavailability.

\section{Methods}

\section{Animals}

All procedures in this study were approved by the Institutional Animal Care and Use Committees at West Virginia University. All methods complied fully with guidelines set in the Guide for the Care and Use of Laboratory Animals (National Institutes of Health, revised 1996). 
Young ( $3 \mathrm{mo}$ ) and old (22 mo) male Fischer 344 rats were obtained from Harlan (Indianapolis, IN), housed under a 12:12-h light-dark cycle, and given food and water ad libitum. This particular strain was chosen because cardiovascular function decreases with age in these rats, without the development of atherosclerosis or hypertension (76).

\section{Exercise training}

All rats were habituated to treadmill exercise, during which each rat walked on a motordriven treadmill at $5 \mathrm{~m} / \mathrm{min}\left(0^{\circ}\right.$ incline), $5 \mathrm{~min} /$ day for 3 days. After habituation, young and old rats were randomly assigned to either a control sedentary (SED) group (young SED, $n=30$, and old SED, $n=32$ ) or an exercise-trained (ET) group (young ET, $n=37$, and old ET, $n=26$ ). ET rats performed treadmill running at $15 \mathrm{~m} / \mathrm{min}$ ( $15^{\circ}$ incline $), 5$ days/wk, for $10-12 \mathrm{wk}$. The duration of running was gradually increased in the first 3 wk until a 60 -min duration was reached. The rats continued to run 5 days/wk for $60 \mathrm{~min} /$ day for the remainder of the 10 - to 12 -wk training period. Vascular responses were determined at least $24 \mathrm{~h}$ after the last exercise bout in ET rats.

\section{Muscle oxidative enzyme activity}

To determine the efficacy of the training protocol, sections of soleus muscle were stored at $-80^{\circ} \mathrm{C}$ for determination of citrate synthase activity, a measure of muscle oxidative capacity $(34$, 124).

Microvessel preparation

Rats were anesthetized with isoflurane $\left(5 \% / \mathrm{O}_{2}\right.$ balance) and euthanized by decapitation. The gastrocnemius-plantaris-soleus muscle group was dissected free from both hind limbs and placed in a cold $\left(4^{\circ} \mathrm{C}\right)$, filtered physiological saline solution (PSS) containing $145.0 \mathrm{mM} \mathrm{NaCl}, 4.7$ $\mathrm{mM} \mathrm{KCl}, 2.0 \mathrm{mM} \mathrm{CaCl}_{2}, 1.17 \mathrm{mM} \mathrm{MgSO}_{4}, 1.2 \mathrm{mM} \mathrm{NaH}_{2} \mathrm{PO}_{4}, 5.0 \mathrm{mM}$ glucose, $2.0 \mathrm{mM}$ pyruvate, $0.02 \mathrm{mM}$ EDTA, 3.0 $\mathrm{mM}$ MOPS buffer, and $1 \mathrm{~g} / 100 \mathrm{ml} \mathrm{BSA}, \mathrm{pH}$ 7.4. With the aid of a dissecting microscope (Olympus SVH10), first-order (1A) arterioles were isolated and dissected from the soleus muscle, composed primarily of high-oxidative fibers (34), as previously described. 
The arterioles were then transferred to a Lucite chamber containing PSS with $1 \%$ albumin (pH 7.4) equilibrated with room air. Each end of the arteriole was cannulated with micropipettes filled with PSS-albumin solution and secured with nylon suture. The sizes and resistances of the pipettes were matched to within $1 \%$. The chamber was placed on the stage of an inverted microscope (Zeiss Axio40), equipped with a video camera (Panasonic BP310), video caliper (Colorado Video), and data-acquisition system (Power Lab). Arterioles were pressurized via two independent reservoirs and checked for leaks. If leaks were present, the arterioles were discarded. Vessels that were free from leaks were pressurized to $70 \mathrm{cmH}_{2} \mathrm{O}$, gradually warmed to $37^{\circ} \mathrm{C}$, and allowed to develop spontaneous tone during an initial equilibration period. The bathing solution was changed every 20 min during the course of the experiment.

Vasodilator Responses to Intraluminal Flow

Upon displaying a steady level of spontaneous tone, arterioles were exposed to graded increases in intraluminal flow in the absence of changes in intraluminal pressure. This was accomplished by altering the heights of independent pressure reservoirs in equal and opposite directions so that a pressure difference was created across the vessel without altering mean intraluminal pressure. Diameter measurements were determined in response to incremental pressure differences of 2, 4, 10, 20, 40, and $60 \mathrm{~cm} \mathrm{H}_{2} \mathrm{O}$. Volumetric flow (Q) was then calculated from inner diameter $(\mathrm{d})$ and mean red cell velocity $\left(\mathrm{V}_{\mathrm{rbc}}\right)$, according the following equation (32, 74, 97):

$$
\mathrm{Q}=\pi\left(\mathrm{V}_{\mathrm{rbc}} / 1.6\right)(\mathrm{d} / 2)^{2}
$$

At the end of the experiment, arterioles were placed in $\mathrm{Ca}^{2+}$-free PSS with $100 \mu \mathrm{M}$ of the NO donor, sodium nitroprusside for $1 \mathrm{hr}$ to obtain the maximal passive diameter $(97,122)$. Effects of ROS Scavengers on Flow-Induced Vasodilation 
To determine the role of $\mathrm{O}_{2}^{-}$, hydrogen peroxide $\left(\mathrm{H}_{2} \mathrm{O}_{2}\right)$, and hydroxyl ion $\left(\mathrm{OH}^{-}\right)$in ageinduced reductions of flow-induced vasodilation, responses to flow were evaluated in the presence of the following: (1) superoxide dismutase mimetic, Tempol (100 $\mu \mathrm{M})(21)$, (2) $\mathrm{H}_{2} \mathrm{O}_{2}$ scavenger, catalase (100U) (44), (3) Tempol (100 $\mu \mathrm{M})$ plus catalase (100U), (5) NADPH oxidase inhibitor, apocynin $(100 \mu \mathrm{M})(153)$, and (6) Tempol plus deferoxamine $(100 \mu \mathrm{M})(131)$, an iron chelator, and inhibitor of $\mathrm{OH}^{-}$formation (131).

\section{Detection of Flow-Induced NO Production}

To evaluate flow-induced production of NO, isolated soleus muscle arterioles were cannulated as described above. 4,5-diaminofluorescein diacetate (DAF-2DA) (Calbiochem) is a non-fluorescent dye until it reacts with $\mathrm{NO}$ in the presence of oxygen to form a fluorescent compound triazolofluorescein (2DAF-2T) (71). The intensity of the fluorescent signal is proportional to NO levels. Following intraluminal loading of DAF-2DA (2.5 uM) for 20 minutes, soleus muscle arterioles were exposed to a flow rate of $34 \mathrm{nl} / \mathrm{sec}$ and fluorescent images were acquired every 15 seconds over 2 minutes. To confirm that production of NO occurred through eNOS, flow-induced DAF-2DA fluorescence was evaluated in the presence of ${ }^{\mathrm{N}}(\mathrm{G})$-nitro-1arginine methyl ester (L-NAME). DAF-2DA fluorescence during exposure to $10 \mathrm{uM}$ DeaNONOate (DEA), an NO donor, was used as a positive control to ensure that the dye was not saturated and to determine maximal fluorescent intensity as a control for loading of dye. After background subtraction, DAF fluorescence was expressed as a ratio of DAF stimulated/DAF at baseline for all conditions. Acquired images were analyzed using ImageJ software (NIH). Detection of Flow-Induced $\mathrm{O}_{2}^{-}$Production

Dihydroethidium (DHE) fluorescence was used to evaluate flow-induced $\mathrm{O}_{2}^{-}$production in real time (128). To evaluate $\mathrm{O}_{2}{ }^{-}$production in response to flow stimulation, soleus muscle arterioles were cannulated as described above. DHE fluorescence was evaluated in arterioles 
similar to those described by Suzuki et al. (128). Following intraluminal loading of DHE (40uM) for 20 minutes, soleus muscle arterioles were exposed to a flow rate of $34 \mathrm{nl} / \mathrm{sec}$ and fluorescent images were acquired every 15 seconds over 2 minutes. To determine whether production of $\mathrm{O}_{2}{ }^{-}$ occurred through eNOS, flow-induced DHE fluorescence was evaluated in the presence of LNAME. DHE fluorescence during exposure to $100 \%$ ethanol was used as a positive control to ensure that the dye was not saturated and to control for equal loading of dye. After background subtraction, DHE fluorescence was expressed as a ratio of DHE stimulated/DHE at baseline for all conditions. Acquired images were analyzed using ImageJ software (NIH).

\section{Arteriolar L-arginine and $\mathrm{BH}_{4}$ measurements}

Arteriolar L-arginine and $\mathrm{BH}_{4}$ levels were determined using the HPLC method as previously described $(33,89,148)$. Briefly, soleus muscle arterioles were dissected from each animal and pooled. For L-arginine analysis, vessels were homogenized with $0.2 \mathrm{ml} 1.5 \mathrm{M} \mathrm{HClO}_{4}$, then $0.1 \mathrm{ml} 2 \mathrm{M} \mathrm{K}_{2} \mathrm{CO}_{3}$ was added. The homogenates were centrifuged at $10000 \mathrm{~g}$ for $1 \mathrm{~min}$, and an aliquot $(0.2 \mathrm{ml})$ of the supernatant was used for sample determination of L-arginine content (148). For $\mathrm{BH}_{4}$ analysis, arterioles were homogenized in $0.1 \mathrm{ml} 0.1 \mathrm{M}$ phosphoric acid containing $5 \mathrm{mM}$ dithioerythritol (an antioxidant), to which $17.5 \mu 12 \mathrm{M}$ trichloroacetic acid was added. Extracts were oxidized with acidic or basic iodine. Acidic oxidation quantitatively converts $\mathrm{BH}_{4}$ and dihydrobiopterin to biopterin; basic oxidation converts dihydrobiopterin and $\mathrm{BH}_{4}$ to biopterin and pterin, respectively. Samples were incubated in the dark for $1 \mathrm{~h}$. Excess iodine was removed by adding ascorbic acid (final concentration, $0.1 \mathrm{M}$ ). The final solution was analyzed on a $\mathrm{C} 18$ reversed-phase column using fluorescence detection and authentic biopterin as a standard. The amount of $\mathrm{BH}_{4}$ in the arteriolar extracts was determined from the difference between acidic and basic iodine-generated biopterin (89). The sensitivity of L-arginine and $\mathrm{BH}_{4}$ analyses by $\mathrm{HPLC}$, which was assessed using detection limits defined as a signal-to-noise ratio of 3 , was 5 and $2 \mu \mathrm{M}$, 
respectively. The reliability of the assays was indicated by the precision (agreement between replicate measurements), evaluated by the relative deviation (mean of absolute deviation/mean of replicate measurements $\times 100 \%$ ), and by the accuracy (the nearness of an experimental value to the true value), determined with known amounts of standards and expressed as the relative errors ((measurement value - true value $) /($ true value $\times 100 \%))$. The precision and accuracy for the $\mathrm{L}^{-}$ arginine analysis were $1.4 \%$ and $1.6 \%$, respectively, and for the $\mathrm{BH}_{4}$ analysis were $2.0 \%$ and $2.3 \%$, respectively. . The values in fmol $\bullet(\mathrm{mg} \text { tissue })^{-1}$ and pmol $\bullet(\mathrm{mg} \text { tissue })^{-1}$ for $\mathrm{BH} 4$ and arginine concentrations, respectively, were calculated on the basis of tissue weight.

\section{Data Analysis}

Data are expressed as means \pm standard error. Spontaneous tone was calculated as a percent constriction in relation to maximal diameter as determined by the following equation:

$$
\text { Spontaneous Tone }(\%)=\left[\left(\mathrm{D}_{\mathrm{M}}-\mathrm{D}_{\mathrm{T}}\right) / \mathrm{D}_{\mathrm{M}}\right] \times 100
$$

where $\mathrm{D}_{M}$ is the maximal diameter recorded at $70 \mathrm{~cm} \mathrm{H}_{2} \mathrm{O}$ and $\mathrm{D}_{T}$ is the steady-state baseline diameter recorded at the same pressure. The vasodilator responses to flow are expressed as percent relaxation as calculated by the formula:

$$
\text { Relaxation }(\%)=\left[\left(D_{S}-D_{B}\right) /\left(D_{M}-D_{B}\right)\right] \times 100
$$

where $\mathrm{D}_{\mathrm{S}}$ is the arteriolar diameter at each respective stage, $\mathrm{D}_{\mathrm{B}}$ is the diameter recorded immediately prior to initiation of the flow- diameter curves, and $\mathrm{D}_{\mathrm{M}}$ is the maximal diameter for the arteriole. For statistical analyses, changes in diameter in response to flow were expressed as a percent of maximal vasodilation as previously described (97). Flow-diameter curves were evaluated by a three-way ANOVA with repeated measures on one factor in order to detect differences within (flow rate) and between (animal groups) factors. Two-way ANOVA was used to determine group differences in animal and vessel characteristics, and group differences in L- 
arginine and $\mathrm{BH}_{4}$ content in soleus muscle arterioles. Three-way ANOVA was used to determine the effect of age, training and L-NAME treatment on DAF fluorescence. Three-way ANOVA was used to determine the effect of age, training and L-NAME treatment on DHE fluorescence, and planned contrasts were use as post-hoc analysis to compare treatment combinations of interest. All data are presented as mean \pm SEM. In all statistical analyses, $n$ indicates the number of animals in each group. Significance was defined as $P \leq 0.05$.

\section{Results}

Animals

Body mass increased with age. Exercise training reduced body mass in both young and old rats (Table 1.1). Soleus muscle mass increased with age but was unaltered by exercise training (Table 1.1). In contrast, soleus muscle mass to body mass ratio decreased with age and increased with exercise training (Table 1.1). Exercise training increased citrate synthase activity by $18.3 \%$ in soleus muscles of young rats, and by $20.1 \%$ in soleus muscles of old rats, confirming the efficacy of the exercise training as previously reported (122).

\section{Vessel characteristics}

Maximal intraluminal diameter in soleus muscle arterioles was not different between groups (Table 1.1). The levels of spontaneous tone were similar between groups (Table 1.1). Treatment with Tempol, Tempol plus catalase, catalase alone, apocynin and Tempol plus deferoxamine had no effect on spontaneous tone in any group (Table 1.1).

\section{Vasodilator responses to flow}

Vasodilation to intraluminal flow was diminished in soleus muscle arterioles from old SED rats (Fig. 1.1). Exercise training restored flow-induced vasodilation in soleus muscle arterioles from old rats to that of young SED rats and exercise training improved flow-induced dilation in soleus muscle arterioles from young rats (Fig. 1.1). 


\section{Arteriolar $\mathrm{BH}_{4}$ and L-arginine content}

Similar to previous findings, age decreased arteriolar $\mathrm{BH}_{4}$ levels (33). Exercise training restored arteriolar $\mathrm{BH}_{4}$ levels of old rats to that of young rats (Fig. 1.2A). Exercise training did not alter $\mathrm{BH}_{4}$ levels in soleus muscle arterioles from young rats. As previously reported (33), aging had no effect on L-arginine levels and exercise training did not effect arteriolar L-arginine levels in either young or old rats (Fig. 1.2B).

\section{Flow-induced NO production in soleus muscle arterioles.}

Age reduced flow-induced NO production in soleus muscle arterioles (Fig. 1.3). Exercise training augmented flow-induced NO production in soleus muscle arterioles of old rats to that of young SED rats. Exercise training increased flow-induced NO production in soleus muscle arterioles of young rats. L-NAME eliminated flow-induced increases in NO in arterioles from all groups of rats, confirming DAF specificity (Fig. 1.3). Maximal DAF fluorescence was not different between groups (young SED, $2.27 \pm 0.30$; old SED 2.17 \pm 0.23 ; young ET, $2.17 \pm 0.27$;

Old ET, $2.23 \pm 0.20$ fluorescence units) confirming that similar dye loading in arterioles from all groups.

Flow-induced $\mathrm{O}_{2}^{-}$production in soleus muscle arterioles

Flow-induced $\mathrm{O}_{2}^{-}$generation was elevated in soleus muscle arterioles from old SED rats as compared to those from young SED rats (Fig 1.4). Exercise training increased flow-induced $\mathrm{O}_{2}{ }^{-}$ production in arterioles of young rats, but did not alter flow-induced $\mathrm{O}_{2}^{-}$production in old rats, indicating that $\mathrm{O}_{2}^{-}$signaling contributes to exercise training-induced improvement of flow-induced vasodilation in young rats. Inhibition of eNOS activity with L-NAME reduced flow-induced $\mathrm{O}_{2}{ }^{-}$ production in arterioles from all but young SED rats (Fig. 1.4). L-NAME inhibition of eNOSderived $\mathrm{O}_{2}{ }^{-}$was greater in arterioles from old SED rats as compared to those from young SED rats. Exercise training increased eNOS-derived $\mathrm{O}_{2}{ }^{-}$production in soleus muscle arterioles from young 
but not old rats (Fig. 1.4). Maximal DHE fluorescence was not different between groups (young SED, $315 \pm 0.50$; old SED $290 \pm 0.29$; young ET, $296 \pm 0.41$; Old ET, $315 \pm 0.35$ fluorescence units) confirming that similar dye loading in arterioles from all groups.

Role of $\mathrm{O}_{2}^{-}$and $\mathrm{H}_{2} \mathrm{O}_{2}$ and in flow-induced vasodilation

In young SED rats, scavenging of $\mathrm{O}_{2}^{-}$with Tempol did not alter flow-induced vasodilation. Catalase, and Tempol plus catalase inhibited flow-induced vasodilation indicating dependence on $\mathrm{H}_{2} \mathrm{O}_{2}$ in young SED rats (Fig 1.5A).

Scavenging of $\mathrm{O}_{2}^{-}$with Tempol inhibited flow-induced vasodilation in arterioles from old SED rats (Fig. 1.5B). Scavenging of $\mathrm{H}_{2} \mathrm{O}_{2}$ with catalase reduced flow-induced vasodilation between flow rates of $5.2 \pm 0.75$ to $22.8 \pm 0.42 \mathrm{nl} / \mathrm{sec}$ but not at higher flow rates, and Tempol plus catalase eliminated flow-induced vasodilation in the old SED rats, suggesting that even though flow-induced vasodilation is reduced in these rats compared to young $\mathrm{SED}, \mathrm{H}_{2} \mathrm{O}_{2}$ is an important vasodilator (Fig. 1.5B).

In young and old ET rats, scavenging of $\mathrm{O}_{2}^{-}$with Tempol reduced flow-induced vasodilation (Fig. 1.5C and D). Scavenging of $\mathrm{H}_{2} \mathrm{O}_{2}$ with catalase alone reduced flow-induced dilation in arterioles from young ET rat (Fig. 1.5C). Similarly, simultaneous scavenging of both $\mathrm{O}_{2}{ }^{-}$and $\mathrm{H}_{2} \mathrm{O}_{2}$ with Tempol plus catalase inhibited flow-induced vasodilation in arterioles from young ET rats (Fig. 1.5C); however, some flow-induced vasodilation remained, suggesting that in young ET rats, flow-induced vasodilation depends on both $\mathrm{H}_{2} \mathrm{O}_{2}$ and NO. In old ET rats, $\mathrm{H}_{2} \mathrm{O}_{2}$ scavenging with catalase alone reduced flow-induced vasodilation (Fig. 1.5D) and scavenging of $\mathrm{O}_{2}{ }^{-}$and $\mathrm{H}_{2} \mathrm{O}_{2}$ with Tempol plus catalase abolished flow-induced vasodilation (Fig. 1.5D) indicating that $\mathrm{H}_{2} \mathrm{O}_{2}$ is critical for flow-induced vasodilation in old ET rats.

Next, we determined the contribution of NADPH oxidase-derived $\mathrm{O}_{2}{ }^{-}$to flow-induced vasodilation in young and old, SED and ET rats. The inhibition of NADPH oxidase with 
apocynin significantly reduced flow-induced vasodilation in young and old SED rats (Fig 1.6A); however, apocynin had no effect on flow-induced vasodilation in young and old ET rats (Fig. 1.6B) suggesting that $\mathrm{O}_{2}{ }^{-}$-derived $\mathrm{H}_{2} \mathrm{O}_{2}$ required for flow-induced vasodilation in the ET rats is not generated from NADPH oxidase-derived $\mathrm{O}_{2}^{-}$.

Role of $\mathrm{OH}$ in flow-induced vasodilation

SOD has the potential to generate $\mathrm{OH}^{-}$in the presence of iron and $\mathrm{OH}^{-}$may cause vasoconstriction (12). The addition of deferoxamine, an iron chelator, to Tempol-treated arterioles had no effect in young SED rats (Fig 1.7A); however, iron chelation restored the Tempol-induced loss of flow-induced vasodilation in arterioles from old SED (Fig 1.7B) indicating that $\mathrm{OH}^{-}$ generated is eliciting a vasoconstriction. Deferoxamine added to Tempol-treated arterioles improved the Tempol-induced loss of flow-induced vasodilation observed in young and old ET rats (Fig. 1.7C and D), confirming that $\mathrm{O}_{2}^{-}$production increases with exercise training and may contribute to increased $\mathrm{OH}^{-}$-induced vasoconstriction in the presence of exogenous SOD and sufficient free iron. 


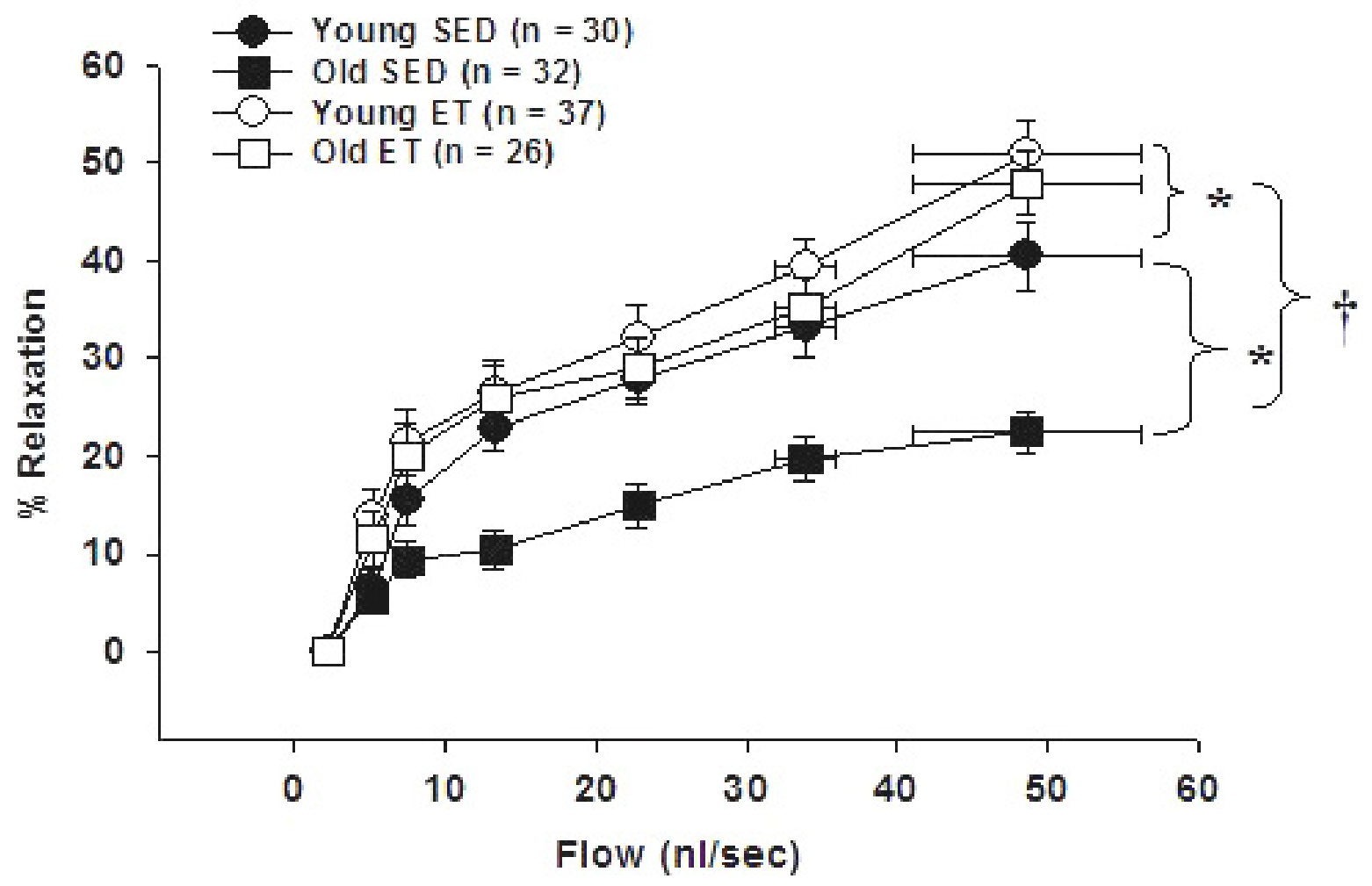

Figure 1.1 Diameter changes in response to increasing intraluminal flow in soleus muscle arterioles. Exercise training restores flow-induced vasodilation in old and improves flow-induced vasodilation in young rats. ${ }^{*} P<0.05$ vs. YSED and $\uparrow P<0.05$ vs. OSED. 

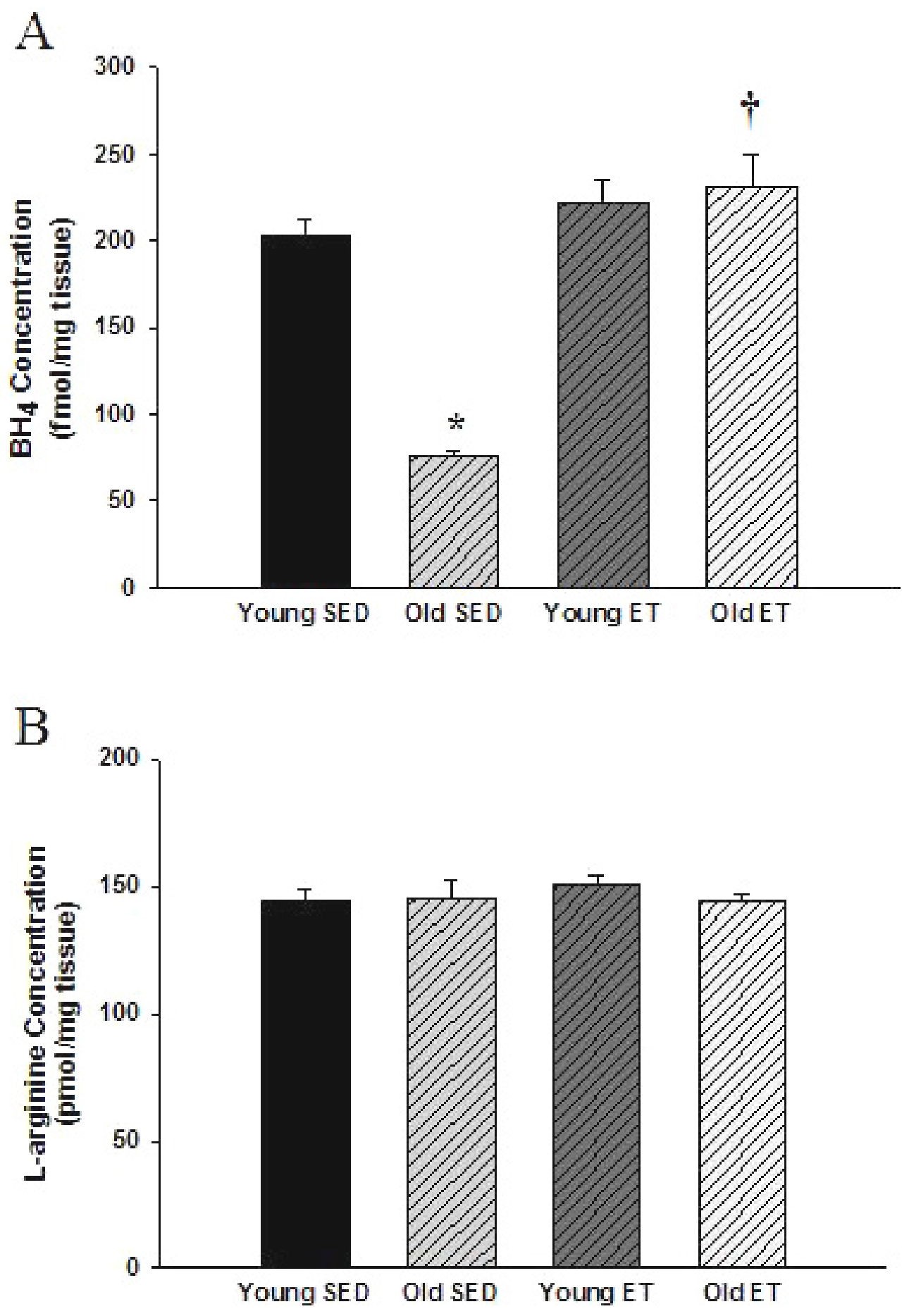

Figure 1.2. Arteriolar $\mathrm{BH}_{4}$ and $\mathrm{L}$-arginine content in soleus muscle arterioles from young and old, sedentary and exercise-trained rats. (A) Exercise training restores age-related declines in arteriolar $\mathrm{BH}_{4}$ levels in soleus muscle arterioles. (B) Aging and exercise training had no effect on arteriolar L-arginine levels in soleus muscle arterioles. ${ }^{*} P<0.05$ vs. YSED and $\dagger P<0.05$ vs. OSED. $\mathrm{n}=6-8$ per group. 
A

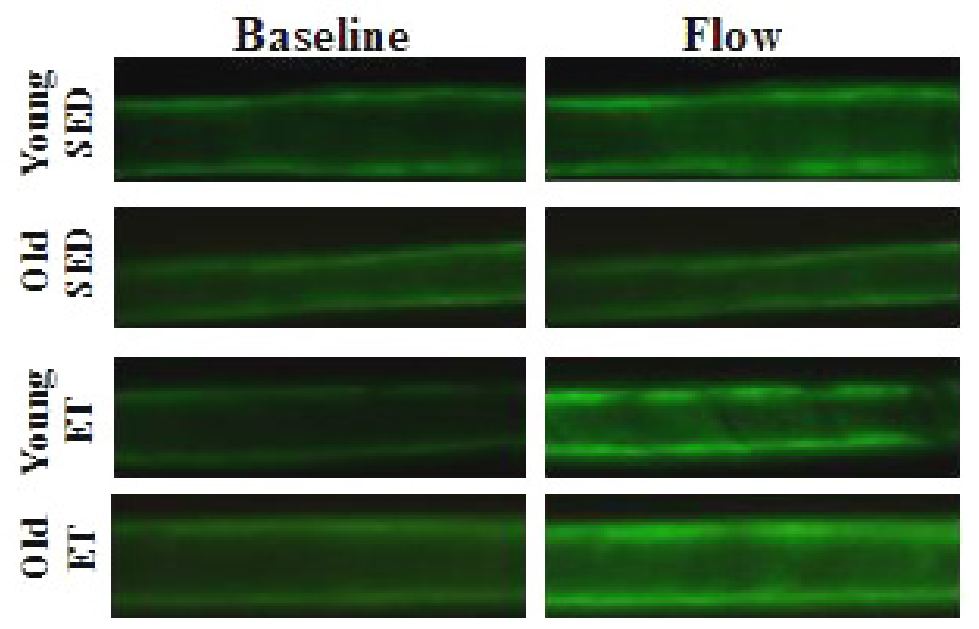

B

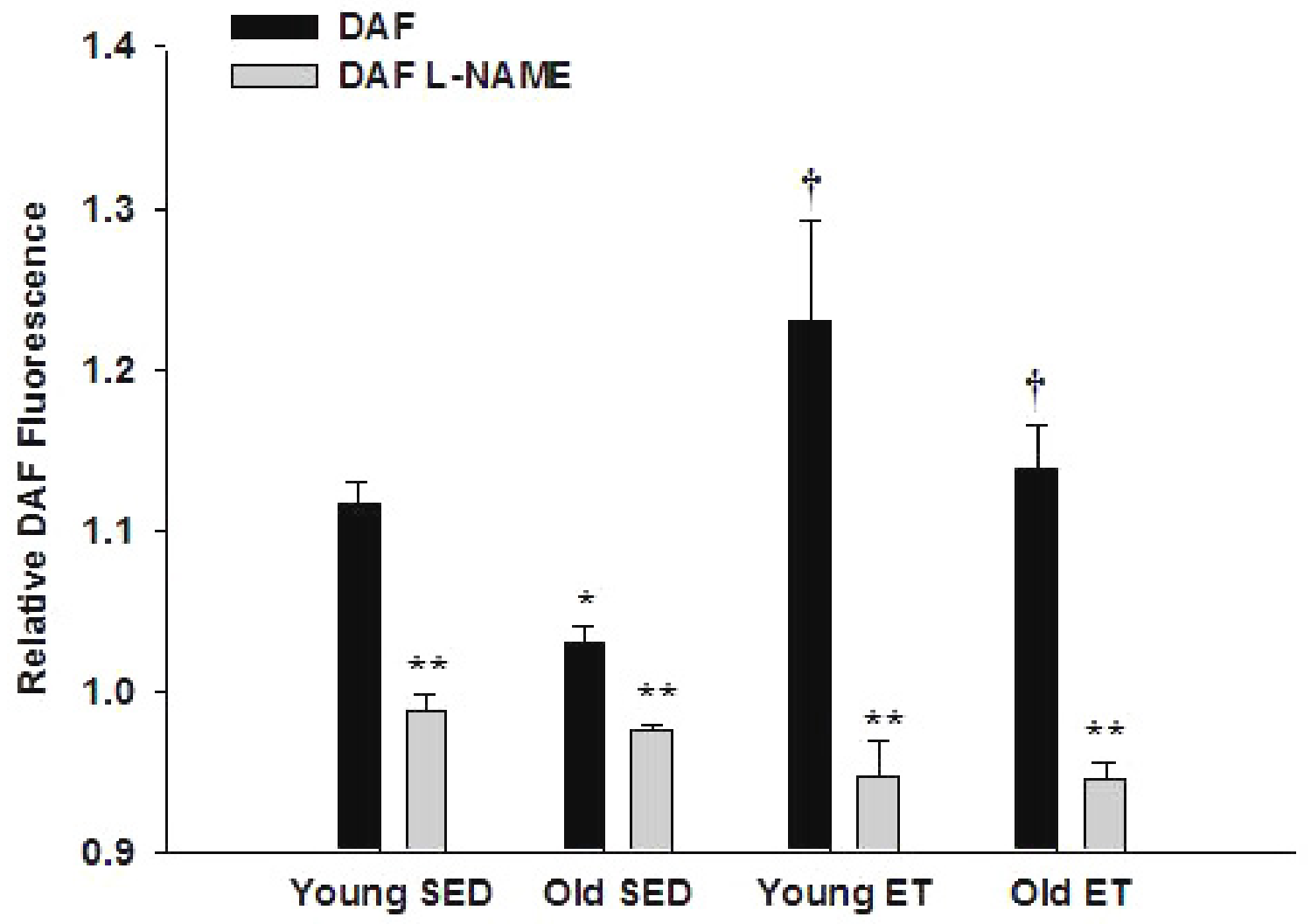

Figure 1.3. Flow-stimulated DAF fluorescence in soleus muscle arterioles from young and old, sedentary and exercise-trained rats. (A) DAF fluorescence indicates NO bioavailability in soleus muscle arterioles from young and old, sedentary and exercise trained rats at baseline and during flow stimulation (34 nl/s). (B) Summarized data indicate that flow-stimulated DAF fluorescence is reduced in soleus muscle arterioles from old SED rats. Exercise training restored flow-stimulated NO availability in arterioles from old rats and increased flow-stimulated NO availability in young rats. L-NAME inhibited DAF fluorescence in soleus muscle arterioles from all rats. ${ }^{*} P<0.05$ vs. young $\mathrm{SED}, \uparrow P<0.05$ vs. respective SED group, and $* * P<0.05$ control vs. L-NAME. $n=8-10$ per group. 


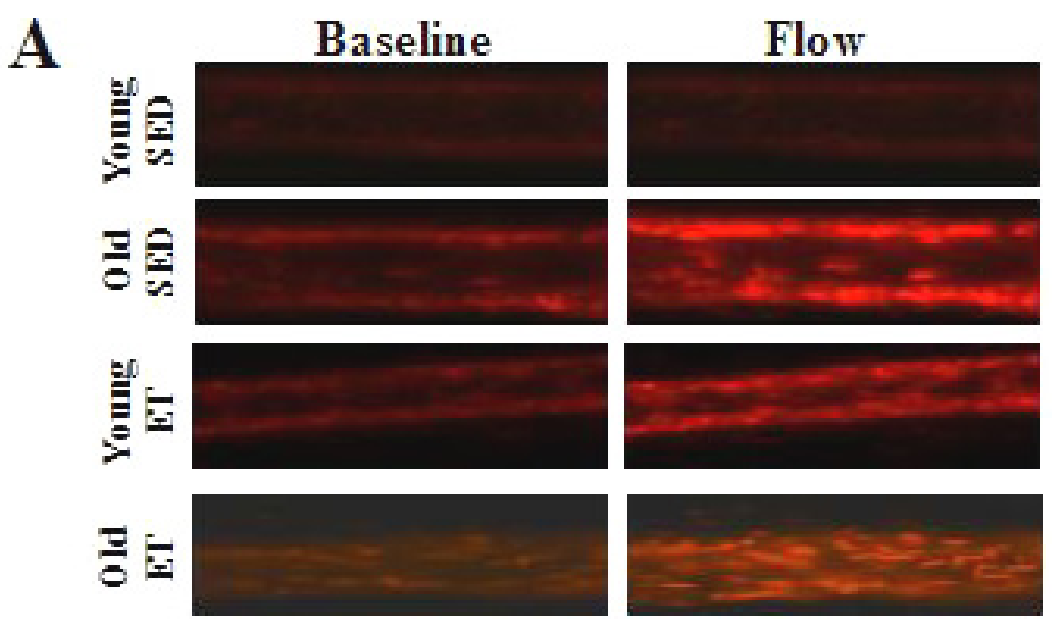

B

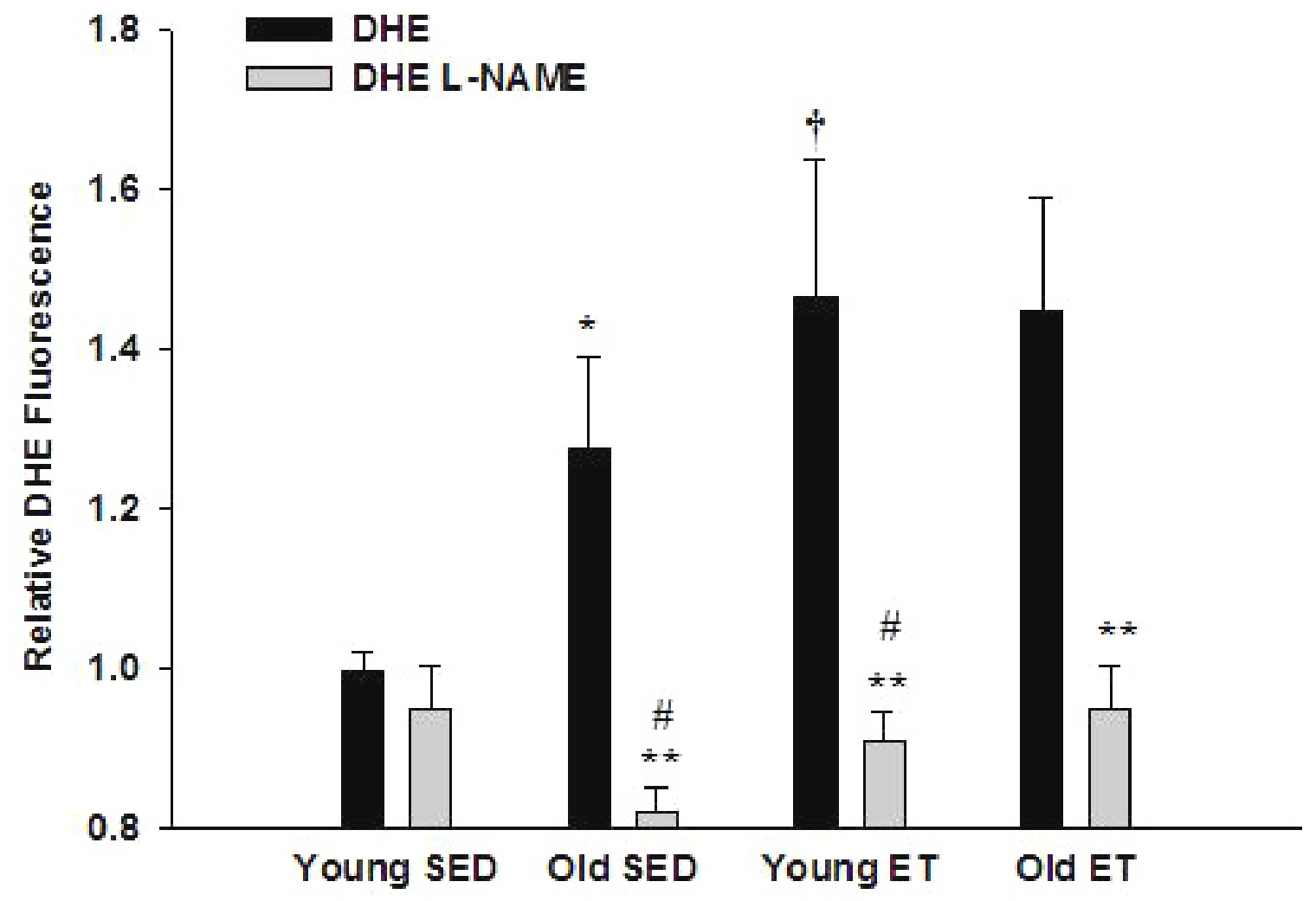

Figure 1.4. Flow-induced DHE fluorescence (an indicator of superoxide production) in soleus muscle arterioles of young and old, sedentary and exercise-trained rats. (A) DHE fluorescence indicates $\mathrm{O}_{2}^{-}$production in soleus muscle arterioles from young and old, sedentary and exercise trained rats at baseline and during flow stimulation (34nl/s). (B) Summarized data indicate that flow stimulated an increase in DHE fluorescence in soleus muscle arterioles from old SED rats. Exercise training increased DHE fluorescence in young rats; however, had no effect in old rats. L-NAME blocks DHE fluorescence in soleus muscle arterioles from all but young SED rats. ${ }^{*} P<0.05$ vs. young SED, $\dagger P<0.05$ vs. old SED, ${ }^{* *} P<0.05$ control vs. L-NAME, and \# $P$ $<0.05 \Delta$ in DHE fluorescence with L-NAME vs. young SED. $\mathrm{n}=9-11$ per group. 

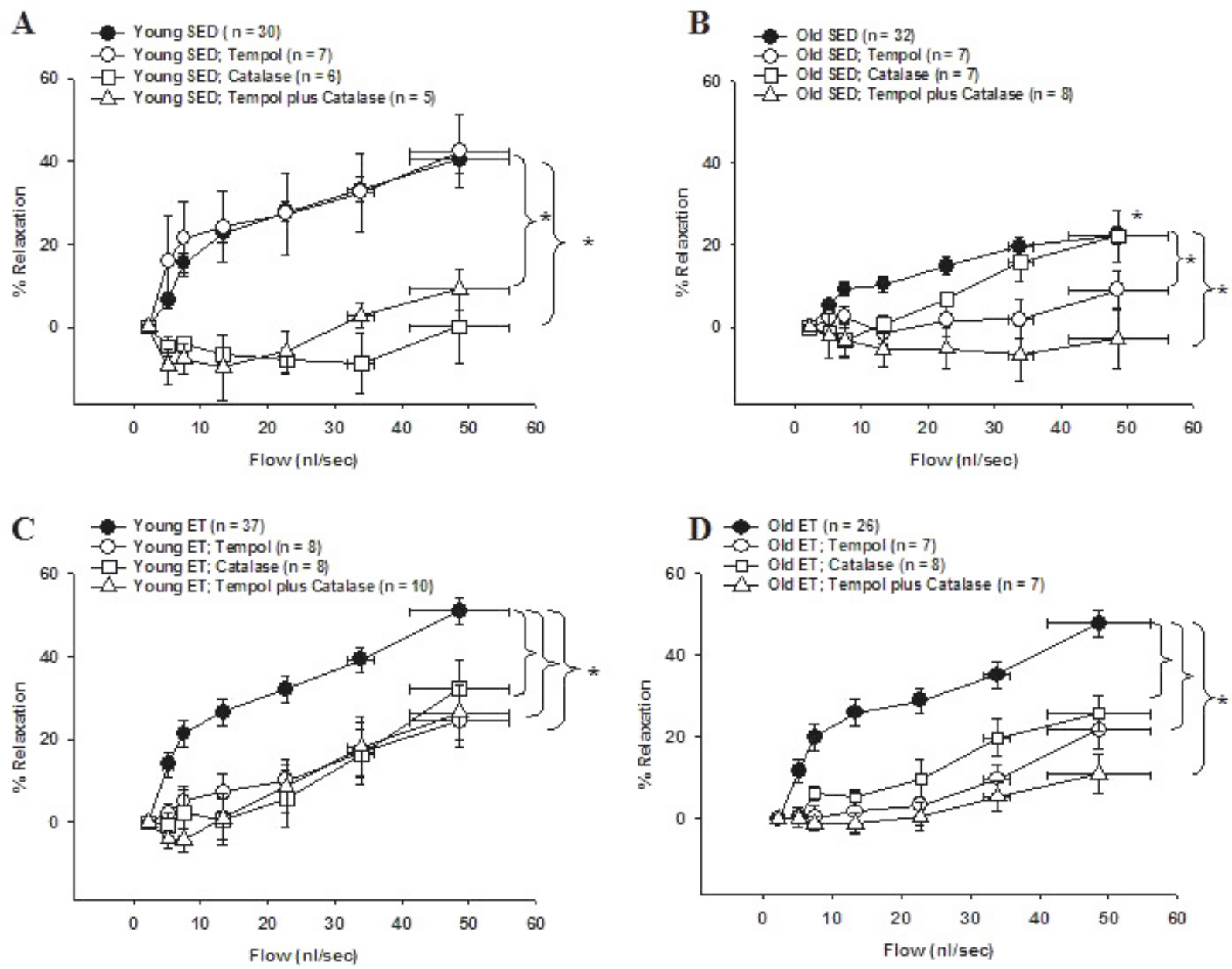

Figure 1.5. Effects of Tempol and catalase on flow-induced vasodilation of soleus muscle arterioles from young and old, sedentary and exercise-trained rats. (A) In young SED rats, Tempol had no effect, but catalase alone and Tempol + catalase completely abolished flow induced vasodilation, (B) In old SED rats, catalase had no effect but Tempol and Tempol + catalase reduced flow induced vasodilation, (C) All treatments reduced flow-induced vasodilation in young ET, and (D) old ET rats. ${ }^{*} P<0.05$ vs. control response. 
A

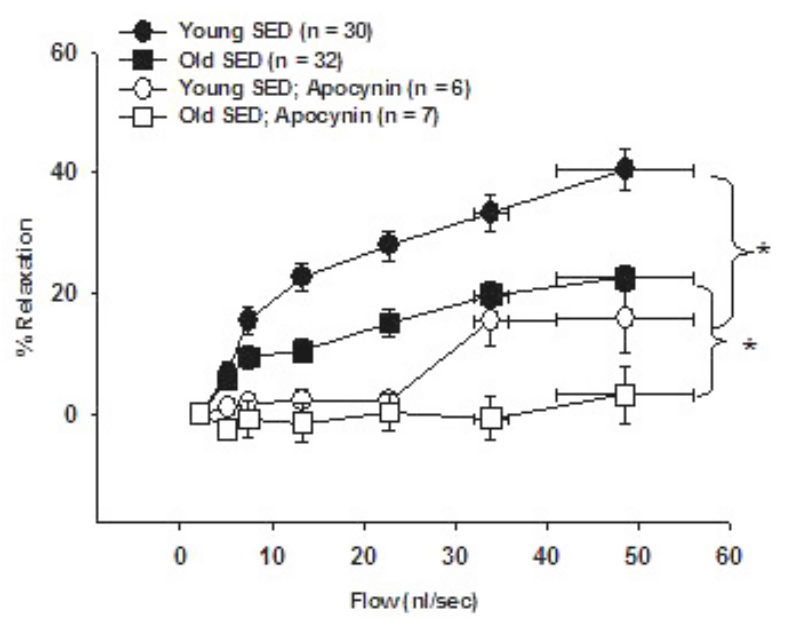

$\mathrm{B}$

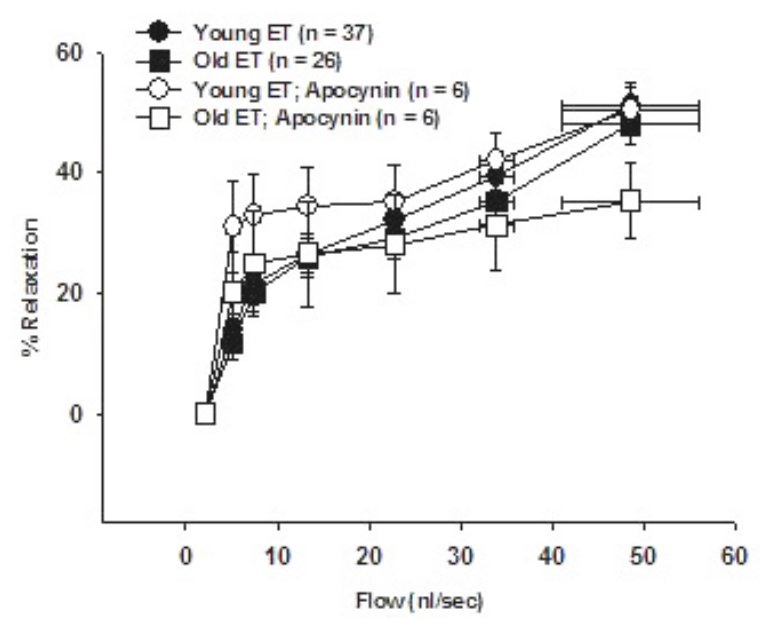

Figure 1.6. Role of NADPH oxidase-derived $\mathrm{O}_{2}^{-}$production in flow-induced vasodilation in soleus muscle arterioles of young and old, sedentary and exercise-trained rats. (A) NADPH oxidase inhibition with Apocynin reduced flow-induced vasodilation in soleus muscle arterioles of young and old SED rats, (B) Inhibition of NADPH oxidase with apocynin had no effect on flowinduced vasodilation in soleus muscle arterioles of young and old ET rats. ${ }^{*} P<0.05$ vs. control response. 

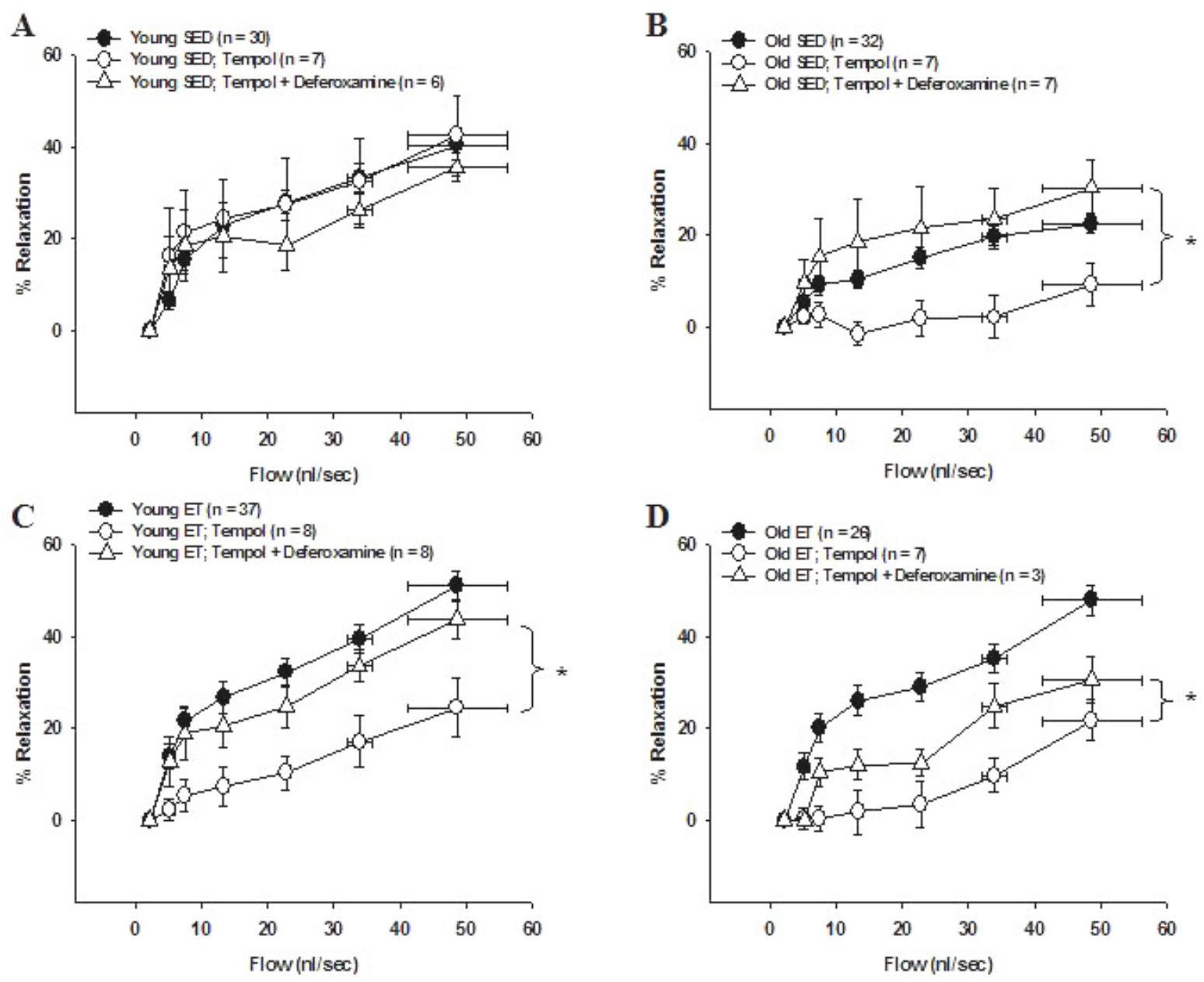

Figure 1.7. Effects of Tempol and Deferoxamine on flow-induced vasodilation in soleus muscle arterioles of young and old, sedentary and exercise-trained rats. (A) In young SED rats, Tempol and Tempol + Deferoxamine, an iron chelator, had no effect on flow-induced vasodilation, (B) In old SED rats, Tempol reduced Tempol + Deferoxamine improved flowinduced vasodilation, (C) In young ET rats, Tempol reduced and Tempol + Deferoxamine restored flow-induced vasodilation, (D) In old SED rats, Tempol reduced flow-induced vasodilation; however, Tempol + Deferoxamine improved flow-induced vasodilation in the old ET. $* P<0.05$ vs. control response. 


$\begin{array}{cccc}\begin{array}{c}\text { Young SED } \\ (\mathrm{n}=30)\end{array} & \begin{array}{c}\text { Young ET } \\ (\mathrm{n}=37)\end{array} & \begin{array}{c}\text { Old SED } \\ (\mathrm{n}=32)\end{array} & \begin{array}{c}\text { Old ET } \\ (\mathrm{n}=26)\end{array}\end{array}$

\section{Animal Characteristics}

Body Wt (g)

$371 \pm 5$

$348 \pm 4$

$437 \pm 6 *$

$379=5 \dagger$

Soleus muscle wt (mg)

$155.9=3.8 \quad 164.6 \pm 3.0$

$165.7 \pm 3.2^{*}$

$168.8=3.9$

Soleus wt/Body wt (mg/g)

$.41 \pm 0.01$

$.47 \pm 0.01^{*}$

$.37 \pm 0.01^{*}$

$.45 \pm 0.01 \dagger$

Vessel Characteristics

\begin{tabular}{|c|c|c|c|c|}
\hline Maximal Diameter $(\mu \mathrm{m})$ & $130=4$ & $127 \pm 4$ & $123 \pm 4$ & $124=5$ \\
\hline Spontaneous tone (\%) & $\begin{array}{l}51=2 \\
(\mathrm{n}=30)\end{array}$ & $\begin{array}{l}54=2 \\
(\mathrm{n}=37)\end{array}$ & $\begin{array}{l}51=2 \\
(\mathrm{n}=33)\end{array}$ & $\begin{array}{l}57=2 \\
(\mathrm{n}=26)\end{array}$ \\
\hline with Tempol & $\begin{array}{l}48=5 \\
(\mathrm{n}=7)\end{array}$ & $\begin{array}{l}47=5 \\
(\mathrm{n}=8)\end{array}$ & $\begin{array}{l}61=6 \\
(\mathrm{n}=7)\end{array}$ & $\begin{array}{l}59 \pm 3 \\
(\mathrm{n}=10)\end{array}$ \\
\hline with Tempol + Catalase & $\begin{array}{l}50=5 \\
(\mathrm{n}=5)\end{array}$ & $\begin{array}{l}53=4 \\
(\mathrm{n}=10)\end{array}$ & $\begin{array}{l}54=3 \\
(\mathrm{n}=10)\end{array}$ & $\begin{array}{l}57=3 \\
(\mathrm{n}=7)\end{array}$ \\
\hline with Catalase & $\begin{array}{l}45 \pm 2 \\
(\mathrm{n}=6)\end{array}$ & $\begin{array}{l}53=5 \\
(\mathrm{n}=9)\end{array}$ & $\begin{array}{l}55 \pm 3 \\
(\mathrm{n}=7)\end{array}$ & $\begin{array}{l}56 \pm 6 \\
(\mathrm{n}=9)\end{array}$ \\
\hline with Apocynin & $\begin{array}{l}46 \pm 3 \\
(\mathrm{n}=6)\end{array}$ & $\begin{array}{l}52=5 \\
(\mathrm{n}=6)\end{array}$ & $\begin{array}{l}57=4 \\
(\mathrm{n}=7)\end{array}$ & $\begin{array}{l}56=4 \\
(\mathrm{n}=6)\end{array}$ \\
\hline $\begin{array}{l}\text { with Tempol + } \\
\text { Deferoxamine }\end{array}$ & $\begin{array}{l}54=4 \\
(\mathrm{n}=6)\end{array}$ & $\begin{array}{l}48=5 \\
(\mathrm{n}=9)\end{array}$ & $\begin{array}{l}64=3 \\
(\mathrm{n}=7)\end{array}$ & $\begin{array}{l}60=5 \\
(\mathrm{n}=3)\end{array}$ \\
\hline
\end{tabular}

Table 1.1. Soleus muscle and vessel characteristics of young and old, sedentary and exercisetrained rats. Maximal diameter was recorded in $\mathrm{Ca}^{2+}$-free physiological saline solution with $100 \mu \mathrm{M}$ sodium nitroprusside. Tone $(\%)=[($ maximal diameter - diameter with tone $) /$ maximal diameter $] \times 100$. $* P<0.05$ vs. YSED and $\uparrow P<0.05$ vs. old SED. 


\section{Discussion}

Several important new findings emerge from this study. (1) The balance between $\mathrm{O}_{2}{ }^{-}$and NO signaling is altered by age and exercise training in skeletal muscle arterioles. (2) $\mathrm{BH}_{4}$ content is reduced with age and restored with exercise training in skeletal muscle arterioles from old rats. The age-related decline in arteriolar $\mathrm{BH}_{4}$ content is concomitant to a decrease in NO signaling and an increase in ROS signaling. The exercise-induced restoration of $\mathrm{BH}_{4}$ content potentially contributes to increased NO signaling in skeletal muscle arterioles of old ET rats. (3) In conditions of limited $\mathrm{BH}_{4}$, such as occurs with age, NO-mediated signaling declines and eNOS-generated $\operatorname{ROS}\left(\mathrm{O}_{2}^{-}\right)$increases in skeletal muscle arterioles. (4) Exercise training increases both NO- and ROS-mediated signaling in skeletal muscle arterioles of young rats, but a balance in these signaling systems is maintained, resulting in robust flow-induced vasodilation.

Aging is associated with declines in flow-induced NO-dependent vasodilation in conduit and resistance arterioles of humans and rats $(38,54,97,145)$. NO bioavailability may be mediated by several possible mechanisms including reduced eNOS protein abundance or activity, limited availability of substrate (L-arginine) or co-factor $\left(\mathrm{BH}_{4}\right)$, or increased degradation of NO by ROS. We recently reported that a deficit in availability of $\mathrm{BH}_{4}$ is associated with an agedependent decline of endothelium-dependent vasodilation in skeletal muscle arterioles (33). When $\mathrm{BH}_{4}$ is limited, eNOS becomes uncoupled, producing both $\mathrm{O}_{2}{ }^{-}$and $\mathrm{NO}(8,26)$. Eskurza et al. reported that an acute bolus of $\mathrm{BH}_{4}$ restored flow-mediated dilation in older sedentary humans (45) and the $\mathrm{BH}_{4}$ precursor, sepiapterin, augments flow-induced vasodilation in skeletal muscle arterioles in aged rats (33). These findings support the hypothesis that the age-associated decrements in $\mathrm{BH}_{4}$ contribute to reduced $\mathrm{NO}$ bioavailability. We tested the hypothesis that eNOS uncoupling increases with age in skeletal muscle arterioles due to lack of $\mathrm{BH}_{4}$. To our knowledge, this is the first study to demonstrate that age-related reduction of $\mathrm{BH}_{4}$ (Fig. 1.2A) is accompanied 
by impaired flow-induced NO signaling (Fig. 1.3) and increased eNOS-derived $\mathrm{O}_{2}{ }^{-}$production in skeletal muscle arterioles.

Increases in $\mathrm{O}_{2}^{-}$production, observed with age, scavenge $\mathrm{NO}$ and may alter endothelial function (40). In soleus muscle feed arteries, SOD-1 protein content, but not mRNA expression, is reduced in aged rats (145); however, SOD-1 activity appears to increase in the aorta of aged rats (37). Additionally, catalase activity declines in aorta from aged rats (37); however, catalase protein content does not change with age in human endothelial cells (40). Exercise training potentially improves NO bioavailability by enhanced regulation of $\mathrm{O}_{2}{ }^{-}$and ROS by inducing antioxidant defense systems and reducing $\mathrm{O}_{2}{ }^{-}$generating systems. Rush et al. demonstrated in aortic endothelial cells (AEC) from young pigs that exercise training increased SOD-1 protein abundance and activity but had no effect on catalase content. In contrast, exercise training decreased the NADPH pro-oxidant subunit, p67phox protein (113). Graham and Rush further demonstrated that the cytosolic subunit of NADPH oxidase, gp91phox, is reduced with training in aorta homogenates from young pigs (56). Based on these observations, it appears that exercise training improves the management of superoxide (and subsequent ROS) generation by enhancing antioxidant mechanisms and reducing pro-oxidant pathways. However, a paradox emerges as $\mathrm{O}_{2}{ }^{-}$ generation and oxidant stress increases with exercise training $(4,5,30)$. Our data suggest that exercise training-induced enhancement of flow-induced vasodilation occurs because both NO and ROS mediated signaling increase in a balanced fashion.

Even though high levels of ROS may potentiate the pathology of cardiovascular diseases (62), it is becoming increasingly clear that ROS can serve as signaling molecules, which mediate normal cellular functions (41). $\mathrm{H}_{2} \mathrm{O}_{2}$ generated by the dismutation of $\mathrm{O}_{2}{ }^{-}$is emerging as an important vasodilator and signaling molecule in the vasculature. Endothelium-derived $\mathrm{H}_{2} \mathrm{O}_{2}$ contributes to flow-induced vasodilation in isolated coronary arterioles (72). Marvar et al. demonstrated that $\mathrm{H}_{2} \mathrm{O}_{2}$ produced by contracting skeletal muscle elicits a vasodilatory response on 
nearby skeletal muscle arterioles (82). Furthermore, exogenous $\mathrm{H}_{2} \mathrm{O}_{2}$ is vasodilatory in a variety of vascular beds including pulmonary (13), skeletal muscle (27), cerebral (139) and mesenteric beds (84). $\mathrm{H}_{2} \mathrm{O}_{2}$ also indirectly alters vascular reactivity by activating eNOS via phosphoinositide 3-kinase (PI3K) (133). Our data indicate that $\mathrm{H}_{2} \mathrm{O}_{2}$ is an important mediator of flow-induced vasodilation of skeletal muscle arterioles from young SED rats. In addition, our data reveal that flow-induced $\mathrm{H}_{2} \mathrm{O}_{2}$ signaling declines with age, but is restored by exercise training.

SOD is an important anti-oxidant enzyme that reduces oxidant stress by dismutating $\mathrm{O}_{2}^{-}$ into $\mathrm{H}_{2} \mathrm{O}_{2}$; however, in the presence of catalytic transition metals, SOD can rapidly form $\mathrm{OH}^{-}$ (107). $\mathrm{H}_{2} \mathrm{O}_{2}$ generates $\mathrm{OH}^{-}$through metal-catalyzed reactions, such as the Fenton reaction as follows: $\mathrm{H}_{2} \mathrm{O}_{2}+\mathrm{Fe}^{2+} \rightarrow \mathrm{Fe}^{3+}+\bullet \mathrm{OH}+\mathrm{OH}^{-}$. The formation of $\mathrm{OH}^{-}$is further promoted by the presence of $\mathrm{O}_{2}^{-}$, which reacts with $\mathrm{Fe}^{3+}$ to produce $\mathrm{Fe}^{2+}$ through the Haber-Weiss reaction (60, 108). The net effect of SOD is the dismutation of $\mathrm{O}_{2}{ }^{-}$to produce either the vasodilatory $\mathrm{H}_{2} \mathrm{O}_{2}$ or in the presence of $\mathrm{Fe}^{2+}, \mathrm{OH}^{-}$, which is a potent vasoconstrictor. Iron chelators, such as deferoxamine, inhibit the generation of $\mathrm{OH}^{-}$by preventing iron ions from catalyzing redox reactions, thereby improving vasodilation in coronary arterioles $(101,131)$. Iron accumulation increases with age in skeletal muscle, liver, and cardiac muscle, and is associated with increased oxidative stress and diminished functional capacity $(12,150)$. Age-associated increases in iron accompanied by diminished catalase activity (37) can produce excess $\mathrm{OH}^{-}$contributing to decreased flow-induced vasodilation in skeletal muscle arterioles of old rats (Fig. 1.2B). Exercise training increases iron in skeletal muscle of rats (99) and catalase activity in the vasculature remains unchanged with exercise training (113). In conjunction with increases in $\mathrm{O}_{2}^{-}$generation with exercise training observed in the present study, elevated $\mathrm{OH}^{-}$production may result when arterioles are treated with an exogenous SOD. Increased $\mathrm{OH}^{-}$production is a potential 
mechanism by which iron chelation improves SOD-associated decrements in flow-induced vasodilation in skeletal muscle arterioles.

In conclusion, the results of the present study confirm previous findings that aging impairs endothelium-dependent, $\mathrm{NO}$-mediated vasodilation and $\mathrm{BH}_{4}$ levels in rat skeletal muscle arterioles $(33,97)$. The present findings further demonstrate that limited availability of $\mathrm{BH}_{4}$, as observed in old SED rats, may contribute to eNOS uncoupling, and both a subsequent decrease in NO signaling and an increase in eNOS-derived $\mathrm{O}_{2}^{-}$generation. Exercise training restores $\mathrm{BH}_{4}$ levels and improves flow-induced NO production in arterioles from aged rats. Furthermore, exercise training increases both $\mathrm{NO}$ and ROS-mediated signaling in skeletal muscle arterioles, suggesting that exercise training-induced enhancement of flow-induced vasodilation in skeletal muscle arterioles involves a balance between $\mathrm{NO}$ and $\mathrm{O}_{2}{ }^{-}$-derived $\mathrm{ROS}$. Our results suggest that the beneficial effects of exercise training in the skeletal muscle resistance vascular involve much more than improvement of NO bioavailability. 


\section{Chapter III}

\section{Age and exercise training alter signaling through reactive oxygen species in the endothelium of skeletal muscle arterioles}

\section{Overview}

Exercise training ameliorates age-related impairments in endothelium-dependent vasodilation in soleus muscle arterioles. Additionally, exercise training is associated with increased $\mathrm{O}_{2}{ }^{-}$ production. The purpose of this study was to determine the role of $\mathrm{O}_{2}{ }^{-}$and $\mathrm{O}_{2}{ }^{-}$-derived reactive oxygen species signaling in mediating endothelium-dependent vasodilation in skeletal muscle resistance arterioles from young and old, sedentary and exercise trained rats. Young (3 mo) and old (22 mo) male rats were either exercise trained (ET) or remained sedentary (SED) for 10 wks. To determine the impact of reactive oxygen species signaling on endothelium-dependent vasodilation, responses to acetylcholine were studied under control conditions and during the scavenging of $\mathrm{O}_{2}{ }^{-}$and/or $\mathrm{H}_{2} \mathrm{O}_{2}$. Reactivity to $\mathrm{O}_{2}{ }^{-}$and $\mathrm{H}_{2} \mathrm{O}_{2}$ was also determined. Exercise training reversed the age-related impairment of endothelium-dependent vasodilation. Tempol, a scavenger of $\mathrm{O}_{2}^{-}$, reduced $\mathrm{ACh}$-induced vasodilation in all groups. Catalase reduced $\mathrm{ACh}$-induced vasodilation in all groups. Similarly, the addition of catalase to Tempol-treated arterioles reduced ACh-induced vasodilation in all groups. Aging had no effect on protein content of SOD-1, catalase, or GPx; however exercise training increased protein content of SOD-1 in young and old rats, catalase in young rats, and GPx in old rats. In summary, exercise training restores endothelium-dependent vasodilation in soleus muscle arterioles. This adaptation is mediated, in part, through enhanced $\mathrm{O}_{2}{ }^{-} / \mathrm{H}_{2} \mathrm{O}_{2}$ signaling. 


\section{Introduction}

Endothelial dysfunction of skeletal muscle declines with age primarily due to decreased nitric oxide (NO) availability $(38,97,122,129)$. In feed arteries of skeletal muscle, reduction of NO-dependent vasodilation is accompanied by reduced expression of endothelial nitric oxide synthase (eNOS) (145). In contrast, we have previously reported that NO-mediated vasodilation of soleus muscle resistance arteries declines with advancing age despite an increase in eNOS protein levels (122). Thus, the age related decline in bioavailability of NO may be dependent upon numerous factors that regulate both its production and degradation. eNOS activity, and subsequent NO production, is regulated by availability of substrate and co-factors, by proteinprotein interactions, and by coordinated phosphorylation and dephosphorylation of eNOS $(48,51$, 61). Degradation of NO is dependent upon the presence of cellular superoxide $\left(\mathrm{O}_{2}^{-}\right)$, a by-product of cellular respiration, which reacts readily with NO, eliminating its vasodilatory action (121).

Cellular $\mathrm{O}_{2}{ }^{-}$is regulated by the enzyme superoxide dismutase (SOD), which catalyzes the dismutation of $\mathrm{O}_{2}{ }^{-}$into hydrogen peroxide $\left(\mathrm{H}_{2} \mathrm{O}_{2}\right)$. Thus, $\mathrm{NO}$ bioavailability and maintenance of NO-mediated vasodilation is linked to SOD activity. In addition, both $\mathrm{O}_{2}{ }^{-}$and $\mathrm{O}_{2}{ }^{-}$-derived reactive oxygen species (ROS) exhibit vasoactive properties. For example, $\mathrm{H}_{2} \mathrm{O}_{2}$ has been reported to produce hyperpolarization and relaxation of vascular smooth muscle $(84,91)$. Furthermore, $\mathrm{H}_{2} \mathrm{O}_{2}$ regulates eNOS protein expression and activity $(133,152)$. Thus, tight regulation of $\mathrm{O}_{2}{ }^{-}$and $\mathrm{O}_{2}{ }^{-}$-derived $\mathrm{ROS}$ is necessary for maintenance of optimal endotheliumdependent function, and an age-related increase in vascular $\mathrm{O}_{2}^{-}$is a likely contributor to ageinduced endothelial dysfunction.

Exercise training reverses age-related reductions in NO bioavailability, thus improving endothelium-dependent vasodilation. In skeletal muscle arterioles of both young and aged rats, exercise training increases eNOS protein expression. This increase in enzyme expression may 
contribute to exercise training-induced amelioration of endothelial function in aged rats (122). Additionally, exercise training has been reported to increase vascular expression of SOD. Rush et al demonstrated that, in aortic endothelial cells (AEC) from young pigs, SOD-1 protein abundance and activity increased with training (113). Although SOD-1 expression declines with age in resistance arteries from skeletal muscle (145) and mesentery (127), the interactive effects of age and exercise training on the expression of anti-oxidant proteins have not been thoroughly investigated in the skeletal muscle resistance vasculature.

Therefore, the purpose of this study was to determine the role of $\mathrm{O}_{2}^{-}$-derived $\mathrm{ROS}$ in mediating endothelium-dependent vasodilation in skeletal muscle resistance arterioles from young and old, sedentary and exercise-trained rats. We tested the hypothesis that age-related increases in $\mathrm{O}_{2}{ }^{-}$-derived ROS would contribute to endothelium-dependent vasodilation of skeletal muscle arterioles, despite an overall decline in endothelial function. We further hypothesized that exercise training would improve endothelium-dependent dilation, in part, through improved regulation of $\mathrm{O}_{2}^{-}$-derived $\mathrm{ROS}$ signaling.

\section{Methods}

Animals

All procedures in this study were approved by the Institutional Animal Care and Use Committees at West Virginia University. All methods complied fully with guidelines set in the Guide for the Care and Use of Laboratory Animals (National Institutes of Health, revised 1996). Young (3 mo) and old (22 mo) male Fischer 344 rats were obtained from Harlan (Indianapolis, IN), housed under a 12:12-h light-dark cycle, and given food and water ad libitum. Fischer 344 rats were chosen because cardiovascular function decreases with age in these rats, without the development of atherosclerosis or hypertension (76). 


\section{Exercise training}

All rats were habituated to treadmill exercise, during which each rat walked on a motor-driven treadmill at $5 \mathrm{~m} / \mathrm{min}\left(0^{\circ}\right.$ incline $), 5 \mathrm{~min} /$ day for 3 days. After habituation, young and old rats were randomly assigned to either a control sedentary (SED) group (young SED, $\mathrm{n}=37$, and old SED, $\mathrm{n}$ $=29$ ) or an exercise-trained (ET) group (young ET, $\mathrm{n}=25$, and old ET, $\mathrm{n}=21$ ). ET rats performed treadmill running at $15 \mathrm{~m} / \mathrm{min}$ ( $15^{\circ}$ incline $), 5$ days/wk, for $10-12 \mathrm{wk}$. The duration of running was gradually increased in the first $3 \mathrm{wk}$ until a 60 -min duration was reached. The rats continued to run 5 days/wk for $60 \mathrm{~min} /$ day for the remainder of the 10 - to 12 -wk training period. Vascular responses were determined at least $24 \mathrm{~h}$ after the last exercise bout in ET rats.

Muscle oxidative enzyme activity

To determine the efficacy of the training protocol, soleus muscle, was stored at $-80^{\circ} \mathrm{C}$ for determination of citrate synthase activity, a measure of muscle oxidative capacity (34).

\section{Microvessel preparation}

Rats were anesthetized with isoflurane $\left(5 \% / \mathrm{O}_{2}\right.$ balance $)$ and euthanized by decapitation. The gastrocnemius-plantaris-soleus muscle group was dissected free from both hindlimbs and placed in a cold $\left(4^{\circ} \mathrm{C}\right)$, filtered physiological saline solution (PSS) containing $145.0 \mathrm{mM} \mathrm{NaCl}, 4.7$ $\mathrm{mM} \mathrm{KCl}, 2.0 \mathrm{mM} \mathrm{CaCl}_{2}, 1.17 \mathrm{mM} \mathrm{MgSO}_{4}, 1.2 \mathrm{mM} \mathrm{NaH}_{2} \mathrm{PO}_{4}, 5.0 \mathrm{mM}$ glucose, $2.0 \mathrm{mM}$ pyruvate, $0.02 \mathrm{mM}$ EDTA, $3.0 \mathrm{mM}$ MOPS buffer, and $1 \mathrm{~g} / 100 \mathrm{ml} \mathrm{BSA}, \mathrm{pH} 7.4$. With the aid of a dissecting microscope (Olympus SVH10), first-order (1A) arterioles were dissected free of the soleus muscle, composed primarily of high-oxidative fibers (34), as described previously (97). The arterioles were then transferred to a Lucite chamber containing PSS with $1 \%$ albumin (pH 7.4) equilibrated with room air. Each end of the arteriole was cannulated with micropipettes filled with PSS-albumin solution and secured with nylon suture. Size and resistance of the pipettes were 
matched to within $1 \%$. The chamber was placed on the stage of an inverted microscope (Zeiss Axio40), equipped with a video camera (Panasonic BP310), video caliper (Colorado Video), and data-acquisition system (Power Lab). Arterioles were pressurized via two independent reservoirs and checked for leaks. If leaks were present, the arterioles were discarded. Vessels that were free from leaks were pressurized to $70 \mathrm{cmH}_{2} \mathrm{O}$, gradually warmed to $37^{\circ} \mathrm{C}$, and allowed to develop spontaneous tone during an initial equilibration period. The bathing solution was changed every 20 min during the course of the experiment.

\section{Evaluation of vasodilator responses}

Once a steady level of spontaneous tone was achieved, vasodilator responses to the cumulative addition of the endothelium-dependent vasodilator acetylcholine (ACh, $\left.10^{-9}-10^{-4} \mathrm{M}\right)$ was determined. To evaluate vascular smooth muscle responsiveness to exogenous NO, a concentration-response to diethylamineNONOate (Dea-NONOate, $10^{-9}-10^{-3} \mathrm{M}$ ) was determined. At the end of the concentration-response determinations, arterioles were placed in $\mathrm{Ca}^{2+}$-free PSS with $100 \mu \mathrm{M}$ of the NO donor, sodium nitroprusside, for $1 \mathrm{~h}$ to obtain the maximal passive diameter $(88,96,97)$.

Evaluation of inhibitory effects of Tempol, Catalase, Tempol + Catalase

To determine the role $\mathrm{O}_{2}{ }^{-}$and $\mathrm{O}_{2}{ }^{-}$-derived $\mathrm{ROS}$ on ACh-induced vasodilatation, responses to ACh were evaluated after a 20-min incubation under one of the following conditions: (1) SOD mimetic Tempol (100 $\mu \mathrm{M})(21),(2) \mathrm{H}_{2} \mathrm{O}_{2}$ scavenger, catalase (100U) (42, 44), or (3) Tempol (100 $\mu \mathrm{M})$ plus catalase (100U). To determine the role of $\mathrm{O}_{2}{ }^{-}$in scavenging of $\mathrm{NO}$, responses to DeaNONOate were evaluated after a 20 -min incubation with the SOD mimetic, Tempol $(100 \mu \mathrm{M})$ (21). 
Evaluation of vasoreactivity to $\mathrm{H}_{2} \mathrm{O}_{2}$ and $\mathrm{O}_{2}{ }^{-}$

To determine the reactivity of soleus muscle arterioles to $\mathrm{H}_{2} \mathrm{O}_{2}$ and a $\mathrm{O}_{2}{ }^{-}$generator, concentration response curves were generated using authentic $\mathrm{H}_{2} \mathrm{O}_{2}\left(1 \mathrm{e}^{-6}-1 \mathrm{e}^{-2} \mathrm{M}\right)$ and pyrogallol, an $\mathrm{O}_{2}^{-}$generator $\left(1 \mathrm{e}^{-8}-1 \mathrm{e}^{-4} \mathrm{M}\right)$.

Immunoblot analysis of soleus muscle arteriolar protein

Differences in SOD-1, catalase, and glutathione peroxidase-1 (GPx1) protein content in skeletal muscle resistance arterioles were assessed by immunoblot analysis. Arterioles were isolated, snap frozen, and stored at $-80^{\circ} \mathrm{C}$ until analysis. Vessels were lysed in $1 \mathrm{X}$ sample buffer (62.5 mM Tris $\mathrm{pH}$ 6.8, 2\% SDS, $6 \mathrm{M}$ urea, $160 \mathrm{mM}$ DTT, 0.1\% bromophenol blue), followed by 3 $\mathrm{X} 2$ minute boil, vortex, and quick spin. After a final 1-minute sonication step, protein concentration was determined using the NanoOrange Protein Quantification Kit (Invitrogen). Samples (10 $\mu \mathrm{g}$ total protein) were subjected to SDS-polyacrylamide gel electrophoresis (10\%) and then transferred to nitrocellulose membranes. Membranes were blocked for $1 \mathrm{~h}$ at room temperature (5\% nonfat dry milk in Tris-buffered saline $+0.1 \%$ Tween-20) and then incubated overnight at $4^{\circ}$ with primary antibodies for SOD-1 1:5000 (Stressgen), catalase 1:6000 (Chemicon), and GPx1 1:4000 (Abcam) or $\beta$-actin 1:2000, (Cell Signaling Technologies). After washing, membranes were incubated with respective horseradish peroxide-conjugated secondary antibody for $1 \mathrm{~h}$ at room temperature. Peroxidase activity was determined using SuperSignal West Femto (Pierce), with image analysis performed using ImageJ (NIH). Loading differences were normalized by expressing all data as densitometric units for protein of interest relative to $\beta$-actin.

\section{Data Analysis}


Data are expressed as means \pm standard error (SE). Spontaneous tone was calculated as a percent constriction in relation to maximal diameter as determined by the following equation:

$$
\text { Spontaneous Tone }(\%)=\left[\left(\mathrm{D}_{\mathrm{M}}-\mathrm{D}_{\mathrm{T}}\right) / \mathrm{D}_{\mathrm{M}}\right] \times 100
$$

where $\mathrm{D}_{M}$ is the maximal diameter recorded at $70 \mathrm{~cm} \mathrm{H}_{2} \mathrm{O}$ and $\mathrm{D}_{T}$ is the steady-state baseline diameter recorded at the same pressure. The vasodilator responses are expressed as percent relaxation as calculated by the formula:

$$
\text { Relaxation \% }=\left[\left(\mathrm{D}_{\mathrm{S}}-\mathrm{D}_{\mathrm{B}}\right) /\left(\mathrm{D}_{\mathrm{M}}-\mathrm{D}_{\mathrm{B}}\right)\right] \times 100
$$

where $\mathrm{D}_{\mathrm{S}}$ is the arteriolar diameter at the respective stage, $\mathrm{D}_{\mathrm{B}}$ is the diameter recorded immediately prior to initiation of the concentration-diameter curves, and $\mathrm{D}_{\mathrm{M}}$ is the maximal diameter for the arteriole. Concentration-diameter curves were evaluated by a three-way ANOVA with repeated measure on one factor, in order to detect differences within concentrations and between experimental groups. Group differences in animal and vessel characteristics and citrate synthase activity were compared by a two-way ANOVA. Group differences in SOD-1, catalase, or GPx1 protein content were assessed using a two-way ANOVA. In all experiments, $\mathrm{n}$ indicated the number of animals studied. Statistical significance was defined as $P \leq 0.05$.

\section{Results}

Animals

Body mass increased with age (Table 2.1). Exercise training resulted in lower body mass in both young and old rats. Soleus muscle mass increased with age, but was unchanged by exercise training (Table 2.1). Soleus muscle mass to body mass ratio decreased with age and increased with exercise training (Table 2.1). Exercise training increased citrate synthase activity by approximately $18.3 \%$ in soleus muscle of young rats, and by approximately $20.1 \%$ in soleus 
muscles of old rats (Table 2.1), confirming the efficacy of the exercise training as previously reported (122).

Vessel characteristics

Maximal diameter of soleus muscle arterioles was not different between groups (Table 2.1). The levels of spontaneous tone were similar between groups (Table 2.1) and treatment with Tempol, catalase or Tempol plus catalase, had no effect on spontaneous tone in any group (Table 2.1).

Endothelium-dependent vasodilation to ACh

ACh-induced vasodilation was impaired in soleus muscle arterioles from old SED rats, confirming previous results (122) (Fig. 2.1). Exercise training restored ACh-induced vasodilation in soleus muscle arterioles from old rats to that of young SED rats and improved ACh-induced dilation in young rats at ACh concentrations of $1 \mathrm{e}^{-5}$ and $1 \mathrm{e}^{-4} \mathrm{M}$ (Fig. 2.1). Effects of Tempol, catalase and Tempol + catalase on ACh-induced vasodilation

Surprisingly, dismutating $\mathrm{O}_{2}{ }^{-}$to $\mathrm{H}_{2} \mathrm{O}_{2}$ with Tempol, reduced ACh-induced vasodilation in young and old, SED and ET rats (Figs. 2.2A and 2.3A). Furthermore, Tempol eliminated the agerelated differences in SED rats suggesting that alterations of $\mathrm{O}_{2}^{-}$-signaling contribute to the ageassociated impairment in ACh-induced vasodilation. Additionally, SOD in the presence of catalytic transition metals, can rapidly form the vasoconstrictor, hydroxyl radical $\left(\mathrm{OH}^{-}\right)(107,131)$. Iron increases with age and with exercise training in skeletal muscle and may contribute to Tempol-induced $\mathrm{OH}^{-}$production, most prominently in old ET rats (Fig. 2.3A) (99, 150). Removal of $\mathrm{H}_{2} \mathrm{O}_{2}$ by catalase reduced ACh-induced vasodilation in all groups of rats (Fig. 2.2B and 2.3B) indicating that $\mathrm{H}_{2} \mathrm{O}_{2}$ is an important signaling molecule in ACh-induced vasodilation in skeletal muscle arterioles. Simultaneous scavenging of $\mathrm{O}_{2}{ }^{-}$and $\mathrm{H}_{2} \mathrm{O}_{2}$ reduced ACh-induced vasodilation all groups (Fig. 2.2C and 2.3C) and eliminated age differences in SED rats (Fig. 2.2C) revealing 
that a proper balance of $\mathrm{O}_{2}{ }^{-}$and $\mathrm{H}_{2} \mathrm{O}_{2}$ must be maintained for ACh-induced vasodilation in SED and ET rats.

Vasoreactivity to $\mathrm{H}_{2} \mathrm{O}_{2}$ and $\mathrm{O}_{2}^{-}$in soleus muscle arterioles

At concentrations above $1 \mathrm{e}^{-4} \mathrm{M}, \mathrm{H}_{2} \mathrm{O}_{2}$ elicited vasodilation in skeletal muscle arterioles, and these vasodilatory responses were not affected by age or exercise training status (Fig. 2.4). $\mathrm{O}_{2}^{-}$generated by the auto-oxidation of pyrogallol $(79,81)$ did not elicit a vasoactive response in arterioles from either young or old SED rats (Fig. 2.5). In arterioles from young but not old ET rats, pyrogallol elicited a slight vasoconstriction.

\section{Vasodilation to DEA-NONOATE}

Confirming previous findings (97), endothelial-independent vasodilation to exogenous NO was preserved with age. In contrast, exercise training increased vasodilation of skeletal muscle arterioles at concentrations of $1 \mathrm{e}^{-7} \mathrm{M}$ Dea-NONOate in both young and old rats (Fig. 2.6A). Scavenging of $\mathrm{O}_{2}^{-}$with Tempol had no effect on endothelium-independent vasodilation in arterioles from any group of rats (Fig. 2.6B and 2.C). Thus, the age-related reduction of NO bioavailability in skeletal muscle arterioles probably does not result from increased scavenging of extracellular NO, demonstrating the specificity of Tempol-induced reductions of vasodilation to ACh (Fig 2.2A and 2.2B).

SOD-1, catalase and GPx1 protein levels

SOD-1 protein levels were not different between arterioles from young and old SED rats. Exercise training increased SOD-1 protein levels by approximately $130 \%$ in arterioles from young rats and by approximately $85 \%$ in arterioles from old rats (Fig. 2.7A). Catalase levels were not different between arterioles from young and old SED rats. Exercise training increased catalase protein by approximately $81 \%$ in arterioles from young rats (Fig. 2.7B). GPX-1 protein levels in 
arterioles were unaffected by age; however, exercise training increased GPx-1 protein levels in arterioles from old rats by approximately 66\% (Fig 2.7C). 


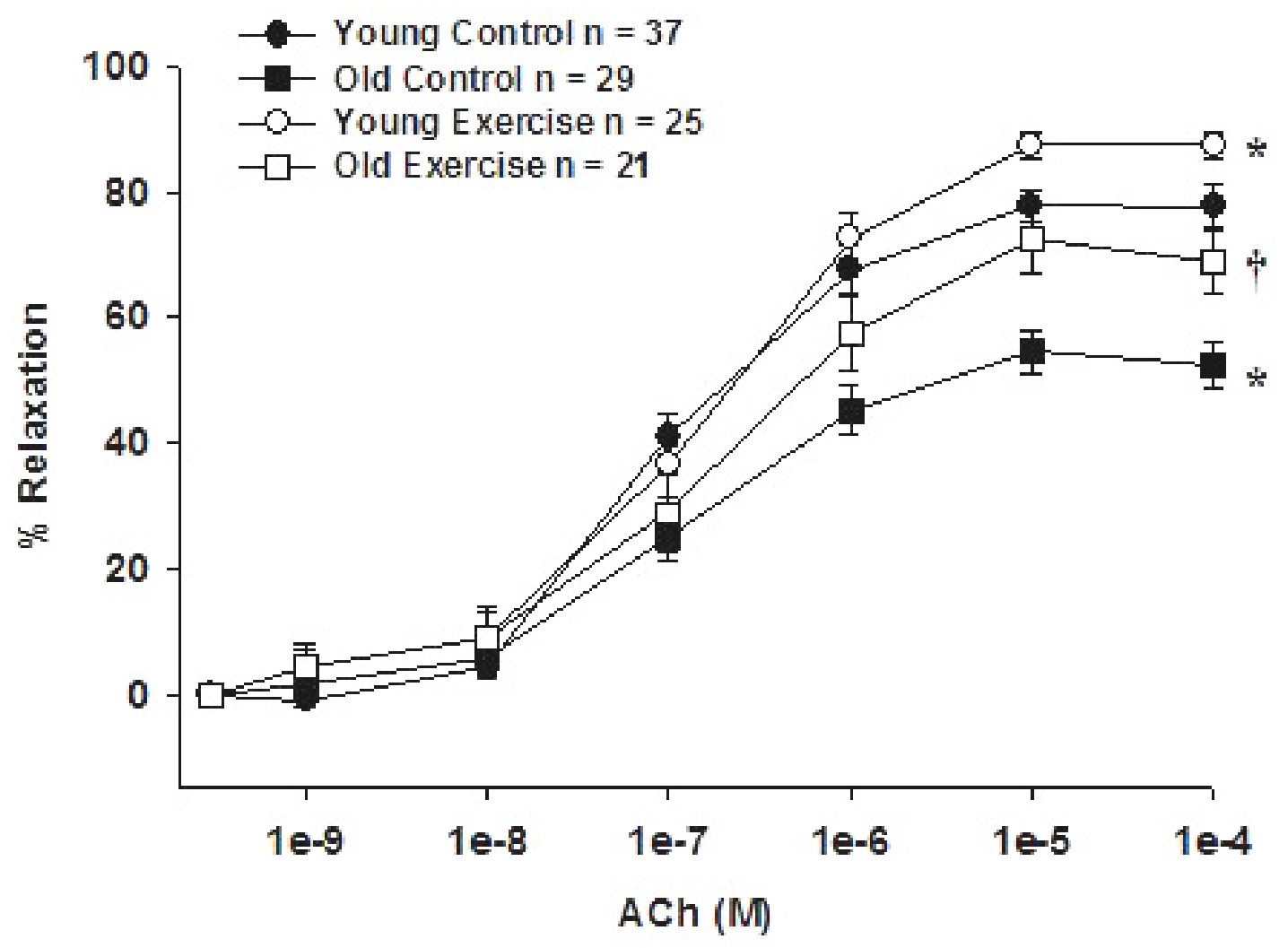

Figure 2.1. ACh-induced vasodilation in soleus muscle arterioles from young and old, sedentary and exercise-trained rats to acetylcholine (ACh). Age significantly reduced vasodilator responses to ACh in soleus muscle arterioles. Exercise training restored vasodilator responses to $\mathrm{ACh}$ in soleus muscle arterioles from old rats. Diameter changes in response to increasing intraluminal pressure in soleus muscle arterioles. ${ }^{*} P<0.05$ vs. YSED and $\dagger P<0.05$ vs. OSED. 

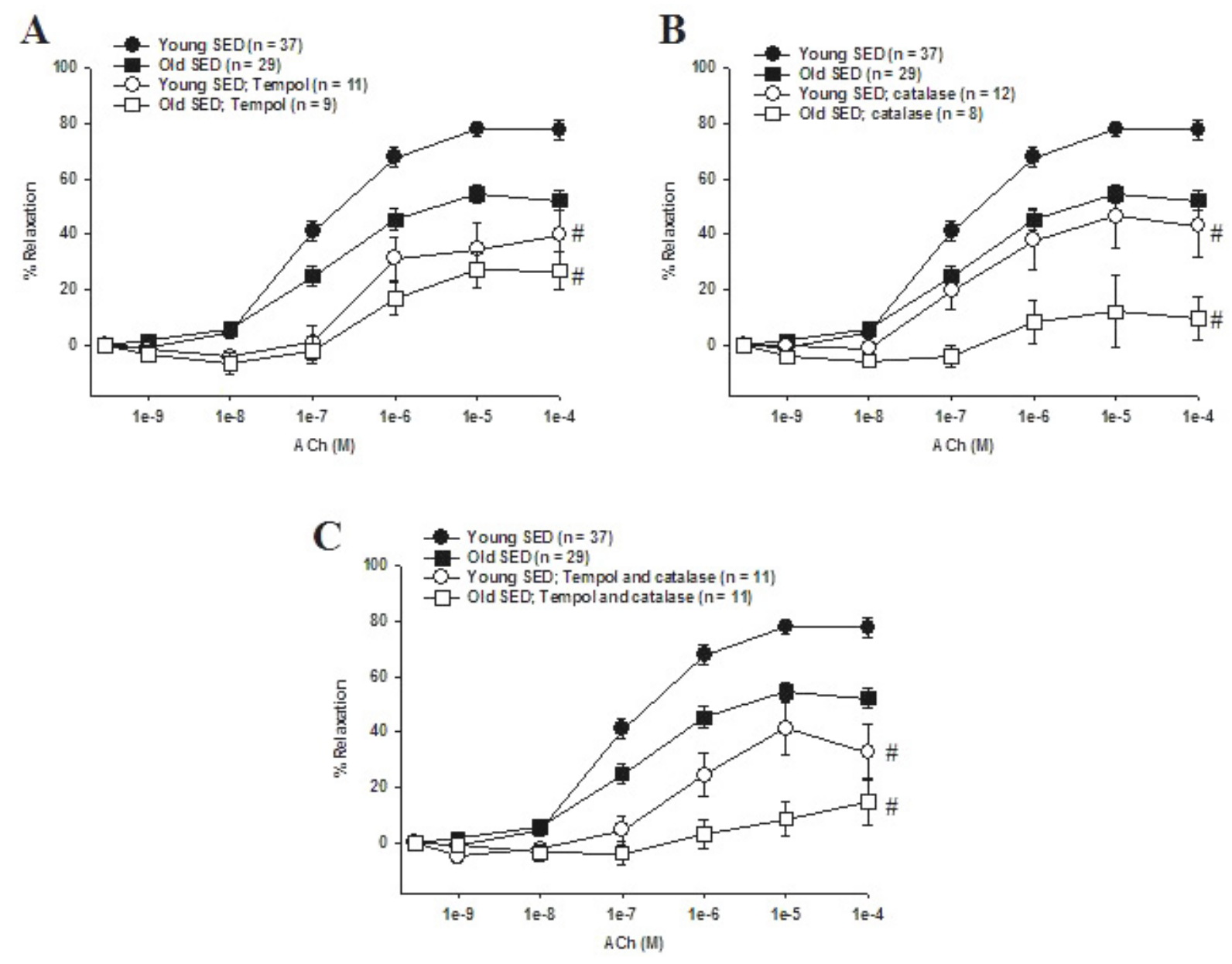

Figure 2.2. Effect of Tempol and catalase on ACh-induced vasodilation of soleus muscle arterioles from young and old sedentary rats. (A) Tempol inhibited the vasodilator response to $\mathrm{ACh}$ in arterioles from all groups and abolished the age differences in $\mathrm{ACh}$-induced vasodilation. (B) Catalase inhibited the vasodilator response to ACh-induced in arterioles from all rats, however the age difference in ACh-induced vasodilation remained. (C) Combination of Tempol and catalase inhibited vasodilator responses to $\mathrm{ACh}$ in arterioles from all rats and abolished the age differences in ACh-induced vasodilation. Data are presented as means \pm SE. $\# P<0.05$ Inhibitor + ACh vs. ACh alone. 

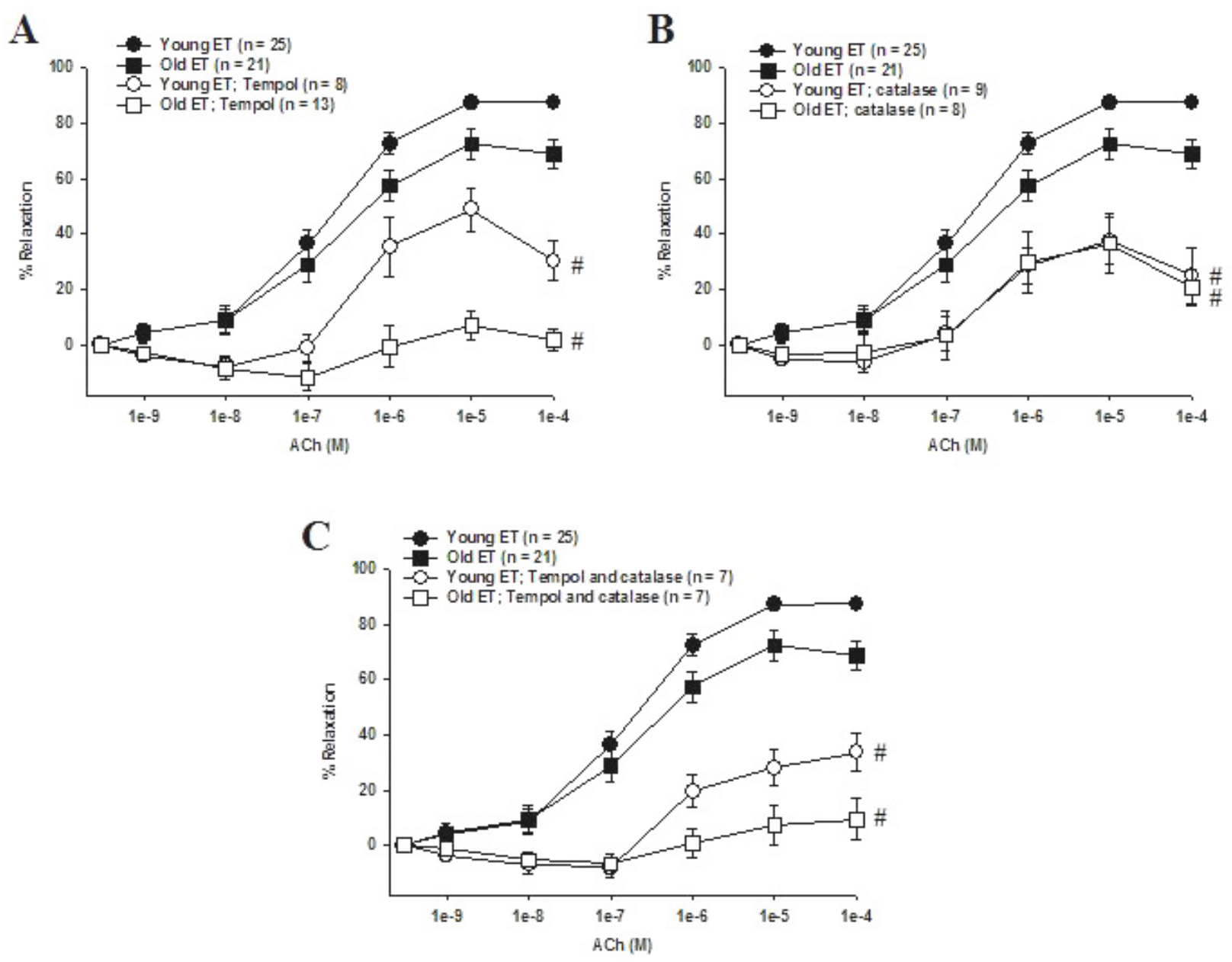

Figure 2.3. Effect of Tempol and catalase on ACh-induced vasodilation of soleus muscle arterioles from young and old exercise-trained rats. (A) Tempol inhibited the vasodilator response to $\mathrm{ACh}$ in arterioles from all groups; however age differences developed in ACh-induced vasodilation. (B) Catalase inhibited the vasodilator response to ACh-induced in arterioles from all rats. (C) Combination of Tempol and catalase inhibited vasodilator responses to ACh in arterioles from all rats. $\# P<0.05$ Inhibitor $+\mathrm{ACh}$ vs. ACh alone. 


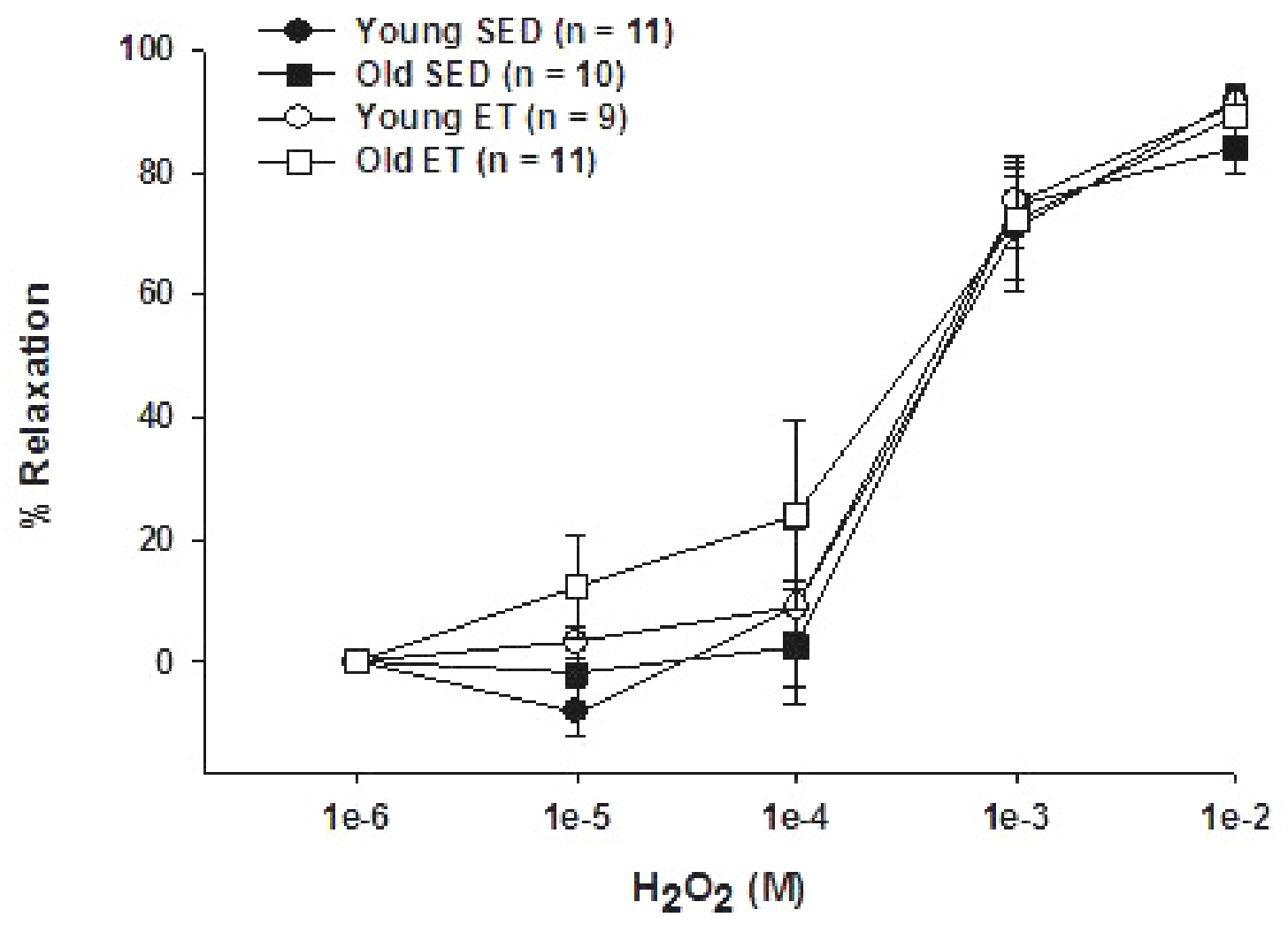

Figure 2.4. $\mathrm{H}_{2} \mathrm{O}_{2}$-induced vasodilation in young and old, sedentary and exercise-trained rats. Vasodilation to exogenous $\mathrm{H}_{2} \mathrm{O}_{2}$ was preserved with age and was unchanged by exercise training. 


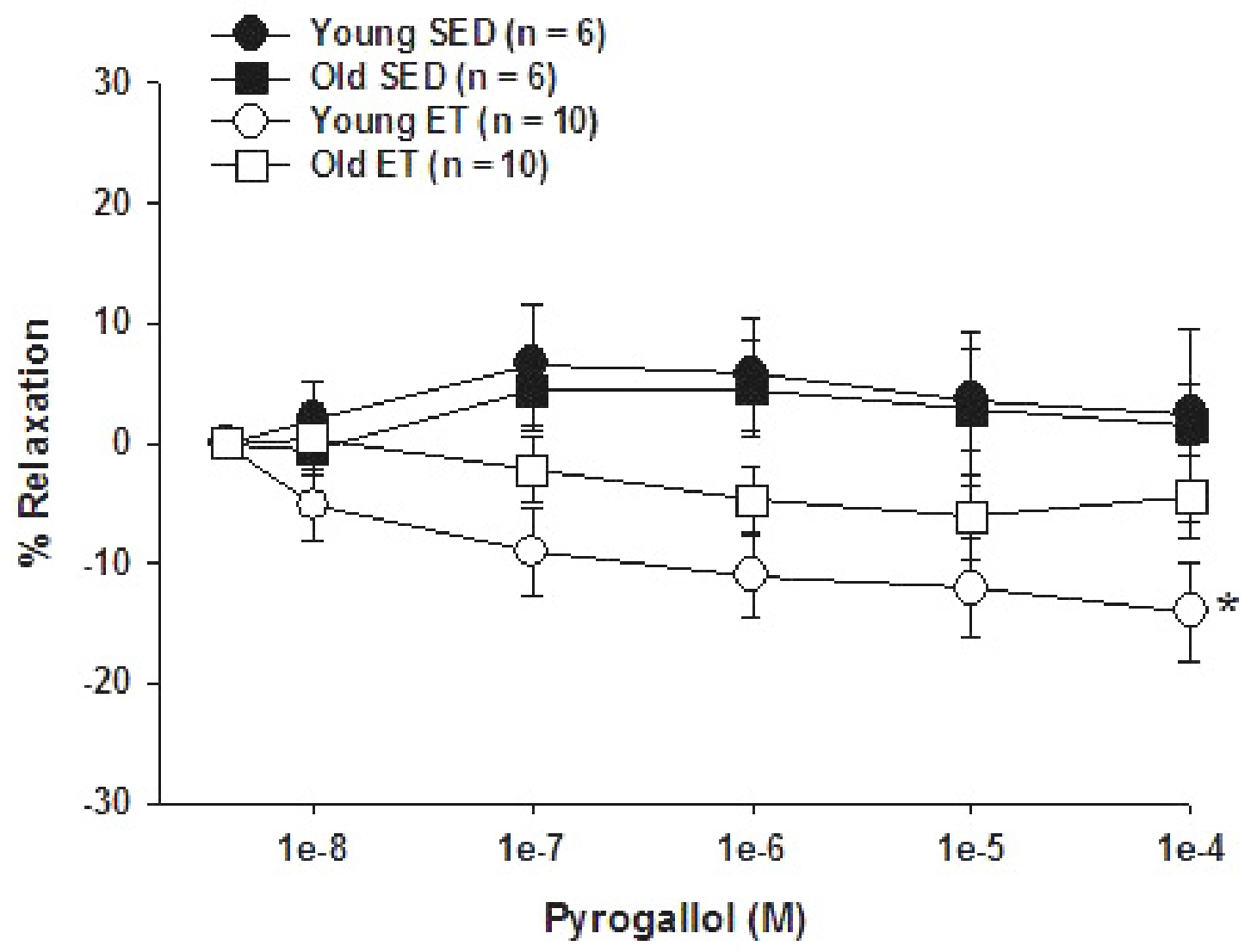

Figure 2.5. $\mathrm{O}_{2}{ }^{-}$-induced vasoactive characteristics in young and old, sedentary and exercisetrained rats. Pyrogallol induced vasoconstriction in old ET rats. ${ }^{*} P<0.05$ OSED vs. OET. 

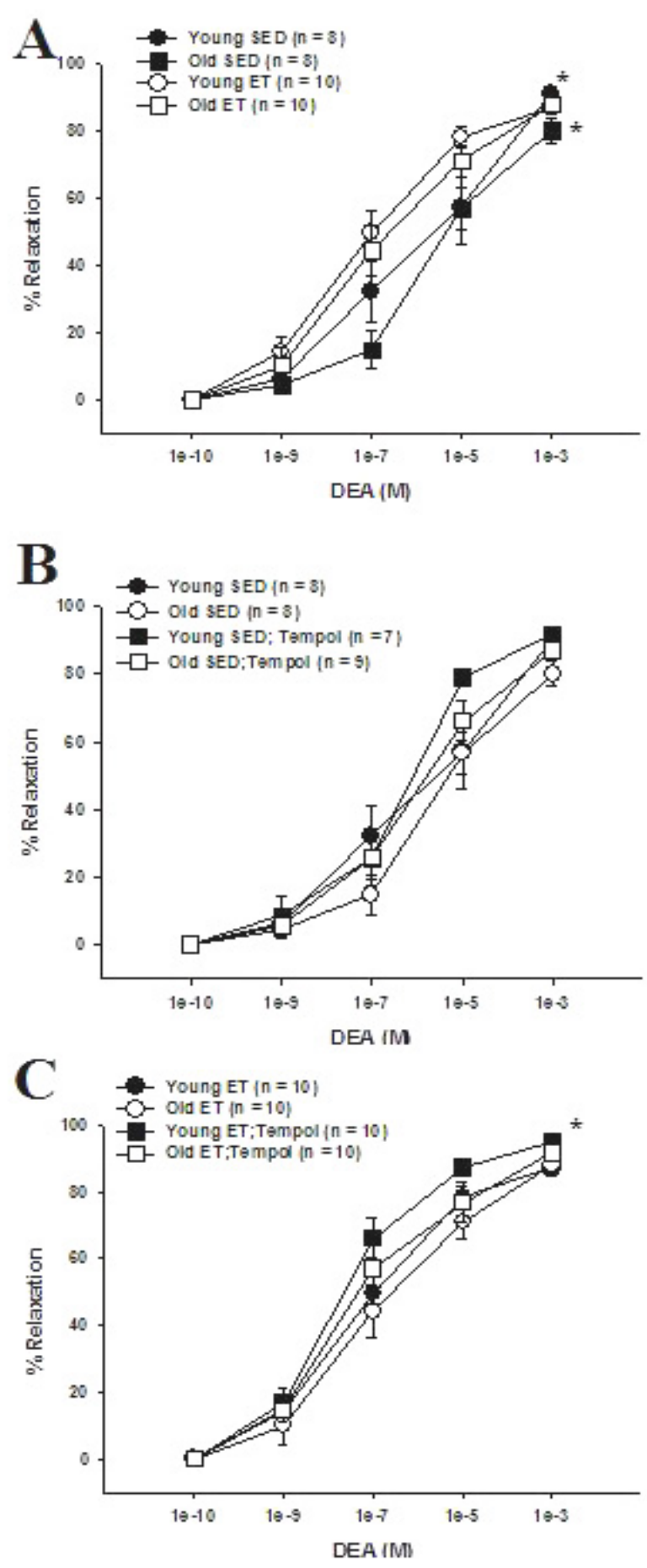

Figure 2.6. Endothelium-independent vasodilation to Dea-NONOate in soleus muscle arterioles from young and old, sedentary and exercise-trained rats. (A) Vasodilation to DeaNONOate was similar in soleus muscle arterioles from young and old SED rats; however, exercise training increased vasodilatory responses to Dea-NONOate in both young and old rats. (B) Scavenging of superoxide with Tempol had no effect on vasodilator responses to Dea-NONOate in soleus muscle arterioles from young and old SED rats. (C) Scavenging of superoxide with Tempol had no effect on vasodilator responses to Dea-NONOate in soleus muscle arterioles from young and old ET rats. ${ }^{*} P<0.05$ SED vs. ET. 


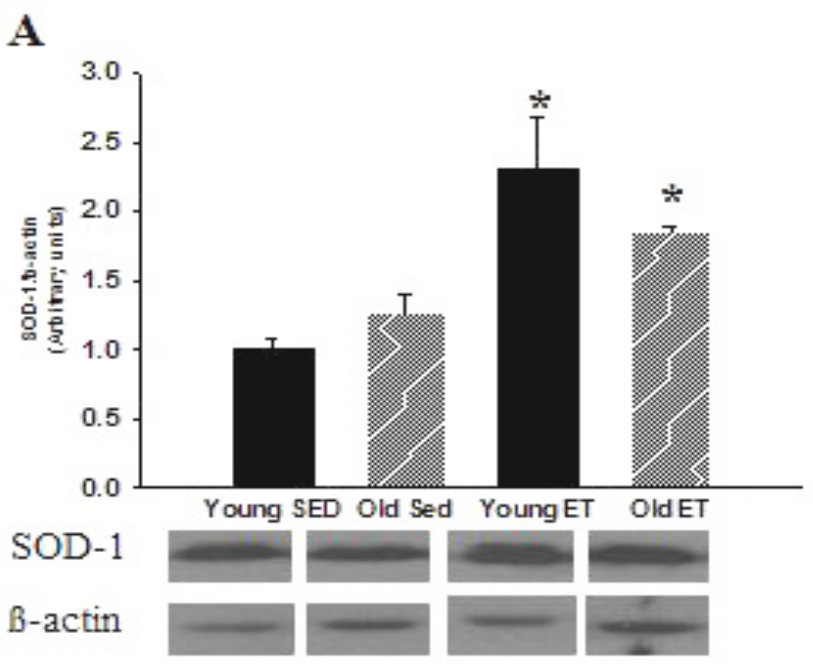

B
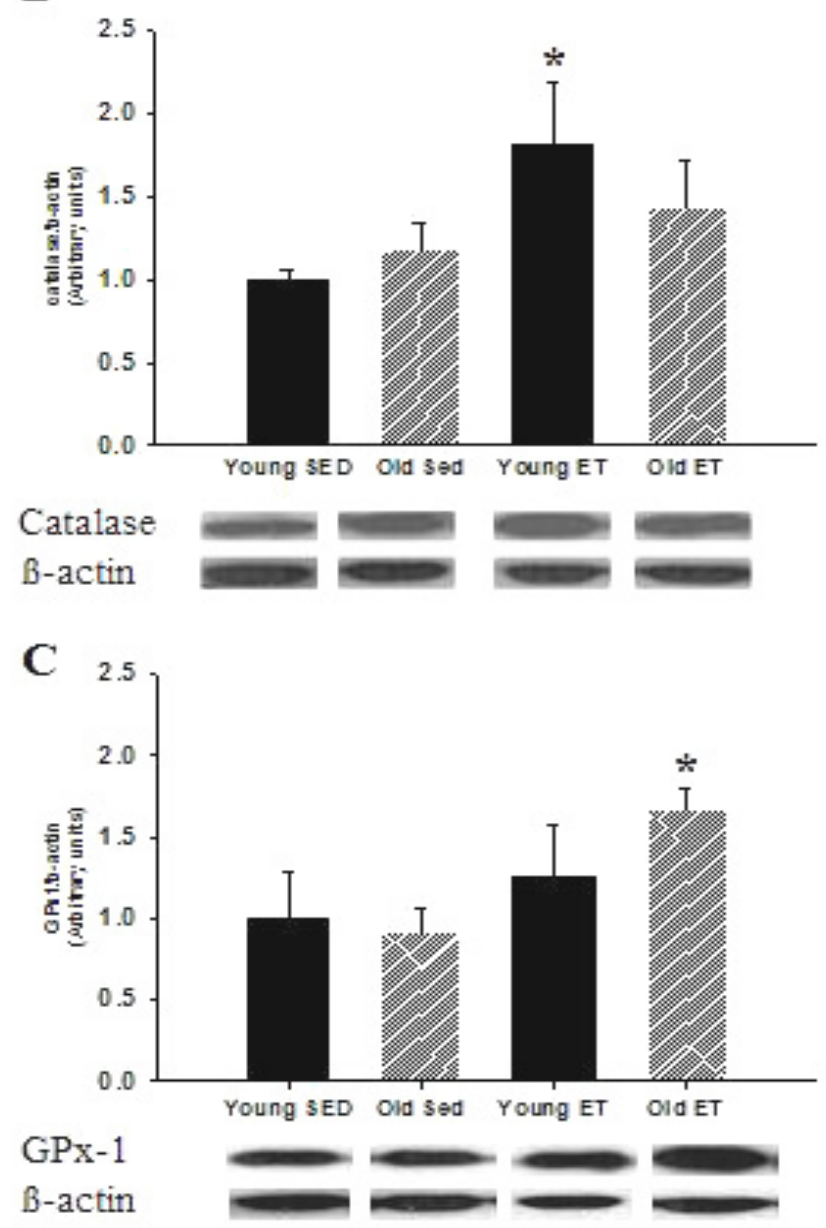

Figure 2.7. (A) Superoxide dismutase (SOD-1), (B) catalase, and (C) glutathione peroxidase (GPx1) protein content in soleus muscle arterioles of young and old, sedentary and exercisetrained rats. ${ }^{*} P<0.05$ indicates exercise training effect. 


\begin{tabular}{|c|c|c|c|c|}
\hline & $\begin{array}{c}\text { Young SED } \\
(\mathrm{n}=37)\end{array}$ & $\begin{array}{l}\text { Young ET } \\
(\mathrm{n}=28)\end{array}$ & $\begin{array}{l}\text { Old SED } \\
(n=29)\end{array}$ & $\begin{array}{l}\text { Old ET } \\
(\mathrm{n}=21)\end{array}$ \\
\hline \multicolumn{5}{|l|}{ Animal Characteristics } \\
\hline Body Wt (g) & $370=4$ & $345=4 \dagger$ & $429 \pm 6^{*}$ & $378=6 \dagger$ \\
\hline Soleus muscle wt (mg) & $153.0=3.1$ & $156.8=4.2$ & $163.7=4.0 *$ & $171.8=5.2$ \\
\hline Soleus wt/Body wt (mg/g) & $.41 \pm 0.01$ & $.45=0.01 *$ & $.38=0.01^{*}$ & $.45 \pm 0.01 \dagger$ \\
\hline \multicolumn{5}{|l|}{ Vessel Characteristics } \\
\hline Maximal Diameter ( $\mu \mathrm{m})$ & $128=4$ & $127=5$ & $120=4$ & $121=5$ \\
\hline Spontaneous tone (\%) & $\begin{array}{c}50=2 \\
(n=37)\end{array}$ & $\begin{array}{c}51=2 \\
(n=28)\end{array}$ & $\begin{array}{c}54=2 \\
(\mathrm{n}=29)\end{array}$ & $\begin{array}{c}56=2 \\
(n=21)\end{array}$ \\
\hline with Tempol & $\begin{array}{c}54=4 \\
(n=11)\end{array}$ & $\begin{array}{l}47=4 \\
(n=9)\end{array}$ & $\begin{array}{l}60=4 \\
(n=9)\end{array}$ & $\begin{array}{c}60=3 \\
(n=13)\end{array}$ \\
\hline with Tempol + Catalase & $\begin{array}{c}50=4 \\
(n=11)\end{array}$ & $\begin{array}{l}51=5 \\
(\mathrm{n}=8)\end{array}$ & $\begin{array}{c}51=3 \\
(n=11)\end{array}$ & $\begin{array}{l}51=2 \\
(n=8)\end{array}$ \\
\hline with Catalase & $\begin{array}{l}52=3 \\
(n=12)\end{array}$ & $\begin{array}{l}51=5 \\
(n=9)\end{array}$ & $\begin{array}{l}57=4 \\
(n=8)\end{array}$ & $\begin{array}{l}56=6 \\
(n=9)\end{array}$ \\
\hline
\end{tabular}

Table 2.1. Animal and vessel characteristics of young and old rat, sedentary and exercise trained rats. Maximal diameter was recorded in $\mathrm{Ca}^{2+}$-free physiological saline solution with $100 \mu \mathrm{M}$ sodium nitroprusside. Tone $(\%)=[($ maximal diameter - diameter with tone $) /$ maximal diameter $] \times 100 .{ }^{*} P<0.05$ indicates age effect. $\dagger P<0.05$ indicates exercise training effect. 


\section{Discussion}

This study confirms our previous report that ACh-induced vasodilation declines with age and is restored by exercise training (122). Several new findings from this study indicate that ROS are important mediators of age- and training-induced adaptations of endothelium-dependent vasodilation in skeletal muscle arterioles. First, $\mathrm{H}_{2} \mathrm{O}_{2}$ is necessary for endothelium-dependent vasodilation in skeletal muscle arterioles. Second, the dependence on ACh-induced vasodilation on $\mathrm{H}_{2} \mathrm{O}_{2}$ increases with age. Third, exercise training improves endothelium-dependent vasodilation in old rats, in part, by decreasing dependence on $\mathrm{H}_{2} \mathrm{O}_{2}$. Fourth, the sensitivity of AChinduced vasodilation to exogenous SOD changes with age and by exercise training. Thus, a tight balance between enzymatic production of $\mathrm{O}_{2}{ }^{-}$and $\mathrm{H}_{2} \mathrm{O}_{2}$ must be maintained for robust endothelium-dependent vasodilation to occur.

It is becoming clear that $\mathrm{O}_{2}^{-}$and $\mathrm{O}_{2}^{-}$-derived ROS are important signaling molecules involved in the regulation of physiological function (41). More specifically, $\mathrm{H}_{2} \mathrm{O}_{2}$ generated by the dismutation of $\mathrm{O}_{2}{ }^{-}$is emerging as an important vasodilator and signaling molecule in the vasculature (21). $\mathrm{O}_{2}{ }^{-}$is derived from several sources in the endothelium including eNOS (42), mitochondria (77), xanthine oxidases (52) and NADPH oxidases (15). Endothelium-derived $\mathrm{H}_{2} \mathrm{O}_{2}$ contributes to vasodilation in isolated coronary arterioles (72). In skeletal muscle arterioles $\mathrm{H}_{2} \mathrm{O}_{2}$

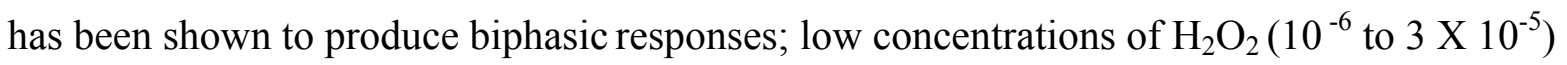
induce vasoconstriction whereas higher concentrations elicit vasodilation (27). Similarly, in pulmonary (13), skeletal muscle (27), cerebral, (139) and mesenteric (84) vascular beds exogenous $\mathrm{H}_{2} \mathrm{O}_{2}$ causes vasodilation. Thus, vasodilation elicited by authentic $\mathrm{H}_{2} \mathrm{O}_{2}$ was preserved with age and was unchanged by exercise training in skeletal muscle arterioles (Fig. 2.4). $\mathrm{H}_{2} \mathrm{O}_{2}$ has been labeled as endothelium-derived hyperpolarization factor (EDHF) because it is produced by the endothelium and elicits vascular smooth muscle relaxation through activation of $\mathrm{Ca}^{2+}$ dependent 
$\mathrm{K}^{+}\left(\mathrm{K}_{\mathrm{Ca}}\right)$ channel activation $(82,85)$. Our results do not indicate the mechanism by which $\mathrm{H}_{2} \mathrm{O}_{2}$ produced vasodilation in skeletal muscle arterioles; however, our findings that neither age or exercise training altered responsiveness of soleus muscle arterioles to exogenous $\mathrm{H}_{2} \mathrm{O}_{2}$ suggests that adaptations in $\mathrm{H}_{2} \mathrm{O}_{2}$ signaling are confined to the endothelium and occur due to changes in endogenous production and/or generation of $\mathrm{H}_{2} \mathrm{O}_{2}$.

In the present study, the dependence of ACh-induced vasodilation on $\mathrm{H}_{2} \mathrm{O}_{2}$ was more pronounced in old SED rats (Fig. 2.2B). This increased dependence on $\mathrm{H}_{2} \mathrm{O}_{2}$ was reversed by exercise training in arterioles from old rats (Fig. 2.3B). Our previous results suggest that age reduces NO-mediated dilation, whereas exercise training promotes endothelial signaling through NO (122). Thus our current results suggest that endothelial $\mathrm{H}_{2} \mathrm{O}_{2}$ signaling increases with age as NO-mediated dilation declines. In contrast, exercise training appears to promote reversal to a younger vasodilatory system, which requires less dependence on $\mathrm{H}_{2} \mathrm{O}_{2}$ signaling, and greater dependence on NO signaling.

Age-related differences in ACh-induced vasodilation were eliminated by scavenging of $\mathrm{O}_{2}{ }^{-}$ with the exogenous SOD mimetic, Tempol (Fig. 2.2A) indicating that alterations of $\mathrm{O}_{2}^{-}{ }^{-}$signaling contribute to age-associated impairment in ACh-induced vasodilation. The finding that Tempol reduced vasodilation in skeletal muscle arterioles from all groups of rats is surprising; however, Marvar et al. reported that locally generated ROS actually contribute to functional dilation (83). We propose that scavenging of $\mathrm{O}_{2}^{-}$in SED rats reduces vasodilation by two possible mechanisms. First, $\mathrm{O}_{2}^{-}$may act as a vasodilatory agent, as reported in cerebral arterioles of mice (140). Second, SOD has the capability of producing $\mathrm{OH}^{-}$in the presence of transition catalytic metals (i.e., iron), as observed in aged rats (12). In coronary arterioles, iron chelation with deferoxamine, reverses $\mathrm{OH}^{-}$-mediated vasoconstriction (131). If the addition of exogenous SOD increases $\mathrm{H}_{2} \mathrm{O}_{2}$ production dramatically, this could overwhelm the endogenous catalase system, leading to rapid production of $\mathrm{OH}^{-}$, and vasoconstriction. 
In the present study, $\mathrm{H}_{2} \mathrm{O}_{2}$-generated by Tempol was catalyzed to $\mathrm{H}_{2} \mathrm{O}$ with the addition of catalase, thus scavenging both $\mathrm{O}_{2}{ }^{-}$and $\mathrm{O}_{2}{ }^{-}$-derived $\mathrm{H}_{2} \mathrm{O}_{2}$. This simultaneous scavenging of both $\mathrm{O}_{2}{ }^{-}$and $\mathrm{H}_{2} \mathrm{O}_{2}$ eliminated ACh-induced vasodilation in old SED rats, supporting our hypothesis that even though ACh-induced vasodilation is already diminished with age, $\mathrm{O}_{2}{ }^{-}$-derived $\mathrm{ROS}$ are necessary for vasodilation in old SED rats. In young SED and ET rats, some dilation to ACh remained during simultaneous scavenging of both $\mathrm{O}_{2}{ }^{-}$and $\mathrm{H}_{2} \mathrm{O}_{2}$ indicating the contribution of ROS-independent signaling in arterioles from these young rats.

The restoration of endothelium-dependent vasodilation observed in old rats subjected to exercise training (Fig. 2.1) confirms our previous study (122). $\mathrm{O}_{2}{ }^{-}$generation and oxidant stress increase with exercise training $(4,5,30)$. This increase in oxidant stress probably contributes to enhanced $\mathrm{O}_{2}{ }^{-}$and $\mathrm{O}_{2}{ }^{-}$-derived ROS signaling in the endothelium of skeletal muscle arterioles of exercise trained rats (Fig. 2.3). The enhanced regulation of $\mathrm{O}_{2}{ }^{-}$and $\mathrm{O}_{2}{ }^{-}$-derived $\mathrm{ROS}$ may depend on protein levels and activities of anti-oxidant enzymes. For example, Rush et al. demonstrated in aortic endothelial cells (AEC) from young pigs that SOD-1 protein abundance and activity increased with training but had no effect on catalase content (113). In our present study, exercise training increased SOD-1 protein levels in skeletal muscle arterioles from young and old rats (Fig. 2.7A) indicating that more $\mathrm{H}_{2} \mathrm{O}_{2}$ was produced in the vasculature of exercise-trained rats. Interestingly, exercise training increased catalase in the young rats only (Fig. 2.7B); however, exercise training increased GPx1 in the old rats (Fig 2.7C). Similar to GPx, catalase catalyzes the breakdown of $\mathrm{H}_{2} \mathrm{O}_{2}$; however, GPx has a higher affinity for $\mathrm{H}_{2} \mathrm{O}_{2}$ at low concentrations $\left(\mathrm{K}_{\mathrm{m}}=1\right.$ $\mu \mathrm{M})$ than catalase $\left(\mathrm{K}_{\mathrm{m}}=1 \mathrm{mM}\right)$, indicating that GPx is a less effective antioxidant (90). These age-specific adaptations to exercise training may contribute to the increased dependence on $\mathrm{H}_{2} \mathrm{O}_{2}$ as a vasodilator in arterioles from old rats. 
In skeletal muscle arterioles, $\mathrm{O}_{2}{ }^{-}$may have direct vasoactive effects. To test this hypothesis, we determined the vasoreactivity of skeletal muscle arterioles to increasing concentrations of pyrogallol, which produces $\mathrm{O}_{2}{ }^{-}$by auto-oxidation (81). Pyrogallol caused slight vasoconstriction only in young ET rats (Fig. 2.5). Addition of exogenous $\mathrm{O}_{2}{ }^{-}$has no effect in SED rats (Fig. 2.5) indicating that $\mathrm{O}_{2}^{-}$is not acting directly to cause vasodilation of vascular smooth muscle, but as a signaling molecule that modulates endothelium-dependent vasodilation. Removal of $\mathrm{O}_{2}{ }^{-}$using Tempol impairs vasodilation, whereas addition of exogenous $\mathrm{O}_{2}{ }^{-}$should increase dilation. Pyrogallol did not have any vasodilatory effects; however, it is possible that $\mathrm{O}_{2}{ }^{-}$ produced by pyrogallol did not permeate the endothelial cell membrane, and thus, did not alter intracellular signaling in the endothelium. Therefore, the inhibition of vasodilation produced by Tempol occurred predominately because of dismutation of $\mathrm{O}_{2}{ }^{-}$to $\mathrm{H}_{2} \mathrm{O}_{2}$; however, direct manipulation of intracellular levels of $\mathrm{O}_{2}{ }^{-}$would be necessary to determine precisely the endothelial signaling pathways that are directly modulated by $\mathrm{O}_{2}{ }^{-}$. These data confirm our results obtained in experiments in which Dea-NONOate and Tempol were applied simultaneously. Tempol did not alter responsiveness to Dea-NONOate except in young ET rats, indicating that $\mathrm{O}_{2}{ }^{-}$ signaling occurs within the endothelium, possibly through $\mathrm{O}_{2}{ }^{-}$-derived $\mathrm{H}_{2} \mathrm{O}_{2}$ and/or $\mathrm{OH}^{-}$ production, or through scavenging of intracellular NO. Therefore, the reduced NO bioavailability that occurred with age in skeletal muscle arterioles, was not the result of increased scavenging of $\mathrm{NO}$ by extracellular $\mathrm{O}_{2}^{-}$.

A limitation of the present study is that we did not directly measure $\mathrm{O}_{2}{ }^{-}$and/or $\mathrm{H}_{2} \mathrm{O}_{2}$ during manipulation of SOD and/or catalase activity. $\mathrm{H}_{2} \mathrm{O}_{2}$ can elicit biphasic responses on skeletal muscle arterioles (27), thus the final effect of manipulation of either SOD or catalase activity may depend on the concentration of $\mathrm{H}_{2} \mathrm{O}_{2}$ generated under these conditions. However, alterations in protein levels measured do correlate with increased reliance on $\mathrm{H}_{2} \mathrm{O}_{2}$ signaling with age, and a reversal of $\mathrm{H}_{2} \mathrm{O}_{2}$ dependence in the endothelium of skeletal muscle arterioles. 
In conclusion, the current study implicates $\mathrm{O}_{2}{ }^{-}$and $\mathrm{O}_{2}{ }^{-}$-derived $\mathrm{ROS}\left(\mathrm{H}_{2} \mathrm{O}_{2}\right)$ as necessary signaling molecules required for endothelium-dependent vasodilation in soleus muscle arterioles. The dependence of ACh-induced vasodilation on $\mathrm{H}_{2} \mathrm{O}_{2}$ increases with age and decreases with exercise training. Furthermore, exercise training contributes to regulation of the relative production of $\mathrm{O}_{2}{ }^{-}$and $\mathrm{H}_{2} \mathrm{O}_{2}$, maintaining endothelium-dependent vasodilation in skeletal muscle arterioles. 


\section{Chapter IV}

\section{General Discussion}

The goal of this project was to better understand the mechanisms by which exercise training reverses age-related impairment of endothelium-dependent vasodilation in skeletal muscle arterioles. Both studies presented confirm our previous work, which indicated that endotheliumdependent vasodilation is reduced in skeletal muscle arterioles from old rats. Exercise training restores endothelium-dependent vasodilation in arterioles from old rats and improves endothelium-dependent vasodilation in skeletal muscle arterioles from young rats.

The first study demonstrated that reductions in flow-induced vasodilation are accompanied by decreases in $\mathrm{BH}_{4}$ levels in skeletal muscle arterioles from old rats. Furthermore, the limited availability of $\mathrm{BH}_{4}$ in arterioles from old SED rats occurred concomitantly to a subsequent decrease in NO signaling and an increase in eNOS-derived $\mathrm{O}_{2}{ }^{-}$generation, suggesting a role for eNOS uncoupling. Exercise training restored $\mathrm{BH}_{4}$ levels and improved flow-induced $\mathrm{NO}$ production in arterioles from old rats. Exercise training increased both NO and ROS-mediated signaling in skeletal muscle arterioles, suggesting that the exercise training-induced enhancement of flow-induced vasodilation in skeletal muscle arterioles involves a balance between $\mathrm{NO}$ and $\mathrm{O}_{2}{ }^{-}-$ derived ROS. Thus, the beneficial effects of exercise training in the skeletal muscle resistance vasculature involves more than improvement of NO bioavailability.

In our second study, we found that $\mathrm{O}_{2}{ }^{-}$and $\mathrm{O}_{2}{ }^{-}$-derived $\mathrm{ROS}\left(\mathrm{H}_{2} \mathrm{O}_{2}\right)$ are required for endothelium-dependent vasodilation in skeletal muscle arterioles. The dependence of AChinduced vasodilation on $\mathrm{H}_{2} \mathrm{O}_{2}$ increases with age and decreases with exercise training. Thus, exercise training contributed to the regulation of the relative production of $\mathrm{O}_{2}{ }^{-}$and $\mathrm{H}_{2} \mathrm{O}_{2}$ and that a balance between these ROS must be maintained for robust endothelium-dependent vasodilation to occur in skeletal muscle arterioles. 
Taken together, these studies demonstrate that both $\mathrm{NO}$ and $\mathrm{H}_{2} \mathrm{O}_{2}$ are important signaling molecules necessary for mediating endothelium-dependent vasodilation in skeletal muscle arterioles. With advancing age, the dependence of endothelial function on $\mathrm{H}_{2} \mathrm{O}_{2}$ increases as $\mathrm{NO}$ signaling declines in skeletal muscle arterioles. The existence of a tight balance between NO and $\mathrm{H}_{2} \mathrm{O}_{2}$ probably exists and is altered with age and with exercise training.

$\mathrm{H}_{2} \mathrm{O}_{2}$ can potentially modulate $\mathrm{NO}$ by a variety of mechanisms to increase NO production. For example, $\mathrm{H}_{2} \mathrm{O}_{2}$ activates eNOS through a series of coordinated phosphorylation and dephosphorylation steps through a phosphoinositide 3-kinase-dependent signaling pathway (133). Additionally, $\mathrm{H}_{2} \mathrm{O}_{2}$ stimulates GTPCH-1 protein, which is the rate-limiting enzyme for de novo synthesis of $\mathrm{BH}_{4}$ and elicits increases in both $\mathrm{BH}_{4}$ synthesis and eNOS activity in endothelial cells $(118,119)$.

In conclusion, impaired endothelium-dependent vasodilation is a risk factor for development of cardiovascular disease in aged individuals. Exercise training augments endothelium-dependent vasodilation, and thus reduces cardiovascular disease risk. However, the underlying mechanisms by which exercise training improves endothelium-dependent vasodilation have not been fully elucidated. The data in this dissertation are the first to demonstrate a potential mechanism by which exercise training restores age-associated impairments in endotheliumdependent vasodilation, by restoring $\mathrm{BH}_{4}$ levels and increasing both $\mathrm{NO}$ - and ROS-mediated signaling in skeletal muscle microcirculation. 


\section{References}

1. Heart Disease and Stroke Statistics - 2007 Update At-a-Glance Dallas, Texas: American Heart Association, 2006.

2. U.S. Interim Projections by Age, Sex, Race, and Hispanic Origin. 2007.

3. Adeagbo AS, Joshua IG, Falkner C, and Matheson PJ. Tempol, an antioxidant, restores endothelium-derived hyperpolarizing factor-mediated vasodilation during hypertension. Eur $J$ Pharmacol. 2003; 481: 91-100.

4. Alessio HM. Exercise-induced oxidative stress. Med Sci Sports Exerc. 1993; 25: 218-224.

5. Alessio HM, Hagerman AE, Fulkerson BK, Ambrose J, Rice RE, and Wiley RL.

Generation of reactive oxygen species after exhaustive aerobic and isometric exercise. Med Sci Sports Exerc. 2000; 32: 1576-1581.

6. Bagi Z, Toth E, Koller A, and Kaley G. Microvascular dysfunction after transient high glucose is caused by superoxide-dependent reduction in the bioavailability of $\mathrm{NO}$ and $\mathrm{BH}(4)$. $\mathrm{Am}$ J Physiol Heart Circ Physiol. 2004; 287: H626-633.

7. Berkowitz DE, White R, Li D, Minhas KM, Cernetich A, Kim S, Burke S, Shoukas AA, Nyhan D, Champion HC, and Hare JM. Arginase reciprocally regulates nitric oxide synthase activity and contributes to endothelial dysfunction in aging blood vessels. Circulation. 2003; 108: 2000-2006.

8. Bevers LM, Braam B, Post JA, van Zonneveld AJ, Rabelink TJ, Koomans HA, Verhaar $\mathrm{MC}$, and Joles JA. Tetrahydrobiopterin, but not L-arginine, decreases NO synthase uncoupling in cells expressing high levels of endothelial NO synthase. Hypertension. 2006; 47: 87-94.

9. Bjornstedt M, Xue J, Huang W, Akesson B, and Holmgren A. The thioredoxin and glutaredoxin systems are efficient electron donors to human plasma glutathione peroxidase. $J$ Biol Chem. 1994; 269: 29382-29384.

10. Blackwell KA, Sorenson JP, Richardson DM, Smith LA, Suda O, Nath K, and Katusic ZS. Mechanisms of aging-induced impairment of endothelium-dependent relaxation: role of tetrahydrobiopterin. Am J Physiol Heart Circ Physiol. 2004; 287: H2448-2453.

11. Bode-Boger SM, Muke J, Surdacki A, Brabant G, Boger RH, and Frolich JC. Oral Larginine improves endothelial function in healthy individuals older than 70 years. Vasc Med. 2003; 8: 77-81.

12. Bulvik B, Grinberg L, Eliashar R, Berenshtein E, and Chevion MM. Iron, ferritin and proteins of the methionine-centered redox cycle in young and old rat hearts. Mech Ageing Dev. 2008.

13. Burke TM, and Wolin MS. Hydrogen peroxide elicits pulmonary arterial relaxation and guanylate cyclase activation. Am J Physiol. 1987; 252: H721-732.

14. Cai H, and Harrison DG. Endothelial dysfunction in cardiovascular diseases: the role of oxidant stress. Circ Res. 2000; 87: 840-844.

15. Cai H, Li Z, Dikalov S, Holland SM, Hwang J, Jo H, Dudley SC, Jr., and Harrison DG. $\mathrm{NAD}(\mathrm{P}) \mathrm{H}$ oxidase-derived hydrogen peroxide mediates endothelial nitric oxide production in response to angiotensin II. J Biol Chem. 2002; 277: 48311-48317.

16. Cai S, Khoo J, and Channon KM. Augmented BH4 by gene transfer restores nitric oxide synthase function in hyperglycemic human endothelial cells. Cardiovasc Res. 2005; 65: 823-831.

17. Celermajer DS, Sorensen KE, Spiegelhalter DJ, Georgakopoulos D, Robinson J, and Deanfield JE. Aging is associated with endothelial dysfunction in healthy men years before the age-related decline in women. J Am Coll Cardiol. 1994; 24: 471-476. 
18. Challah M, Nadaud S, Philippe M, Battle T, Soubrier F, Corman B, and Michel JB. Circulating and cellular markers of endothelial dysfunction with aging in rats. Am J Physiol. 1997; 273: H1941-1948.

19. Chalupsky K, and Cai H. Endothelial dihydrofolate reductase: critical for nitric oxide bioavailability and role in angiotensin II uncoupling of endothelial nitric oxide synthase. Proc Natl Acad Sci U S A. 2005; 102: 9056-9061.

20. Chen K, Thomas SR, and Keaney JF, Jr. Beyond LDL oxidation: ROS in vascular signal transduction. Free Radic Biol Med. 2003; 35: 117-132.

21. Chen Y, Pearlman A, Luo Z, and Wilcox CS. Hydrogen peroxide mediates a transient vasorelaxation with tempol during oxidative stress. Am J Physiol Heart Circ Physiol. 2007; 293: H2085-2092.

22. Cooke JP. Does ADMA cause endothelial dysfunction? Arterioscler Thromb Vasc Biol. 2000; 20: 2032-2037.

23. Cosentino F, and Katusic ZS. Tetrahydrobiopterin and dysfunction of endothelial nitric oxide synthase in coronary arteries. Circulation. 1995; 91: 139-144.

24. Cosentino F, and Luscher TF. Tetrahydrobiopterin and endothelial nitric oxide synthase activity. Cardiovasc Res. 1999; 43: 274-278.

25. Cosentino F, Patton S, d'Uscio LV, Werner ER, Werner-Felmayer G, Moreau P, Malinski $\mathrm{T}$, and Luscher TF. Tetrahydrobiopterin alters superoxide and nitric oxide release in prehypertensive rats. J Clin Invest. 1998; 101: 1530-1537.

26. Crabtree MJ, Tatham AL, Al-Wakeel Y, Warrick N, Hale AB, Cai S, Channon KM, and Alp NJ. Quantitative Regulation of Intracellular Endothelial Nitric-oxide Synthase (eNOS) Coupling by Both Tetrahydrobiopterin-eNOS Stoichiometry and Biopterin Redox Status: Insights from cells with TET-regulated GTP cyclohydrolase I expression. J Biol Chem. 2009; 284: 11361144.

27. Cseko C, Bagi Z, and Koller A. Biphasic effect of hydrogen peroxide on skeletal muscle arteriolar tone via activation of endothelial and smooth muscle signaling pathways. $J$ Appl Physiol. 2004; 97: 1130-1137.

28. Csiszar A, Ungvari Z, Edwards JG, Kaminski P, Wolin MS, Koller A, and Kaley G. Aging-induced phenotypic changes and oxidative stress impair coronary arteriolar function. Circ Res. 2002; 90: 1159-1166.

29. Darley-Usmar V, Wiseman H, and Halliwell B. Nitric oxide and oxygen radicals: a question of balance. FEBS Lett. 1995; 369: 131-135.

30. Davies KJ, Quintanilha AT, Brooks GA, and Packer L. Free radicals and tissue damage produced by exercise. Biochem Biophys Res Commun. 1982; 107: 1198-1205.

31. Davis ME, Cai H, McCann L, Fukai T, and Harrison DG. Role of c-Src in regulation of endothelial nitric oxide synthase expression during exercise training. Am J Physiol Heart Circ Physiol. 2003; 284: H1449-1453.

32. Davis MJ. Determination of volumetric flow in capillary tubes using an optical Doppler velocimeter. Microvasc Res. 1987; 34: 223-230.

33. Delp MD, Behnke BJ, Spier SA, Wu G, and Muller-Delp JM. Ageing diminishes endothelium-dependent vasodilatation and tetrahydrobiopterin content in rat skeletal muscle arterioles. J Physiol. 2008; 586: 1161-1168.

34. Delp MD, and Duan C. Composition and size of type I, IIA, IID/X, and IIB fibers and citrate synthase activity of rat muscle. J Appl Physiol. 1996; 80: 261-270.

35. Delp MD, Evans MV, and Duan C. Effects of aging on cardiac output, regional blood flow, and body composition in Fischer-344 rats. J Appl Physiol. 1998; 85: 1813-1822.

36. Delp MD, McAllister RM, and Laughlin MH. Exercise training alters endotheliumdependent vasoreactivity of rat abdominal aorta. J Appl Physiol. 1993; 75: 1354-1363. 
37. Demaree SR, Lawler JM, Linehan J, and Delp MD. Ageing alters aortic antioxidant enzyme activities in Fischer-344 rats. Acta Physiol Scand. 1999; 166: 203-208.

38. DeSouza CA, Shapiro LF, Clevenger CM, Dinenno FA, Monahan KD, Tanaka H, and Seals DR. Regular aerobic exercise prevents and restores age-related declines in endotheliumdependent vasodilation in healthy men. Circulation. 2000; 102: 1351-1357.

39. Dinenno FA, Jones PP, Seals DR, and Tanaka H. Limb blood flow and vascular conductance are reduced with age in healthy humans: relation to elevations in sympathetic nerve activity and declines in oxygen demand. Circulation. 1999; 100: 164-170.

40. Donato AJ, Eskurza I, Silver AE, Levy AS, Pierce GL, Gates PE, and Seals DR. Direct evidence of endothelial oxidative stress with aging in humans: relation to impaired endotheliumdependent dilation and upregulation of nuclear factor-kappaB. Circ Res. 2007; 100: 1659-1666.

41. Droge W. Free radicals in the physiological control of cell function. Physiol Rev. 2002; 82: 47-95.

42. Drouin A, Thorin-Trescases N, Hamel E, Falck JR, and Thorin E. Endothelial nitric oxide synthase activation leads to dilatory $\mathrm{H}(2) \mathrm{O}(2)$ production in mouse cerebral arteries. Cardiovasc Res. 2007; 73: 73-81.

43. Du YH, Guan YY, Alp NJ, Channon KM, and Chen AF. Endothelium-specific GTP cyclohydrolase I overexpression attenuates blood pressure progression in salt-sensitive low-renin hypertension. Circulation. 2008; 117: 1045-1054.

44. Emsley AM, Jeremy JY, Gomes GN, Angelini GD, and Plane F. Investigation of the inhibitory effects of homocysteine and copper on nitric oxide-mediated relaxation of rat isolated aorta. Br J Pharmacol. 1999; 126: 1034-1040.

45. Eskurza I, Myerburgh LA, Kahn ZD, and Seals DR. Tetrahydrobiopterin augments endothelium-dependent dilatation in sedentary but not in habitually exercising older adults. $J$ Physiol. 2005; 568: 1057-1065.

46. Feng MG, Dukacz SA, and Kline RL. Selective effect of tempol on renal medullary hemodynamics in spontaneously hypertensive rats. Am J Physiol Regul Integr Comp Physiol. 2001; 281: R1420-1425.

47. Fitzgerald MD, Tanaka H, Tran ZV, and Seals DR. Age-related declines in maximal aerobic capacity in regularly exercising vs. sedentary women: a meta-analysis. J Appl Physiol. 1997; 83: 160-165.

48. Fleming I, Fisslthaler B, Dimmeler S, Kemp BE, and Busse R. Phosphorylation of $\mathrm{Thr}(495)$ regulates $\mathrm{Ca}(2+) /$ calmodulin-dependent endothelial nitric oxide synthase activity. Circ Res. 2001; 88: E68-75.

49. Forstermann U, Pollock JS, Schmidt HH, Heller M, and Murad F. Calmodulin-dependent endothelium-derived relaxing factor/nitric oxide synthase activity is present in the particulate and cytosolic fractions of bovine aortic endothelial cells. Proc Natl Acad Sci U S A. 1991; 88: 17881792.

50. Fukai T, Siegfried MR, Ushio-Fukai M, Cheng Y, Kojda G, and Harrison DG. Regulation of the vascular extracellular superoxide dismutase by nitric oxide and exercise training. J Clin Invest. 2000; 105: 1631-1639.

51. Fulton D, Gratton JP, McCabe TJ, Fontana J, Fujio Y, Walsh K, Franke TF, Papapetropoulos A, and Sessa WC. Regulation of endothelium-derived nitric oxide production by the protein kinase Akt. Nature. 1999; 399: 597-601.

52. Gao H, Korthuis RJ, and Benoit JN. Effects of reactive oxygen metabolites on norepinephrine-induced vasoconstriction. Free Radic Biol Med. 1994; 16: 839-843.

53. Gates PE, Boucher ML, Silver AE, Monahan KD, and Seals DR. Impaired flow-mediated dilation with age is not explained by L-arginine bioavailability or endothelial asymmetric dimethylarginine protein expression. J Appl Physiol. 2007; 102: 63-71. 
54. Gerhard M, Roddy MA, Creager SJ, and Creager MA. Aging progressively impairs endothelium-dependent vasodilation in forearm resistance vessels of humans. Hypertension. 1996; 27: 849-853.

55. Goldstein S, and Czapski G. The reaction of NO. with O2.- and HO2.: a pulse radiolysis study. Free Radic Biol Med. 1995; 19: 505-510.

56. Graham DA, and Rush JW. Exercise training improves aortic endothelium-dependent vasorelaxation and determinants of nitric oxide bioavailability in spontaneously hypertensive rats. J Appl Physiol. 2004; 96: 2088-2096.

57. Griendling KK, Sorescu D, and Ushio-Fukai M. NAD(P)H oxidase: role in cardiovascular biology and disease. Circ Res. 2000; 86: 494-501.

58. Guo ZM, Yang H, Hamilton ML, VanRemmen H, and Richardson A. Effects of age and food restriction on oxidative DNA damage and antioxidant enzyme activities in the mouse aorta. Mech Ageing Dev. 2001; 122: 1771-1786.

59. Halliwell B. Biochemistry of oxidative stress. Biochem Soc Trans. 2007; 35: 1147-1150.

60. Halliwell B. Protection against tissue damage in vivo by desferrioxamine: what is its mechanism of action? Free Radic Biol Med. 1989; 7: 645-651.

61. Harris MB, Ju H, Venema VJ, Liang H, Zou R, Michell BJ, Chen ZP, Kemp BE, and Venema RC. Reciprocal phosphorylation and regulation of endothelial nitric-oxide synthase in response to bradykinin stimulation. J Biol Chem. 2001; 276: 16587-16591.

62. Harrison DG. Endothelial function and oxidant stress. Clin Cardiol. 1997; 20: II-11-17.

63. Heath GW, Hagberg JM, Ehsani AA, and Holloszy JO. A physiological comparison of young and older endurance athletes. J Appl Physiol. 1981; 51: 634-640.

64. Higashi Y, Sasaki S, Nakagawa K, Kimura M, Noma K, Hara K, Jitsuiki D, Goto C, Oshima T, Chayama K, and Yoshizumi M. Tetrahydrobiopterin improves aging-related impairment of endothelium-dependent vasodilation through increase in nitric oxide production. Atherosclerosis. 2006; 186: 390-395.

65. Ignarro LJ. Nitric oxide as a unique signaling molecule in the vascular system: a historical overview. J Physiol Pharmacol. 2002; 53: 503-514.

66. Inoue N, Ramasamy S, Fukai T, Nerem RM, and Harrison DG. Shear stress modulates expression of $\mathrm{Cu} / \mathrm{Zn}$ superoxide dismutase in human aortic endothelial cells. Circ Res. 1996; 79: 32-37.

67. Irion GL, Vasthare US, and Tuma RF. Age-related change in skeletal muscle blood flow in the rat. J Gerontol. 1987; 42: 660-665.

68. Johnson LR, Rush JW, Turk JR, Price EM, and Laughlin MH. Short-term exercise training increases ACh-induced relaxation and eNOS protein in porcine pulmonary arteries. $J$ Appl Physiol. 2001; 90: 1102-1110.

69. Knowles RG, and Moncada S. Nitric oxide synthases in mammals. Biochem J. 1994; 298 ( Pt 2): 249-258.

70. Kojda G, and Harrison D. Interactions between NO and reactive oxygen species: pathophysiological importance in atherosclerosis, hypertension, diabetes and heart failure. Cardiovasc Res. 1999; 43: 562-571.

71. Kojima H, Nakatsubo N, Kikuchi K, Kawahara S, Kirino Y, Nagoshi H, Hirata Y, and Nagano T. Detection and imaging of nitric oxide with novel fluorescent indicators: diaminofluoresceins. Anal Chem. 1998; 70: 2446-2453.

72. Koller A, and Bagi Z. Nitric oxide and $\mathrm{H} 2 \mathrm{O} 2$ contribute to reactive dilation of isolated coronary arterioles. Am J Physiol Heart Circ Physiol. 2004; 287: H2461-2467.

73. Kunsch C, and Medford RM. Oxidative stress as a regulator of gene expression in the vasculature. Circ Res. 1999; 85: 753-766. 
74. Kuo L, Davis MJ, and Chilian WM. Endothelium-dependent, flow-induced dilation of isolated coronary arterioles. Am J Physiol. 1990; 259: H1063-1070.

75. Kuzkaya N, Weissmann N, Harrison DG, and Dikalov S. Interactions of peroxynitrite, tetrahydrobiopterin, ascorbic acid, and thiols: implications for uncoupling endothelial nitric-oxide synthase. J Biol Chem. 2003; 278: 22546-22554.

76. Lakatta EG. Cardiovascular system. In: Handbook of Physiology: Aging. 1995, p. 413474.

77. Liu Y, Zhao H, Li H, Kalyanaraman B, Nicolosi AC, and Gutterman DD. Mitochondrial sources of $\mathrm{H} 2 \mathrm{O} 2$ generation play a key role in flow-mediated dilation in human coronary resistance arteries. Circ Res. 2003; 93: 573-580.

78. Luscher TF, and Barton M. Biology of the endothelium. Clin Cardiol. 1997; 20: II-3-10.

79. Ma X, Li YF, Gao Q, Ye ZG, Lu XJ, Wang HP, Jiang HD, Bruce IC, and Xia Q. Inhibition of superoxide anion-mediated impairment of endothelium by treatment with luteolin and apigenin in rat mesenteric artery. Life Sci. 2008; 83: 110-117.

80. Maier W, Cosentino F, Lutolf RB, Fleisch M, Seiler C, Hess OM, Meier B, and Luscher TF. Tetrahydrobiopterin improves endothelial function in patients with coronary artery disease. $J$ Cardiovasc Pharmacol. 2000; 35: 173-178.

81. Marklund S, and Marklund G. Involvement of the superoxide anion radical in the autoxidation of pyrogallol and a convenient assay for superoxide dismutase. Eur J Biochem. 1974; 47: 469-474.

82. Marvar PJ, Hammer LW, and Boegehold MA. Hydrogen peroxide-dependent arteriolar dilation in contracting muscle of rats fed normal and high salt diets. Microcirculation. 2007; 14: 779-791.

83. Marvar PJ, Nurkiewicz TR, and Boegehold MA. Reduced arteriolar responses to skeletal muscle contraction after ingestion of a high salt diet. J Vasc Res. 2005; 42: 226-236.

84. Matoba T, and Shimokawa H. Hydrogen peroxide is an endothelium-derived hyperpolarizing factor in animals and humans. J Pharmacol Sci. 2003; 92: 1-6.

85. Matoba T, Shimokawa H, Nakashima M, Hirakawa Y, Mukai Y, Hirano K, Kanaide H, and Takeshita A. Hydrogen peroxide is an endothelium-derived hyperpolarizing factor in mice. $J$ Clin Invest. 2000; 106: 1521-1530.

86. Mayhan WG, Arrick DM, Sharpe GM, and Sun H. Age-related alterations in reactivity of cerebral arterioles: role of oxidative stress. Microcirculation. 2008; 15: 225-236.

87. McAllister RM, Jasperse JL, and Laughlin MH. Nonuniform effects of endurance exercise training on vasodilation in rat skeletal muscle. J Appl Physiol. 2005; 98: 753-761.

88. McCurdy MR, Colleran PN, Muller-Delp J, and Delp MD. Effects of fiber composition and hindlimb unloading on the vasodilator properties of skeletal muscle arterioles. $J$ Appl Physiol. 2000; 89: 398-405.

89. Meininger CJ, Marinos RS, Hatakeyama K, Martinez-Zaguilan R, Rojas JD, Kelly KA, and $\mathrm{Wu}$ G. Impaired nitric oxide production in coronary endothelial cells of the spontaneously diabetic BB rat is due to tetrahydrobiopterin deficiency. Biochem J. 2000; 349: 353-356.

90. Meister A, and Anderson ME. Glutathione. Annu Rev Biochem. 1983; 52: 711-760.

91. Miura H, Bosnjak JJ, Ning G, Saito T, Miura M, and Gutterman DD. Role for hydrogen peroxide in flow-induced dilation of human coronary arterioles. Circ Res. 2003; 92: e31-40.

92. Mohazzab KM, Kaminski PM, and Wolin MS. NADH oxidoreductase is a major source of superoxide anion in bovine coronary artery endothelium. Am J Physiol. 1994; 266: H2568-2572.

93. Morris S. Regulation of arginine availability and its impact on NO synthesis. Nitric Oxide: Biology and Pathobiology. 2000; 187-197. 
94. Mugge A, Elwell JH, Peterson TE, and Harrison DG. Release of intact endotheliumderived relaxing factor depends on endothelial superoxide dismutase activity. Am J Physiol. 1991; 260: C219-225.

95. Mugge A, Elwell JH, Peterson TE, Hofmeyer TG, Heistad DD, and Harrison DG. Chronic treatment with polyethylene-glycolated superoxide dismutase partially restores endotheliumdependent vascular relaxations in cholesterol-fed rabbits. Circ Res. 1991; 69: 1293-1300.

96. Muller-Delp J, Spier SA, Ramsey MW, Lesniewski LA, Papadopoulos A, Humphrey JD, and Delp MD. Effects of aging on vasoconstrictor and mechanical properties of rat skeletal muscle arterioles. Am J Physiol Heart Circ Physiol. 2002; 282: H1843-1854.

97. Muller-Delp JM, Spier SA, Ramsey MW, and Delp MD. Aging impairs endotheliumdependent vasodilation in rat skeletal muscle arterioles. Am J Physiol Heart Circ Physiol. 2002; 283: H1662-1672.

98. Musch TI, Eklund KE, Hageman KS, and Poole DC. Altered regional blood flow responses to submaximal exercise in older rats. J Appl Physiol. 2004; 96: 81-88.

99. Navas FJ, and Cordova A. Iron distribution in different tissues in rats following exercise. Biol Trace Elem Res. 2000; 73: 259-268.

100. Nichol CA, Lee CL, Edelstein MP, Chao JY, and Duch DS. Biosynthesis of tetrahydrobiopterin by de novo and salvage pathways in adrenal medulla extracts, mammalian cell cultures, and rat brain in vivo. Proc Natl Acad Sci U S A. 1983; 80: 1546-1550.

101. Nitenberg A, Paycha F, Ledoux S, Sachs R, Attali JR, and Valensi P. Coronary artery responses to physiological stimuli are improved by deferoxamine but not by L-arginine in noninsulin-dependent diabetic patients with angiographically normal coronary arteries and no other risk factors. Circulation. 1998; 97: 736-743.

102. Nossaman BD, Bivalacqua TJ, Champion HC, Baber SR, and Kadowitz PJ. Analysis of vasodilator responses to peroxynitrite in the hindlimb vascular bed of the cat. J CardiovasC Pharmacol. 2007; 50: 358-366.

103. Nossaman BD, Dabisch PA, Liles JT, Baber SR, Champion HC, Kaye AD, Feng CJ, Anwar M, Bivalacqua TJ, Santiago JA, De Witt BJ, and Kadowitz PJ. Peroxynitrite does not impair pulmonary and systemic vascular responses. J Appl Physiol. 2004; 96: 455-462.

104. Ogawa T, Spina RJ, Martin WH, 3rd, Kohrt WM, Schechtman KB, Holloszy JO, and Ehsani AA. Effects of aging, sex, and physical training on cardiovascular responses to exercise. Circulation. 1992; 86: 494-503.

105. Oury TD, Day BJ, and Crapo JD. Extracellular superoxide dismutase in vessels and airways of humans and baboons. Free Radic Biol Med. 1996; 20: 957-965.

106. Oury TD, Day BJ, and Crapo JD. Extracellular superoxide dismutase: a regulator of nitric oxide bioavailability. Lab Invest. 1996; 75: 617-636.

107. Pattwell DM, McArdle A, Morgan JE, Patridge TA, and Jackson MJ. Release of reactive oxygen and nitrogen species from contracting skeletal muscle cells. Free Radic Biol Med. 2004; 37: 1064-1072.

108. Powers SK, and Jackson MJ. Exercise-induced oxidative stress: cellular mechanisms and impact on muscle force production. Physiol Rev. 2008; 88: 1243-1276.

109. Proctor DN, Shen PH, Dietz NM, Eickhoff TJ, Lawler LA, Ebersold EJ, Loeffler DL, and Joyner MJ. Reduced leg blood flow during dynamic exercise in older endurance-trained men. $J$ Appl Physiol. 1998; 85: 68-75.

110. Reid MB. Invited Review: redox modulation of skeletal muscle contraction: what we know and what we don't. J Appl Physiol. 2001; 90: 724-731.

111. Reid MB. Nitric oxide, reactive oxygen species, and skeletal muscle contraction. Med Sci Sports Exerc. 2001; 33: 371-376. 
112. Rodeheffer RJ, Gerstenblith G, Becker LC, Fleg JL, Weisfeldt ML, and Lakatta EG. Exercise cardiac output is maintained with advancing age in healthy human subjects: cardiac dilatation and increased stroke volume compensate for a diminished heart rate. Circulation. 1984; 69: 203-213.

113. Rush JW, Laughlin MH, Woodman CR, and Price EM. SOD-1 expression in pig coronary arterioles is increased by exercise training. Am J Physiol Heart Circ Physiol. 2000; 279: H20682076.

114. Rush JW, Turk JR, and Laughlin MH. Exercise training regulates SOD-1 and oxidative stress in porcine aortic endothelium. Am J Physiol Heart Circ Physiol. 2003; 284: H1378-1387. 115. Saitoh S, Zhang C, Tune JD, Potter B, Kiyooka T, Rogers PA, Knudson JD, Dick GM, Swafford A, and Chilian WM. Hydrogen peroxide: a feed-forward dilator that couples myocardial metabolism to coronary blood flow. Arterioscler Thromb Vasc Biol. 2006; 26: 2614-2621.

116. Schmidt HH, Pollock JS, Nakane M, Forstermann U, and Murad F. Ca2+/calmodulinregulated nitric oxide synthases. Cell Calcium. 1992; 13: 427-434.

117. Sessa WC, Pritchard K, Seyedi N, Wang J, and Hintze TH. Chronic exercise in dogs increases coronary vascular nitric oxide production and endothelial cell nitric oxide synthase gene expression. Circ Res. 1994; 74: 349-353.

118. Shimizu S, Hiroi T, Ishii M, Hagiwara T, Wajima T, Miyazaki A, and Kiuchi Y. Hydrogen peroxide stimulates tetrahydrobiopterin synthesis through activation of the Jak2 tyrosine kinase pathway in vascular endothelial cells. Int J Biochem Cell Biol. 2008; 40: 755-765.

119. Shimizu S, Shiota K, Yamamoto S, Miyasaka Y, Ishii M, Watabe T, Nishida M, Mori Y, Yamamoto T, and Kiuchi Y. Hydrogen peroxide stimulates tetrahydrobiopterin synthesis through the induction of GTP-cyclohydrolase I and increases nitric oxide synthase activity in vascular endothelial cells. Free Radic Biol Med. 2003; 34: 1343-1352.

120. Smith MA, and Reid MB. Redox modulation of contractile function in respiratory and limb skeletal muscle. Respir Physiol Neurobiol. 2006; 151: 229-241.

121. Somers MJ, and Harrison DG. Reactive oxygen species and the control of vasomotor tone. Curr Hypertens Rep. 1999; 1: 102-108.

122. Spier SA, Delp MD, Meininger CJ, Donato AJ, Ramsey MW, and Muller-Delp JM. Effects of ageing and exercise training on endothelium-dependent vasodilatation and structure of rat skeletal muscle arterioles. J Physiol. 2004; 556: 947-958.

123. Spier SA, Delp MD, Stallone JN, Dominguez JM, 2nd, and Muller-Delp JM. Exercise training enhances flow-induced vasodilation in skeletal muscle resistance arteries of aged rats: role of PGI2 and nitric oxide. Am J Physiol Heart Circ Physiol. 2007; 292: H3119-3127.

124. Srere P. Citrate Synthase. Methods Enzymol. 1969; 13: 3-5.

125. Stratton JR, Levy WC, Cerqueira MD, Schwartz RS, and Abrass IB. Cardiovascular responses to exercise. Effects of aging and exercise training in healthy men. Circulation. 1994; 89: 1648-1655.

126. Stroes E, Kastelein J, Cosentino F, Erkelens W, Wever R, Koomans H, Luscher T, and Rabelink T. Tetrahydrobiopterin restores endothelial function in hypercholesterolemia. J Clin Invest. 1997; 99: 41-46.

127. Sun D, Huang A, Yan EH, Wu Z, Yan C, Kaminski PM, Oury TD, Wolin MS, and Kaley G. Reduced release of nitric oxide to shear stress in mesenteric arteries of aged rats. Am J Physiol Heart Circ Physiol. 2004; 286: H2249-2256.

128. Suzuki H, Swei A, Zweifach BW, and Schmid-Schonbein GW. In vivo evidence for microvascular oxidative stress in spontaneously hypertensive rats. Hydroethidine microfluorography. Hypertension. 1995; 25: 1083-1089. 
129. Taddei S, Galetta F, Virdis A, Ghiadoni L, Salvetti G, Franzoni F, Giusti C, and Salvetti A. Physical activity prevents age-related impairment in nitric oxide availability in elderly athletes. Circulation. 2000; 101: 2896-2901.

130. Taddei S, Virdis A, Mattei P, Ghiadoni L, Gennari A, Fasolo CB, Sudano I, and Salvetti A. Aging and endothelial function in normotensive subjects and patients with essential hypertension. Circulation. 1995; 91: 1981-1987.

131. Thengchaisri N, Hein TW, Wang W, Xu X, Li Z, Fossum TW, and Kuo L. Upregulation of arginase by $\mathrm{H} 2 \mathrm{O} 2$ impairs endothelium-dependent nitric oxide-mediated dilation of coronary arterioles. Arterioscler Thromb Vasc Biol. 2006; 26: 2035-2042.

132. Thengchaisri N, and Kuo L. Hydrogen peroxide induces endothelium-dependent and independent coronary arteriolar dilation: role of cyclooxygenase and potassium channels. Am J Physiol Heart Circ Physiol. 2003; 285: H2255-2263.

133. Thomas SR, Chen K, and Keaney JF, Jr. Hydrogen peroxide activates endothelial nitricoxide synthase through coordinated phosphorylation and dephosphorylation via a phosphoinositide 3-kinase-dependent signaling pathway. J Biol Chem. 2002; 277: 6017-6024. 134. Thony B, Auerbach G, and Blau N. Tetrahydrobiopterin biosynthesis, regeneration and functions. Biochem J. 2000; 347 Pt 1: 1-16.

135. Tiefenbacher CP. Tetrahydrobiopterin: a critical cofactor for eNOS and a strategy in the treatment of endothelial dysfunction? Am J Physiol Heart Circ Physiol. 2001; 280: H2484-2488.

136. Tominaga M, Fujii K, Abe I, Takata Y, Kobayashi K, and Fujishima M. Hypertension and ageing impair acetylcholine-induced vasodilation in rats. J Hypertens. 1994; 12: 259-268.

137. Vasquez-Vivar J, Kalyanaraman B, Martasek P, Hogg N, Masters BS, Karoui H, Tordo P, and Pritchard KA, Jr. Superoxide generation by endothelial nitric oxide synthase: the influence of cofactors. Proc Natl Acad Sci U S A. 1998; 95: 9220-9225.

138. Walsh JH, Bilsborough W, Maiorana A, Best M, O'Driscoll GJ, Taylor RR, and Green DJ. Exercise training improves conduit vessel function in patients with coronary artery disease. $J$ Appl Physiol. 2003; 95: 20-25.

139. Wei EP, and Kontos HA. H2O2 and endothelium-dependent cerebral arteriolar dilation. Implications for the identity of endothelium-derived relaxing factor generated by acetylcholine. Hypertension. 1990; 16: 162-169.

140. Wei EP, Kontos HA, and Beckman JS. Mechanisms of cerebral vasodilation by superoxide, hydrogen peroxide, and peroxynitrite. Am J Physiol. 1996; 271: H1262-1266.

141. White AR, Ryoo S, Li D, Champion HC, Steppan J, Wang D, Nyhan D, Shoukas AA, Hare JM, and Berkowitz DE. Knockdown of arginase I restores NO signaling in the vasculature of old rats. Hypertension. 2006; 47: 245-251.

142. Widder JD, Chen W, Li L, Dikalov S, Thony B, Hatakeyama K, and Harrison DG. Regulation of tetrahydrobiopterin biosynthesis by shear stress. Circ Res. 2007; 101: 830-838. 143. Williams MD, Van Remmen H, Conrad CC, Huang TT, Epstein CJ, and Richardson A. Increased oxidative damage is correlated to altered mitochondrial function in heterozygous manganese superoxide dismutase knockout mice. J Biol Chem. 1998; 273: 28510-28515. 144. Woodman CR, Muller JM, Laughlin MH, and Price EM. Induction of nitric oxide synthase mRNA in coronary resistance arteries isolated from exercise-trained pigs. Am J Physiol. 1997; 273: H2575-2579.

145. Woodman CR, Price EM, and Laughlin MH. Aging induces muscle-specific impairment of endothelium-dependent dilation in skeletal muscle feed arteries. J Appl Physiol. 2002; 93: 16851690 .

146. Woodman CR, Price EM, and Laughlin MH. Shear stress induces eNOS mRNA expression and improves endothelium-dependent dilation in senescent soleus muscle feed arteries. J Appl Physiol. 2005; 98: 940-946. 
147. Woodman CR, Turk JR, Rush JW, and Laughlin MH. Exercise attenuates the effects of hypercholesterolemia on endothelium-dependent relaxation in coronary arteries from adult female pigs. J Appl Physiol. 2004; 96: 1105-1113.

148. $\mathrm{Wu} \mathrm{G}$, and Meininger CJ. Impaired arginine metabolism and NO synthesis in coronary endothelial cells of the spontaneously diabetic BB rat. Am J Physiol. 1995; 269: H1312-1318.

149. Xiang L, Naik J, and Hester RL. Exercise-induced increase in skeletal muscle vasodilatory responses in obese Zucker rats. Am J Physiol Regul Integr Comp Physiol. 2005; 288: R987-991.

150. Xu J, Knutson MD, Carter CS, and Leeuwenburgh C. Iron accumulation with age, oxidative stress and functional decline. PLOS ONE. 2008; 3: e2865.

151. Yen MH, Yang JH, Sheu JR, Lee YM, and Ding YA. Chronic exercise enhances endothelium-mediated dilation in spontaneously hypertensive rats. Life Sci. 1995; 57: 2205-2213. 152. Zhen J, Lu H, Wang XQ, Vaziri ND, and Zhou XJ. Upregulation of endothelial and inducible nitric oxide synthase expression by reactive oxygen species. Am J Hypertens. 2008; 21 : 28-34.

153. Zhu J, Huang T, and Lombard JH. Effect of high-salt diet on vascular relaxation and oxidative stress in mesenteric resistance arteries. J Vasc Res. 2007; 44: 382-390.

154. Zhu J, Mori T, Huang T, and Lombard JH. Effect of high-salt diet on NO release and superoxide production in rat aorta. Am J Physiol Heart Circ Physiol. 2004; 286: H575-583. 


\title{
Curriculum Vitae
}

\author{
Amy L. Sindler \\ Center for Interdisciplinary Research in Cardiovascular Sciences \\ West Virginia University \\ 1 Medical Center Drive \\ 3130 Health Science Center \\ Morgantown, WV 26506 \\ 304-293-4559 (lab), 304-288-7851 (cell) \\ amysindler@yahoo.com
}

\section{Current Research Projects}

- Understanding the underlying mechanisms by which exercise training restores ageassociated declines in endothelium-dependent vasodilation in skeletal muscle arterioles

\section{Education}

Ph.D. May 2009 Cellular and Integrative Physiology, West Virginia University

M.S. May $2003 \quad$ Exercise Physiology, West Virginia University

B.S. May $2001 \quad$ Exercise Physiology, West Virginia University

\section{Professional Experience}

2006-present Graduate Research Assistant, Department of Cellular and Integrative Physiology, Dr. Judy Muller-Delp, West Virginia University

2004-2006 Graduate Research Assistant, Department of Cellular and Integrative Physiology, Dr. Stan Hileman, West Virginia University

2003-2004 Graduate Research Assistant, Department of Physiology and Pharmacology, Dr. Chris Baylis, West Virginia University

2001-2003 Graduate Research Assistant, Department of Exercise Physiology, Human Performance Lab, West Virginia University

\section{Honors and Awards}

$2008 \quad$ Van Liere \& Research Day Poster Presentation, $2^{\text {nd }}$ place Basic Science 7, School of Medicine, WVU

2006 Biomedical Research and Graduate Education Travel Award, WVU

2003 Master of Science Student of the Year, Exercise Physiology, School of Medicine

2001 Graduated cum laude B.S. in Exercise Physiology, School of Medicine

\section{Publications}

Peterson JM, Bryner RW, Sindler A, Frisbee JC, Alway SE, Mitochondrial apoptotic signaling is elevated in cardiac but not skeletal muscle in the obese Zucker rat and is reduced with aerobic exercise. J Appl Physiol, 2008. 105(6):1934-43. 
Spranger, J., S. Verma, I. Gohring, T. Bobbert, J. Seifert, A.L. Sindler, A. Pfeiffer, S.M. Hileman, M. Tschop, and W.A. Banks, Adiponectin does not cross the blood-brain barrier but modifies cytokine expression of brain endothelial cells. Diabetes, 2006. 55(1): p. 141-7.

\section{Manuscripts in Review and/or Preparation}

Sindler, A.L., Reyes, R.A., Muller-Delp, J.M. Age and exercise training alter signaling through reactive oxygen species in the endothelium of skeletal muscle arterioles (in preparation)

Sindler, A.L., Delp, M.D., Reyes, R., Wu, G., Muller-Delp, J.M. Effects of aging and exercise training on eNOS uncoupling in skeletal muscle resistance arterioles (in preparation)

Kang, L.S., Kim S.J., Sindler, A.L., Dick, G.M., and Muller-Delp, J.M. Contribution of K ${ }^{+}$ Channels to the Myogenic Response in Skeletal Muscle Arterioles: Effects of Aging and Fiber Type (in preparation)

Sindler, A.L., Hileman, S.M., Peterson, J.M, Bryner, R.W., Frisbee, J.C. and Muller-Delp, J.M. Effect of Exercise Training on Adiponectin and Adiponectin Receptors in Zucker Rats. Med Sci Sports Exerc. 2008 (in preparation)1. Heart Disease and Stroke Statistics - 2007 Update At-aGlance. Dallas, Texas: American Heart Association, 2006.

2. U.S. Interim Projections by Age, Sex, Race, and Hispanic Origin. . In: U.S. Sensus Bureau, 2007.

3. Adeagbo AS, Joshua IG, Falkner C, and Matheson PJ. Tempol, an antioxidant, restores endothelium-derived hyperpolarizing factor-mediated vasodilation during hypertension. Eur $J$ Pharmacol 481: 91-100, 2003.

4. Alessio HM. Exercise-induced oxidative stress. Med Sci Sports Exerc 25: 218-224, 1993.

5. Alessio HM, Hagerman AE, Fulkerson BK, Ambrose J, Rice RE, and Wiley RL. Generation of reactive oxygen species after exhaustive aerobic and isometric exercise. Med Sci Sports Exerc 32: 1576-1581, 2000.

6. Bagi Z, Toth E, Koller A, and Kaley G. Microvascular dysfunction after transient high glucose is caused by superoxide-dependent reduction in the bioavailability of $\mathrm{NO}$ and $\mathrm{BH}(4)$. $\mathrm{Am}$ J Physiol Heart Circ Physiol 287: H626-633, 2004.

7. Berkowitz DE, White R, Li D, Minhas KM, Cernetich A, Kim S, Burke S, Shoukas AA, Nyhan D, Champion HC, and Hare JM. Arginase reciprocally regulates nitric oxide synthase activity and contributes to endothelial dysfunction in aging blood vessels. Circulation 108: 2000-2006, 2003.

8. Bevers LM, Braam B, Post JA, van Zonneveld AJ, Rabelink TJ, Koomans HA, Verhaar MC, and Joles JA. Tetrahydrobiopterin, but not L-arginine, decreases NO synthase uncoupling in cells expressing high levels of endothelial NO synthase. Hypertension 47: 87-94, 2006.

9. Bjornstedt M, Xue J, Huang W, Akesson B, and Holmgren A. The thioredoxin and glutaredoxin systems are efficient electron donors to human plasma glutathione peroxidase. $J$ Biol Chem 269: 29382-29384, 1994.

10. Blackwell KA, Sorenson JP, Richardson DM, Smith LA, Suda O, Nath K, and

Katusic ZS. Mechanisms of aging-induced impairment of endothelium-dependent relaxation: role of tetrahydrobiopterin. Am J Physiol Heart Circ Physiol 287: H2448-2453, 2004. 
11. Bode-Boger SM, Muke J, Surdacki A, Brabant G, Boger RH, and Frolich JC. Oral Larginine improves endothelial function in healthy individuals older than 70 years. Vasc Med 8: 77 81, 2003.

12. Bulvik B, Grinberg L, Eliashar R, Berenshtein E, and Chevion MM. Iron, ferritin and proteins of the methionine-centered redox cycle in young and old rat hearts. Mech Ageing Dev, 2008.

13. Burke TM and Wolin MS. Hydrogen peroxide elicits pulmonary arterial relaxation and guanylate cyclase activation. Am J Physiol 252: H721-732, 1987.

14. Cai H and Harrison DG. Endothelial dysfunction in cardiovascular diseases: the role of oxidant stress. Circ Res 87: 840-844, 2000.

15. Cai H, Li Z, Dikalov S, Holland SM, Hwang J, Jo H, Dudley SC, Jr., and Harrison DG. NAD(P)H oxidase-derived hydrogen peroxide mediates endothelial nitric oxide production in response to angiotensin II. J Biol Chem 277: 48311-48317, 2002.

16. Cai S, Khoo J, and Channon KM. Augmented BH4 by gene transfer restores nitric oxide synthase function in hyperglycemic human endothelial cells. Cardiovasc Res 65: 823-831, 2005.

17. Celermajer DS, Sorensen KE, Spiegelhalter DJ, Georgakopoulos D, Robinson J, and Deanfield JE. Aging is associated with endothelial dysfunction in healthy men years before the age-related decline in women. J Am Coll Cardiol 24: 471-476, 1994.

18. Challah M, Nadaud S, Philippe M, Battle T, Soubrier F, Corman B, and Michel JB. Circulating and cellular markers of endothelial dysfunction with aging in rats. Am J Physiol 273: H1941-1948, 1997.

19. Chalupsky K and Cai H. Endothelial dihydrofolate reductase: critical for nitric oxide bioavailability and role in angiotensin II uncoupling of endothelial nitric oxide synthase. Proc Natl Acad Sci U S A 102: 9056-9061, 2005.

20. Chen K, Thomas SR, and Keaney JF, Jr. Beyond LDL oxidation: ROS in vascular signal transduction. Free Radic Biol Med 35: 117-132, 2003.

21. Chen Y, Pearlman A, Luo Z, and Wilcox CS. Hydrogen peroxide mediates a transient vasorelaxation with tempol during oxidative stress. Am J Physiol Heart Circ Physiol 293: H20852092, 2007.

22. Cooke JP. Does ADMA cause endothelial dysfunction? Arterioscler Thromb Vasc Biol 20: 2032-2037, 2000.

23. Cosentino F and Katusic ZS. Tetrahydrobiopterin and dysfunction of endothelial nitric oxide synthase in coronary arteries. Circulation 91: 139-144, 1995.

24. Cosentino F and Luscher TF. Tetrahydrobiopterin and endothelial nitric oxide synthase activity. Cardiovasc Res 43: 274-278, 1999.

25. Cosentino F, Patton S, d'Uscio LV, Werner ER, Werner-Felmayer G, Moreau P, Malinski T, and Luscher TF. Tetrahydrobiopterin alters superoxide and nitric oxide release in prehypertensive rats. J Clin Invest 101: 1530-1537, 1998.

26. Crabtree MJ, Tatham AL, Al-Wakeel Y, Warrick N, Hale AB, Cai S, Channon KM, and Alp NJ. Quantitative Regulation of Intracellular Endothelial Nitric-oxide Synthase (eNOS) Coupling by Both Tetrahydrobiopterin-eNOS Stoichiometry and Biopterin Redox Status: Insights from cells with TET-regulated GTP cyclohydrolase I expression. J Biol Chem 284: 1136-1144, 2009.

27. Cseko C, Bagi Z, and Koller A. Biphasic effect of hydrogen peroxide on skeletal muscle arteriolar tone via activation of endothelial and smooth muscle signaling pathways. J Appl Physiol 97: 1130-1137, 2004.

28. Csiszar A, Ungvari Z, Edwards JG, Kaminski P, Wolin MS, Koller A, and Kaley G. Aging-induced phenotypic changes and oxidative stress impair coronary arteriolar function. Circ Res 90: 1159-1166, 2002. 
29. Darley-Usmar V, Wiseman $\mathbf{H}$, and Halliwell B. Nitric oxide and oxygen radicals: a question of balance. FEBS Lett 369: 131-135, 1995.

30. Davies KJ, Quintanilha AT, Brooks GA, and Packer L. Free radicals and tissue damage produced by exercise. Biochem Biophys Res Commun 107: 1198-1205, 1982.

31. Davis ME, Cai H, McCann L, Fukai T, and Harrison DG. Role of c-Src in regulation of endothelial nitric oxide synthase expression during exercise training. Am J Physiol Heart Circ Physiol 284: H1449-1453, 2003.

32. Davis MJ. Determination of volumetric flow in capillary tubes using an optical Doppler velocimeter. Microvasc Res 34: 223-230, 1987.

33. Delp MD, Behnke BJ, Spier SA, Wu G, and Muller-Delp JM. Ageing diminishes endothelium-dependent vasodilatation and tetrahydrobiopterin content in rat skeletal muscle arterioles. J Physiol 586: 1161-1168, 2008.

34. Delp MD and Duan C. Composition and size of type I, IIA, IID/X, and IIB fibers and citrate synthase activity of rat muscle. J Appl Physiol 80: 261-270, 1996.

35. Delp MD, Evans MV, and Duan C. Effects of aging on cardiac output, regional blood flow, and body composition in Fischer-344 rats. J Appl Physiol 85: 1813-1822, 1998.

36. Delp MD, McAllister RM, and Laughlin MH. Exercise training alters endotheliumdependent vasoreactivity of rat abdominal aorta. J Appl Physiol 75: 1354-1363, 1993.

37. Demaree SR, Lawler JM, Linehan J, and Delp MD. Ageing alters aortic antioxidant enzyme activities in Fischer-344 rats. Acta Physiol Scand 166: 203-208, 1999.

38. DeSouza CA, Shapiro LF, Clevenger CM, Dinenno FA, Monahan KD, Tanaka H, and Seals DR. Regular aerobic exercise prevents and restores age-related declines in endotheliumdependent vasodilation in healthy men. Circulation 102: 1351-1357, 2000.

39. Dinenno FA, Jones PP, Seals DR, and Tanaka H. Limb blood flow and vascular conductance are reduced with age in healthy humans: relation to elevations in sympathetic nerve activity and declines in oxygen demand. Circulation 100: 164-170, 1999.

40. Donato AJ, Eskurza I, Silver AE, Levy AS, Pierce GL, Gates PE, and Seals DR. Direct evidence of endothelial oxidative stress with aging in humans: relation to impaired endothelium-dependent dilation and upregulation of nuclear factor-kappaB. Circ Res 100: 16591666, 2007.

41. Droge W. Free radicals in the physiological control of cell function. Physiol Rev 82: 4795, 2002.

42. Drouin A, Thorin-Trescases N, Hamel E, Falck JR, and Thorin E. Endothelial nitric oxide synthase activation leads to dilatory $\mathrm{H}(2) \mathrm{O}(2)$ production in mouse cerebral arteries. Cardiovasc Res 73: 73-81, 2007.

43. Du YH, Guan YY, Alp NJ, Channon KM, and Chen AF. Endothelium-specific GTP cyclohydrolase I overexpression attenuates blood pressure progression in salt-sensitive low-renin hypertension. Circulation 117: 1045-1054, 2008.

44. Emsley AM, Jeremy JY, Gomes GN, Angelini GD, and Plane F. Investigation of the inhibitory effects of homocysteine and copper on nitric oxide-mediated relaxation of rat isolated aorta. Br J Pharmacol 126: 1034-1040, 1999.

45. Eskurza I, Myerburgh LA, Kahn ZD, and Seals DR. Tetrahydrobiopterin augments endothelium-dependent dilatation in sedentary but not in habitually exercising older adults. $J$ Physiol 568: 1057-1065, 2005.

46. Feng MG, Dukacz SA, and Kline RL. Selective effect of tempol on renal medullary hemodynamics in spontaneously hypertensive rats. Am J Physiol Regul Integr Comp Physiol 281: R1420-1425, 2001. 
47. Fitzgerald MD, Tanaka H, Tran ZV, and Seals DR. Age-related declines in maximal aerobic capacity in regularly exercising vs. sedentary women: a meta-analysis. $J$ Appl Physiol 83: 160-165, 1997.

48. Fleming I, Fisslthaler B, Dimmeler S, Kemp BE, and Busse R. Phosphorylation of $\operatorname{Thr}(495)$ regulates $\mathrm{Ca}(2+) /$ calmodulin-dependent endothelial nitric oxide synthase activity. Circ Res 88: E68-75, 2001.

49. Forstermann U, Pollock JS, Schmidt HH, Heller M, and Murad F. Calmodulindependent endothelium-derived relaxing factor/nitric oxide synthase activity is present in the particulate and cytosolic fractions of bovine aortic endothelial cells. Proc Natl Acad Sci U S A 88: 1788-1792, 1991.

50. Fukai T, Siegfried MR, Ushio-Fukai M, Cheng Y, Kojda G, and Harrison DG.

Regulation of the vascular extracellular superoxide dismutase by nitric oxide and exercise training. J Clin Invest 105: 1631-1639, 2000.

51. Fulton D, Gratton JP, McCabe TJ, Fontana J, Fujio Y, Walsh K, Franke TF, Papapetropoulos A, and Sessa WC. Regulation of endothelium-derived nitric oxide production by the protein kinase Akt. Nature 399: 597-601, 1999.

52. Gao H, Korthuis RJ, and Benoit JN. Effects of reactive oxygen metabolites on norepinephrine-induced vasoconstriction. Free Radic Biol Med 16: 839-843, 1994.

53. Gates PE, Boucher ML, Silver AE, Monahan KD, and Seals DR. Impaired flowmediated dilation with age is not explained by L-arginine bioavailability or endothelial asymmetric dimethylarginine protein expression. J Appl Physiol 102: 63-71, 2007.

54. Gerhard M, Roddy MA, Creager SJ, and Creager MA. Aging progressively impairs endothelium-dependent vasodilation in forearm resistance vessels of humans. Hypertension 27: 849-853, 1996.

55. Goldstein S and Czapski G. The reaction of NO. with O2.- and HO2.: a pulse radiolysis study. Free Radic Biol Med 19: 505-510, 1995.

56. Graham DA and Rush JW. Exercise training improves aortic endothelium-dependent vasorelaxation and determinants of nitric oxide bioavailability in spontaneously hypertensive rats. J Appl Physiol 96: 2088-2096, 2004.

57. Griendling KK, Sorescu D, and Ushio-Fukai M. NAD(P)H oxidase: role in cardiovascular biology and disease. Circ Res 86: 494-501, 2000.

58. Guo ZM, Yang H, Hamilton ML, VanRemmen H, and Richardson A. Effects of age and food restriction on oxidative DNA damage and antioxidant enzyme activities in the mouse aorta. Mech Ageing Dev 122: 1771-1786, 2001.

59. Halliwell B. Biochemistry of oxidative stress. Biochem Soc Trans 35: 1147-1150, 2007.

60. Halliwell B. Protection against tissue damage in vivo by desferrioxamine: what is its mechanism of action? Free Radic Biol Med 7: 645-651, 1989.

61. Harris MB, Ju H, Venema VJ, Liang H, Zou R, Michell BJ, Chen ZP, Kemp BE, and Venema RC. Reciprocal phosphorylation and regulation of endothelial nitric-oxide synthase in response to bradykinin stimulation. J Biol Chem 276: 16587-16591, 2001.

62. Harrison DG. Endothelial function and oxidant stress. Clin Cardiol 20: II-11-17, 1997.

63. Heath GW, Hagberg JM, Ehsani AA, and Holloszy JO. A physiological comparison of young and older endurance athletes. J Appl Physiol 51: 634-640, 1981.

64. Higashi Y, Sasaki S, Nakagawa K, Kimura M, Noma K, Hara K, Jitsuiki D, Goto C, Oshima T, Chayama K, and Yoshizumi M. Tetrahydrobiopterin improves aging-related impairment of endothelium-dependent vasodilation through increase in nitric oxide production. Atherosclerosis 186: 390-395, 2006.

65. Ignarro LJ. Nitric oxide as a unique signaling molecule in the vascular system: a historical overview. J Physiol Pharmacol 53: 503-514, 2002. 
66. Inoue N, Ramasamy S, Fukai T, Nerem RM, and Harrison DG. Shear stress modulates expression of $\mathrm{Cu} / \mathrm{Zn}$ superoxide dismutase in human aortic endothelial cells. Circ Res 79: 32-37, 1996.

67. Irion GL, Vasthare US, and Tuma RF. Age-related change in skeletal muscle blood flow in the rat. J Gerontol 42: 660-665, 1987.

68. Johnson LR, Rush JW, Turk JR, Price EM, and Laughlin MH. Short-term exercise training increases ACh-induced relaxation and eNOS protein in porcine pulmonary arteries. $J$ Appl Physiol 90: 1102-1110, 2001.

69. Knowles RG and Moncada S. Nitric oxide synthases in mammals. Biochem J 298 ( Pt 2): 249-258, 1994.

70. Kojda G and Harrison D. Interactions between NO and reactive oxygen species: pathophysiological importance in atherosclerosis, hypertension, diabetes and heart failure. Cardiovasc Res 43: 562-571, 1999.

71. Kojima H, Nakatsubo N, Kikuchi K, Kawahara S, Kirino Y, Nagoshi H, Hirata Y, and Nagano T. Detection and imaging of nitric oxide with novel fluorescent indicators: diaminofluoresceins. Anal Chem 70: 2446-2453, 1998.

72. Koller A and Bagi Z. Nitric oxide and $\mathrm{H} 2 \mathrm{O} 2$ contribute to reactive dilation of isolated coronary arterioles. Am J Physiol Heart Circ Physiol 287: H2461-2467, 2004.

73. Kunsch $\mathbf{C}$ and Medford RM. Oxidative stress as a regulator of gene expression in the vasculature. Circ Res 85: 753-766, 1999.

74. Kuo L, Davis MJ, and Chilian WM. Endothelium-dependent, flow-induced dilation of isolated coronary arterioles. Am J Physiol 259: H1063-1070, 1990.

75. Kuzkaya N, Weissmann N, Harrison DG, and Dikalov S. Interactions of peroxynitrite, tetrahydrobiopterin, ascorbic acid, and thiols: implications for uncoupling endothelial nitric-oxide synthase. J Biol Chem 278: 22546-22554, 2003.

76. Lakatta EG. Cardiovascular system. In: Handbook of Physiology: Aging, 1995.

77. Liu Y, Zhao H, Li H, Kalyanaraman B, Nicolosi AC, and Gutterman DD.

Mitochondrial sources of $\mathrm{H} 2 \mathrm{O} 2$ generation play a key role in flow-mediated dilation in human coronary resistance arteries. Circ Res 93: 573-580, 2003.

78. Luscher TF and Barton M. Biology of the endothelium. Clin Cardiol 20: II-3-10, 1997.

79. Ma X, Li YF, Gao Q, Ye ZG, Lu XJ, Wang HP, Jiang HD, Bruce IC, and Xia Q.

Inhibition of superoxide anion-mediated impairment of endothelium by treatment with luteolin and apigenin in rat mesenteric artery. Life Sci 83: 110-117, 2008.

80. Maier W, Cosentino F, Lutolf RB, Fleisch M, Seiler C, Hess OM, Meier B, and Luscher TF. Tetrahydrobiopterin improves endothelial function in patients with coronary artery disease. J Cardiovasc Pharmacol 35: 173-178, 2000.

81. Marklund S and Marklund G. Involvement of the superoxide anion radical in the autoxidation of pyrogallol and a convenient assay for superoxide dismutase. Eur J Biochem 47: 469-474, 1974.

82. Marvar PJ, Hammer LW, and Boegehold MA. Hydrogen peroxide-dependent arteriolar dilation in contracting muscle of rats fed normal and high salt diets. Microcirculation 14: 779-791, 2007.

83. Marvar PJ, Nurkiewicz TR, and Boegehold MA. Reduced arteriolar responses to skeletal muscle contraction after ingestion of a high salt diet. J Vasc Res 42: 226-236, 2005.

84. Matoba $\mathbf{T}$ and Shimokawa $\mathbf{H}$. Hydrogen peroxide is an endothelium-derived hyperpolarizing factor in animals and humans. J Pharmacol Sci 92: 1-6, 2003.

85. Matoba T, Shimokawa H, Nakashima M, Hirakawa Y, Mukai Y, Hirano K, Kanaide H, and Takeshita A. Hydrogen peroxide is an endothelium-derived hyperpolarizing factor in mice. J Clin Invest 106: 1521-1530, 2000. 
86. Mayhan WG, Arrick DM, Sharpe GM, and Sun H. Age-related alterations in reactivity of cerebral arterioles: role of oxidative stress. Microcirculation 15: 225-236, 2008.

87. McAllister RM, Jasperse JL, and Laughlin MH. Nonuniform effects of endurance exercise training on vasodilation in rat skeletal muscle. J Appl Physiol 98: 753-761, 2005.

88. McCurdy MR, Colleran PN, Muller-Delp J, and Delp MD. Effects of fiber composition and hindlimb unloading on the vasodilator properties of skeletal muscle arterioles. J Appl Physiol 89: 398-405, 2000.

89. Meininger CJ, Marinos RS, Hatakeyama K, Martinez-Zaguilan R, Rojas JD, Kelly KA, and Wu G. Impaired nitric oxide production in coronary endothelial cells of the spontaneously diabetic BB rat is due to tetrahydrobiopterin deficiency. Biochem J 349: 353-356, 2000.

90. Meister A and Anderson ME. Glutathione. Annu Rev Biochem 52: 711-760, 1983.

91. Miura H, Bosnjak JJ, Ning G, Saito T, Miura M, and Gutterman DD. Role for hydrogen peroxide in flow-induced dilation of human coronary arterioles. Circ Res 92: e31-40, 2003.

92. Mohazzab KM, Kaminski PM, and Wolin MS. NADH oxidoreductase is a major source of superoxide anion in bovine coronary artery endothelium. Am J Physiol 266: H2568-2572, 1994.

93. Morris S. Regulation of arginine availability and its impact on NO synthesis. Nitric Oxide: Biology and Pathobiology: 187-197, 2000.

94. Mugge A, Elwell JH, Peterson TE, and Harrison DG. Release of intact endotheliumderived relaxing factor depends on endothelial superoxide dismutase activity. Am J Physiol 260: C219-225, 1991.

95. Mugge A, Elwell JH, Peterson TE, Hofmeyer TG, Heistad DD, and Harrison DG. Chronic treatment with polyethylene-glycolated superoxide dismutase partially restores endothelium-dependent vascular relaxations in cholesterol-fed rabbits. Circ Res 69: 1293-1300, 1991.

96. Muller-Delp J, Spier SA, Ramsey MW, Lesniewski LA, Papadopoulos A, Humphrey JD, and Delp MD. Effects of aging on vasoconstrictor and mechanical properties of rat skeletal muscle arterioles. Am J Physiol Heart Circ Physiol 282: H1843-1854, 2002.

97. Muller-Delp JM, Spier SA, Ramsey MW, and Delp MD. Aging impairs endotheliumdependent vasodilation in rat skeletal muscle arterioles. Am J Physiol Heart Circ Physiol 283: H1662-1672, 2002.

98. Musch TI, Eklund KE, Hageman KS, and Poole DC. Altered regional blood flow responses to submaximal exercise in older rats. J Appl Physiol 96: 81-88, 2004.

99. Navas F J and Cordova A. Iron distribution in different tissues in rats following exercise. Biol Trace Elem Res 73: 259-268, 2000.

100. Nichol CA, Lee CL, Edelstein MP, Chao JY, and Duch DS. Biosynthesis of tetrahydrobiopterin by de novo and salvage pathways in adrenal medulla extracts, mammalian cell cultures, and rat brain in vivo. Proc Natl Acad Sci U S A 80: 1546-1550, 1983.

101. Nitenberg A, Paycha F, Ledoux S, Sachs R, Attali JR, and Valensi P. Coronary artery responses to physiological stimuli are improved by deferoxamine but not by L-arginine in noninsulin-dependent diabetic patients with angiographically normal coronary arteries and no other risk factors. Circulation 97: 736-743, 1998.

102. Nossaman BD, Bivalacqua TJ, Champion HC, Baber SR, and Kadowitz PJ. Analysis of vasodilator responses to peroxynitrite in the hindlimb vascular bed of the cat. J CardiovasC Pharmacol 50: 358-366, 2007.

103. Nossaman BD, Dabisch PA, Liles JT, Baber SR, Champion HC, Kaye AD, Feng CJ, Anwar M, Bivalacqua TJ, Santiago JA, De Witt BJ, and Kadowitz PJ. Peroxynitrite does not impair pulmonary and systemic vascular responses. J Appl Physiol 96: 455-462, 2004. 
104. Ogawa T, Spina RJ, Martin WH, 3rd, Kohrt WM, Schechtman KB, Holloszy JO, and Ehsani AA. Effects of aging, sex, and physical training on cardiovascular responses to exercise. Circulation 86: 494-503, 1992.

105. Oury TD, Day BJ, and Crapo JD. Extracellular superoxide dismutase in vessels and airways of humans and baboons. Free Radic Biol Med 20: 957-965, 1996.

106. Oury TD, Day BJ, and Crapo JD. Extracellular superoxide dismutase: a regulator of nitric oxide bioavailability. Lab Invest 75: 617-636, 1996.

107. Pattwell DM, McArdle A, Morgan JE, Patridge TA, and Jackson MJ. Release of reactive oxygen and nitrogen species from contracting skeletal muscle cells. Free Radic Biol Med 37: 1064-1072, 2004.

108. Powers SK and Jackson MJ. Exercise-induced oxidative stress: cellular mechanisms and impact on muscle force production. Physiol Rev 88: 1243-1276, 2008.

109. Proctor DN, Shen PH, Dietz NM, Eickhoff TJ, Lawler LA, Ebersold EJ, Loeffler DL, and Joyner MJ. Reduced leg blood flow during dynamic exercise in older endurance-trained men. J Appl Physiol 85: 68-75, 1998.

110. Reid MB. Invited Review: redox modulation of skeletal muscle contraction: what we know and what we don't. J Appl Physiol 90: 724-731, 2001.

111. Reid MB. Nitric oxide, reactive oxygen species, and skeletal muscle contraction. Med Sci Sports Exerc 33: 371-376, 2001.

112. Rodeheffer RJ, Gerstenblith G, Becker LC, Fleg JL, Weisfeldt ML, and Lakatta EG. Exercise cardiac output is maintained with advancing age in healthy human subjects: cardiac dilatation and increased stroke volume compensate for a diminished heart rate. Circulation 69: 203-213, 1984.

113. Rush JW, Laughlin MH, Woodman CR, and Price EM. SOD-1 expression in pig coronary arterioles is increased by exercise training. Am J Physiol Heart Circ Physiol 279: H20682076, 2000.

114. Rush JW, Turk JR, and Laughlin MH. Exercise training regulates SOD-1 and oxidative stress in porcine aortic endothelium. Am J Physiol Heart Circ Physiol 284: H1378-1387, 2003. 115. Saitoh S, Zhang C, Tune JD, Potter B, Kiyooka T, Rogers PA, Knudson JD, Dick GM, Swafford A, and Chilian WM. Hydrogen peroxide: a feed-forward dilator that couples myocardial metabolism to coronary blood flow. Arterioscler Thromb Vasc Biol 26: 2614-2621, 2006.

116. Schmidt HH, Pollock JS, Nakane M, Forstermann U, and Murad F. Ca2+/calmodulinregulated nitric oxide synthases. Cell Calcium 13: 427-434, 1992.

117. Sessa WC, Pritchard K, Seyedi N, Wang J, and Hintze TH. Chronic exercise in dogs increases coronary vascular nitric oxide production and endothelial cell nitric oxide synthase gene expression. Circ Res 74: 349-353, 1994.

118. Shimizu S, Hiroi T, Ishii M, Hagiwara T, Wajima T, Miyazaki A, and Kiuchi Y. Hydrogen peroxide stimulates tetrahydrobiopterin synthesis through activation of the Jak2 tyrosine kinase pathway in vascular endothelial cells. Int J Biochem Cell Biol 40: 755-765, 2008. 119. Shimizu S, Shiota K, Yamamoto S, Miyasaka Y, Ishii M, Watabe T, Nishida M, Mori Y, Yamamoto T, and Kiuchi Y. Hydrogen peroxide stimulates tetrahydrobiopterin synthesis through the induction of GTP-cyclohydrolase I and increases nitric oxide synthase activity in vascular endothelial cells. Free Radic Biol Med 34: 1343-1352, 2003.

120. Smith MA and Reid MB. Redox modulation of contractile function in respiratory and limb skeletal muscle. Respir Physiol Neurobiol 151: 229-241, 2006.

121. Somers MJ and Harrison DG. Reactive oxygen species and the control of vasomotor tone. Curr Hypertens Rep 1: 102-108, 1999. 
122. Spier SA, Delp MD, Meininger CJ, Donato AJ, Ramsey MW, and Muller-Delp JM. Effects of ageing and exercise training on endothelium-dependent vasodilatation and structure of rat skeletal muscle arterioles. J Physiol 556: 947-958, 2004.

123. Spier SA, Delp MD, Stallone JN, Dominguez JM, 2nd, and Muller-Delp JM. Exercise training enhances flow-induced vasodilation in skeletal muscle resistance arteries of aged rats: role of PGI2 and nitric oxide. Am J Physiol Heart Circ Physiol 292: H3119-3127, 2007.

124. Srere P. Citrate Synthase. Methods Enzymol 13: 3-5, 1969.

125. Stratton JR, Levy WC, Cerqueira MD, Schwartz RS, and Abrass IB. Cardiovascular responses to exercise. Effects of aging and exercise training in healthy men. Circulation 89: 1648$1655,1994$.

126. Stroes E, Kastelein J, Cosentino F, Erkelens W, Wever R, Koomans H, Luscher T, and Rabelink T. Tetrahydrobiopterin restores endothelial function in hypercholesterolemia. $J$ Clin Invest 99: 41-46, 1997.

127. Sun D, Huang A, Yan EH, Wu Z, Yan C, Kaminski PM, Oury TD, Wolin MS, and Kaley G. Reduced release of nitric oxide to shear stress in mesenteric arteries of aged rats. Am $J$ Physiol Heart Circ Physiol 286: H2249-2256, 2004.

128. Suzuki H, Swei A, Zweifach BW, and Schmid-Schonbein GW. In vivo evidence for microvascular oxidative stress in spontaneously hypertensive rats. Hydroethidine microfluorography. Hypertension 25: 1083-1089, 1995.

129. Taddei S, Galetta F, Virdis A, Ghiadoni L, Salvetti G, Franzoni F, Giusti C, and Salvetti A. Physical activity prevents age-related impairment in nitric oxide availability in elderly athletes. Circulation 101: 2896-2901, 2000.

130. Taddei S, Virdis A, Mattei P, Ghiadoni L, Gennari A, Fasolo CB, Sudano I, and

Salvetti A. Aging and endothelial function in normotensive subjects and patients with essential hypertension. Circulation 91: 1981-1987, 1995.

131. Thengchaisri N, Hein TW, Wang W, Xu X, Li Z, Fossum TW, and Kuo L.

Upregulation of arginase by $\mathrm{H} 2 \mathrm{O} 2$ impairs endothelium-dependent nitric oxide-mediated dilation of coronary arterioles. Arterioscler Thromb Vasc Biol 26: 2035-2042, 2006.

132. Thengchaisri $\mathbf{N}$ and Kuo L. Hydrogen peroxide induces endothelium-dependent and independent coronary arteriolar dilation: role of cyclooxygenase and potassium channels. Am J Physiol Heart Circ Physiol 285: H2255-2263, 2003.

133. Thomas SR, Chen K, and Keaney JF, Jr. Hydrogen peroxide activates endothelial nitricoxide synthase through coordinated phosphorylation and dephosphorylation via a phosphoinositide 3-kinase-dependent signaling pathway. J Biol Chem 277: 6017-6024, 2002.

134. Thony B, Auerbach G, and Blau N. Tetrahydrobiopterin biosynthesis, regeneration and functions. Biochem J 347 Pt 1: 1-16, 2000.

135. Tiefenbacher CP. Tetrahydrobiopterin: a critical cofactor for eNOS and a strategy in the treatment of endothelial dysfunction? Am J Physiol Heart Circ Physiol 280: H2484-2488, 2001.

136. Tominaga M, Fujii K, Abe I, Takata Y, Kobayashi K, and Fujishima M. Hypertension and ageing impair acetylcholine-induced vasodilation in rats. J Hypertens 12: 259-268, 1994.

137. Vasquez-Vivar J, Kalyanaraman B, Martasek P, Hogg N, Masters BS, Karoui H, Tordo P, and Pritchard KA, Jr. Superoxide generation by endothelial nitric oxide synthase: the influence of cofactors. Proc Natl Acad Sci U S A 95: 9220-9225, 1998.

138. Walsh JH, Bilsborough W, Maiorana A, Best M, O'Driscoll GJ, Taylor RR, and Green DJ. Exercise training improves conduit vessel function in patients with coronary artery disease. J Appl Physiol 95: 20-25, 2003.

139. Wei EP and Kontos HA. H2O2 and endothelium-dependent cerebral arteriolar dilation. Implications for the identity of endothelium-derived relaxing factor generated by acetylcholine. Hypertension 16: 162-169, 1990. 
140. Wei EP, Kontos HA, and Beckman JS. Mechanisms of cerebral vasodilation by superoxide, hydrogen peroxide, and peroxynitrite. Am J Physiol 271: H1262-1266, 1996. 141. White AR, Ryoo S, Li D, Champion HC, Steppan J, Wang D, Nyhan D, Shoukas AA, Hare JM, and Berkowitz DE. Knockdown of arginase I restores NO signaling in the vasculature of old rats. Hypertension 47: 245-251, 2006.

142. Widder JD, Chen W, Li L, Dikalov S, Thony B, Hatakeyama K, and Harrison DG. Regulation of tetrahydrobiopterin biosynthesis by shear stress. Circ Res 101: 830-838, 2007. 143. Williams MD, Van Remmen H, Conrad CC, Huang TT, Epstein CJ, and Richardson A. Increased oxidative damage is correlated to altered mitochondrial function in heterozygous manganese superoxide dismutase knockout mice. J Biol Chem 273: 28510-28515, 1998. 144. Woodman CR, Muller JM, Laughlin MH, and Price EM. Induction of nitric oxide synthase mRNA in coronary resistance arteries isolated from exercise-trained pigs. Am J Physiol 273: H2575-2579, 1997.

145. Woodman CR, Price EM, and Laughlin MH. Aging induces muscle-specific impairment of endothelium-dependent dilation in skeletal muscle feed arteries. J Appl Physiol 93: 1685-1690, 2002.

146. Woodman CR, Price EM, and Laughlin MH. Shear stress induces eNOS mRNA expression and improves endothelium-dependent dilation in senescent soleus muscle feed arteries. J Appl Physiol 98: 940-946, 2005.

147. Woodman CR, Turk JR, Rush JW, and Laughlin MH. Exercise attenuates the effects of hypercholesterolemia on endothelium-dependent relaxation in coronary arteries from adult female pigs. J Appl Physiol 96: 1105-1113, 2004.

148. Wu G and Meininger CJ. Impaired arginine metabolism and NO synthesis in coronary endothelial cells of the spontaneously diabetic BB rat. Am J Physiol 269: H1312-1318, 1995. 149. Xiang L, Naik J, and Hester RL. Exercise-induced increase in skeletal muscle vasodilatory responses in obese Zucker rats. Am J Physiol Regul Integr Comp Physiol 288: R987991, 2005.

150. Xu J, Knutson MD, Carter CS, and Leeuwenburgh C. Iron accumulation with age, oxidative stress and functional decline. PLOS ONE 3: e2865, 2008.

151. Yen MH, Yang JH, Sheu JR, Lee YM, and Ding YA. Chronic exercise enhances endothelium-mediated dilation in spontaneously hypertensive rats. Life Sci 57: 2205-2213, 1995. 152. Zhen J, Lu H, Wang XQ, Vaziri ND, and Zhou XJ. Upregulation of endothelial and inducible nitric oxide synthase expression by reactive oxygen species. Am J Hypertens 21: 28-34, 2008.

153. Zhu J, Huang T, and Lombard JH. Effect of high-salt diet on vascular relaxation and oxidative stress in mesenteric resistance arteries. J Vasc Res 44: 382-390, 2007.

154. Zhu J, Mori T, Huang T, and Lombard JH. Effect of high-salt diet on NO release and superoxide production in rat aorta. Am J Physiol Heart Circ Physiol 286: H575-583, 2004. 


\section{Appendix}

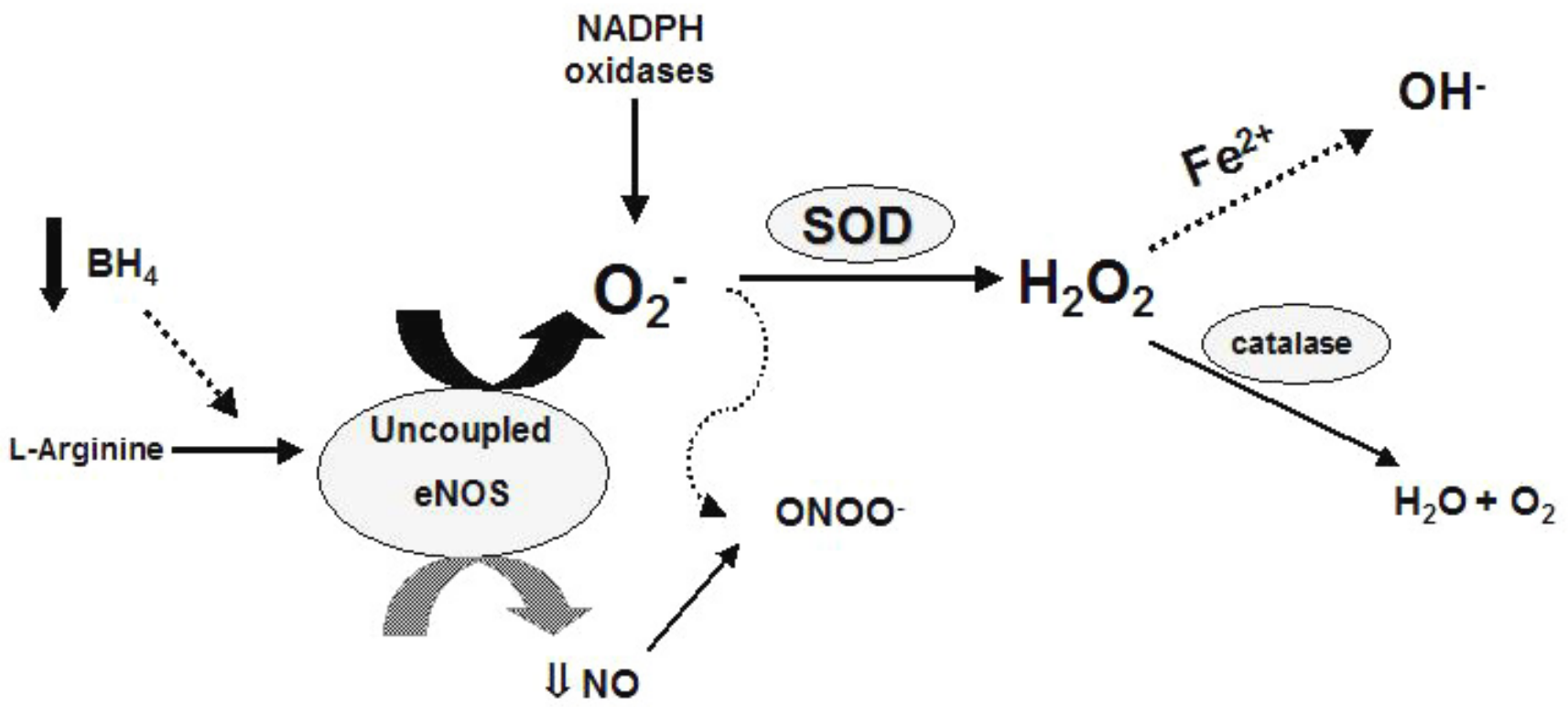

Proposed effects of aging on eNOS uncoupling. $\mathrm{BH}_{4}$ content is reduced in soleus muscle arterioles of aged rats. With limited availability of $\mathrm{BH}_{4}$, eNOS becomes uncoupled and leads to generation of $\mathrm{O}_{2}^{-}$rather than NO. Peroxynitrite $\left(\mathrm{ONOO}^{-}\right)$, a product of $\mathrm{NO}$ and $\mathrm{O}_{2}^{-}$generated through eNOS uncoupling, NADPH oxidases and other sources, could further reduce $\mathrm{BH}_{4}$ availability. Vascular SOD scavenges $\mathrm{O}_{2}^{-}$, which can produce the vasodilator $\mathrm{H}_{2} \mathrm{O}_{2}$. In the presence of catalytic transition metals (i.e., $\mathrm{Fe}^{+2}$ ), $\mathrm{H}_{2} \mathrm{O}_{2}$ can produce the potent vasoconstrictor $\mathrm{OH}^{-} \cdot \mathrm{H}_{2} \mathrm{O}_{2}$ is converted to $\mathrm{H}_{2} \mathrm{O}$ and $\mathrm{O}_{2}$ in the presence of catalase. 